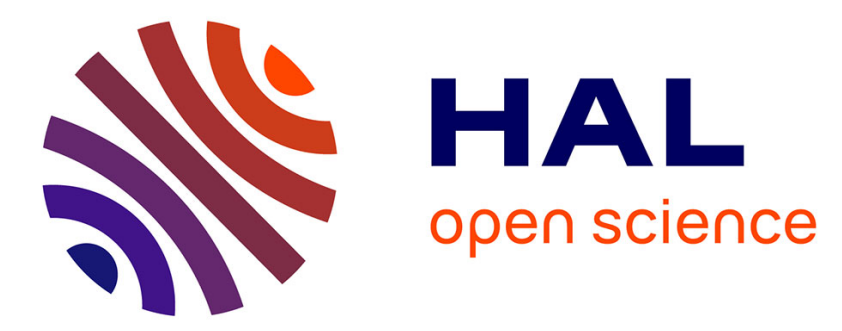

\title{
Molecular Simulation of CO2- and CO3-Brine-Mineral Systems
}

Laura M. Hamm, Ian C. Bourg, Adam F. Wallace, Benjamin Rotenberg

\section{To cite this version:}

Laura M. Hamm, Ian C. Bourg, Adam F. Wallace, Benjamin Rotenberg. Molecular Simulation of CO2- and CO3-Brine-Mineral Systems. Reviews in Mineralogy and Geochemistry, 2013, 77, pp.189228. 10.2138/rmg.2013.77.6 . hal-01488417

\section{HAL Id: hal-01488417 https://hal.sorbonne-universite.fr/hal-01488417}

Submitted on 16 Nov 2018

HAL is a multi-disciplinary open access archive for the deposit and dissemination of scientific research documents, whether they are published or not. The documents may come from teaching and research institutions in France or abroad, or from public or private research centers.
L'archive ouverte pluridisciplinaire $\mathbf{H A L}$, est destinée au dépôt et à la diffusion de documents scientifiques de niveau recherche, publiés ou non, émanant des établissements d'enseignement et de recherche français ou étrangers, des laboratoires publics ou privés. 


\title{
Molecular Simulation of $\mathrm{CO}_{2-}$ and $\mathrm{CO}_{3}$-Brine-Mineral Systems
}

\author{
Laura M. Hamm, Ian C. Bourg \\ Earth Sciences Division \\ Lawrence Berkeley National Laboratory \\ Berkeley, CA 94720, U.S.A. \\ Adam F. Wallace \\ Department of Geological Sciences \\ University of Delaware \\ Newark, DE 19716 \\ Benjamin Rotenberg \\ Laboratoire PECSA \\ CNRS and UPMC Université Paris 06 \\ 75005 Paris, France
}

\section{INTRODUCTION}

Atomistic simulations - molecular dynamics (MD) and Monte Carlo (MC) simulations, ab initio and density functional theory (DFT) calculations - have proved useful in gaining insight into the molecular basis of fundamental processes in aquatic geochemistry, such as solvation, ion pair formation, adsorption, molecular diffusion, and the energetics of mineral phases (Rotenberg et al. 2007; Bickmore et al. 2009; Hamm et al., 2010; Kerisit and Liu 2010; Hofmann et al. 2012; Stack et al. 2012; Wallace et al., 2013). Key strengths of these simulations are their ability to examine the behavior of individual atoms (where spectroscopic and other experimental methods would probe the average behavior of large numbers of molecules) and to allow constraints that would be difficult or impossible to impose in the laboratory. These features make atomistic simulations powerful tools for elucidating the manner in which collective phenomena arise from molecular scale properties in geochemical systems. The range of length and time scales probed by atomistic simulations (from angstroms to tens of nanometers and from femtoseconds to microseconds, continuously expanding with advances in the availability and sophistication of computational resources) makes them ideally suited to complement several spectroscopic techniques, including x-ray, neutron, and nuclear magnetic resonance methods.

A major limitation of the methods described in the present chapter, particularly in the case of classical mechanical (MD and MC) simulations, is the approximate nature of the models that are used to describe interatomic forces. In the simplest of these simulations, bond lengths and angles are fixed; inter-atomic interactions are modeled as the sum of two-body interactions that depend only on the identity of the interacting atoms and the distance between them; and chemical bonds are not allowed to break or form during a simulation (Allen and Tildesley, 1987; Frenkel and Smit, 2001). The choice of 
force fields (i.e., interatomic potential models) can strongly influence predicted properties such as the structure of liquid water (Hura et al. 2003; Bickmore et al. 2009), the solubility of $\mathrm{CO}_{2}$ in water (Lísal et al. 2005), $\mathrm{CO}_{2}$-water interfacial tension (Nielsen et al. 2012), and the structure of calcite-water interfaces (Fenter et al. 2013). In this chapter, we describe how, despite these limitations, carefully designed atomistic simulations can generate useful fundamental insight into the geochemical properties of mineral-water$\mathrm{CO}_{2}$ and $-\mathrm{CO}_{3}$ systems at conditions relevant to geologic carbon sequestration (GCS).

\section{$\mathrm{CO}_{3}$-BRINE-MINERAL SYSTEMS}

\section{$\mathrm{CO}_{3}$-brine speciation}

The aqueous speciation of carbonate-bearing solutions has been extensively studied due to its importance as the primary buffer system in natural waters and in many engineered settings. Thermodynamic solution speciation models account for the equilibria between gaseous and solvated $\mathrm{CO}_{2(\mathrm{aq})}$ as well as the step wise decomposition of carbonic acid, $\mathrm{H}_{2} \mathrm{CO}_{3}$, into bicarbonate and carbonate ions, $\mathrm{HCO}_{3}{ }^{-}$and $\mathrm{CO}_{3}{ }^{2-}$. As aqueous carbon dioxide and carbonic acid are not easily distinguishable by analytical titration and carbonic acid is far less abundant in solution than aqueous carbon dioxide, it has become commonplace to represent the concentrations of both species collectively as the hypothetical species $\mathrm{H}_{2} \mathrm{CO}_{3}{ }^{*}$. In addition to these basic relations, speciation models also include mineral solubility products (i.e. $K_{\mathrm{sp}}=\{\mathrm{M}(\mathrm{II})\}\left\{\mathrm{CO}_{3}{ }^{2-}\right\}$ ) and equilibrium constants for ion hydrolysis (i.e. $\left.K_{\text {hyd }}=\left\{\mathrm{M}(\mathrm{II}) \mathrm{OH}^{+}\right\}\left\{\mathrm{H}^{+}\right\} /\{\mathrm{M}(\mathrm{II})\}\right)$ and ion pair formation (i.e. $K_{\text {ip }}$ $\left.=\{\mathrm{M}(\mathrm{II})\}\left\{\mathrm{HCO}_{3}{ }^{-}\right\} /\left\{\mathrm{M}(\mathrm{II}) \mathrm{HCO}_{3}{ }^{+}\right\}\right)$, such that the solubility of a given $\mathrm{M}(\mathrm{II})$-carbonate mineral phase is equal to the sum over the activities of all the M(II)-containing species in solution under a given set of environmental conditions (temperature, pressure, $\mathrm{CO}_{2}$ fugacity, ionic strength). Although evermore sophisticated activity coefficient corrections must be applied to account for non-ideal interactions between species at higher concentrations (Debye and Hückel 1923; Davies 1962; Pitzer 1973), ion activity models remain the preeminent means by which dilute solutions and brines are modeled.

Recent experimental work on the early stages of homogeneous $\mathrm{CaCO}_{3}$ crystallization, however, has challenged the standard treatment of electrolyte solutions as presented above. Titration experiments (Gebauer et al. 2008) show that the calcium ion activity of a sodium bicarbonate buffer solution deviates from the amount of calcium dosed into the solution. On its own, this result is completely consistent with traditional speciation models that predict non-ideal solution behavior (i.e., ion pairing). However, analytical ultracentrifugation (Gebauer et al. 2008; Gebauer and Coelfen 2011) and cryoTEM (Pouget et al. 2009) also suggest that ions are concentrated in subnanometer clusters that are not accounted for by ion activity models. While the presence of clusters is expected in supersaturated solutions such as those employed in these experiments, the apparently monodisperse cluster size distribution has been interpreted as evidence that the species are stable or metastable "prenucleation" clusters (PNC), although there are alternative mechanisms that can also produce similar distributions (Faatz et al. 2004; Binder and Fratzl 2005). If indeed ions more favorably reside in cluster species than as ion pairs and free ions, perhaps even at equilibrium (Gebauer et al. 2008, 2010; Gebauer 
and Coelfen 2011), then presumably the formation of calcium carbonate from solution follows a non-classical nucleation pathway dominated by cluster-cluster aggregation (PNC theory) rather than ion-by-ion addition as assumed by classical theory. Moreover, if ions are concentrated in cluster phases rather than distributed throughout solution, theoretical treatments of mass transport may need to be modified or adjusted to make more accurate predictions of real system behavior.

The possible existence of additional stable calcium carbonate/bicarbonate ion species in solution that are larger than ion pairs is not necessarily inconsistent with the tenants of standard ion activity models. Indeed the presence of triple and quadruple ion species has been suspected previously in a number of systems including iron bicarbonate solutions (Marcus and Hefter 2006; Fosbøl et al. 2010). However, in order to reconcile the existence of additional ion species with the demonstrated predictive capabilities of existing speciation models, the abundance of the additional species must be negligible near equilibrium such that their omission from standard thermodynamic databases has little effect on model predictions. Since the assertion of PNC theory (Gebauer et al. 2008, 2010; Gebauer and Coelfen 2011; Bewernitz et al. 2012), numerous MD simulation based investigations have probed the onset of $\mathrm{CaCO}_{3}$ formation from supersaturated solutions in search of stable prenucleation clusters. To date, these studies have been unable to attribute special thermodynamic significance to a cluster of any size, which is the hallmark of PNC theory (Tribello et al. 2009; Raiteri and Gale 2010; Demichelis et al. 2011; Wallace et al. 2013). In the high $\mathrm{pH}$ limit, it has been demonstrated, by inference (Tribello et al. 2009; Raiteri and Gale 2010) and by direct quantification of the free energy landscape (Demichelis et al. 2011; Wallace et al. 2013), that there is no thermodynamic barrier opposing cluster formation in concentrated solutions $(>15 \mathrm{mmol}$ $\mathrm{dm}^{-3}$ as $\mathrm{CaCO}_{3}{ }^{\circ}$ ). This is most consistent with spinodal decomposition as a phaseseparation mechanism (Markov 2004; Binder and Fratzl 2005) and implies that there is a binodal in the system that describes the coexistence of an ion-rich dense liquid phase, and an ion-poor dilute solution phase (Figure 1) (Faatz et al. 2004; Rieger et al. 2007; Wolf et al. 2008, 2011; Wallace et al. 2013). However, where bicarbonate ions persist at lower $\mathrm{pH}$, the cluster size distribution is exponential (Demichelis et al. 2011), which is in line with the expectations of classical nucleation theory (Markov 2004). 


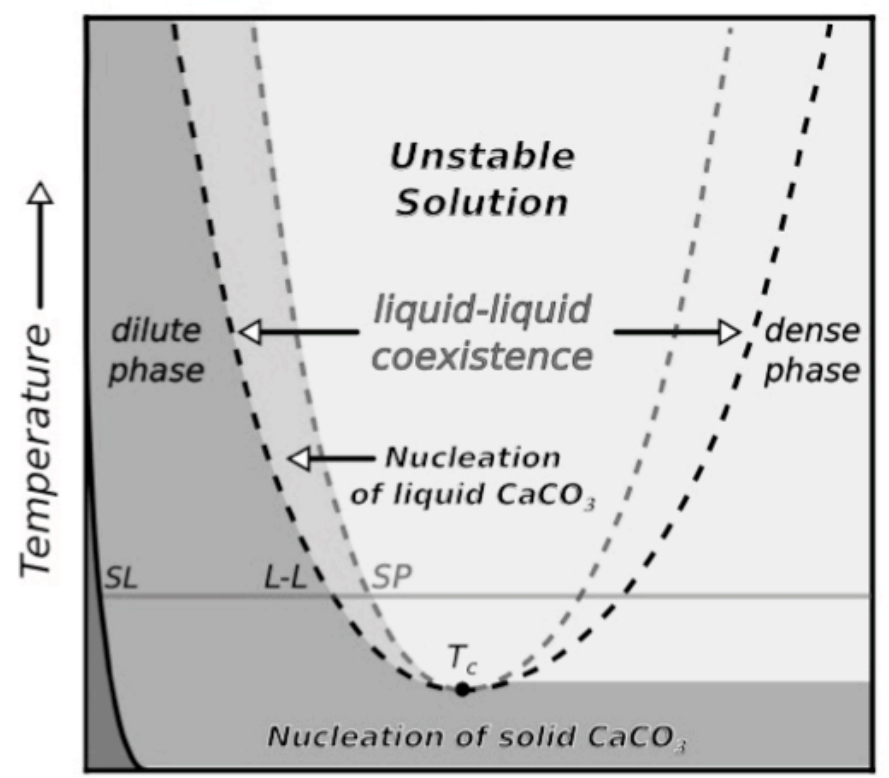

Ion Activity Product $\longrightarrow$

Figure 1: Schematic representation of the presumptive phase relationships in the $\mathrm{CaCO}_{3}-\mathrm{H}_{2} \mathrm{O}$ system at ambient pressure (Wallace et al. 2013). The gray horizontal line represents a constant temperature slice through the stability fields as the solution ion activity product is increased. The solubility of all polymorphs is represented by a single solubility line (SL), which bounds the undersaturated solution field (dark gray region in the lower left corner). This simplification highlights that the solid phases of $\mathrm{CaCO}_{3}$ (calcite, aragonite, vaterite, presumably ACC) all display the same general retrograde solubility behavior. Indirect nucleation of the solid phases proceeds to the high concentration side of the dashed black liquid-liquid coexistence line (L-L). The phase field bounded by the L-L line and the dashed gray spinodal line (SP) and labeled "Nucleation of liquid $\mathrm{CaCO}_{3}$ " indicates the conditions where nucleation of the dense liquid phase (DLP) is possible. In the region bounded by the spinodal line the solution is unstable to fluctuations and liquid-liquid separation proceeds spontaneously. The retrograde solubility of the DLP (i.e. concave up orientation of the system binodal) is assumed based on the behavior of the $\mathrm{MgSO}_{4}-\mathrm{H}_{2} \mathrm{O}$ system at high temperature (Wallace et al. 2013) and the arguments in support of a lower critical point temperature presented by Faatz et al. (2004). [From Wallace AF et al. (2013) Science 341:885-889. Reprinted with permission from AAAS]

Recent molecular dynamics studies have also posited that liquid-like or bona fide liquid phases of calcium carbonate may form in solution (Demichelis et al. 2011; Wallace et al. 2013). Demichelis et al. (2011) first noted that at high concentrations ( $>50 \mathrm{mmol}$ $\mathrm{dm}^{-3}$ ) hydrated Ca-carbonate and Ca-bicarbonate cluster phases adopt linear and branched configurations that are highly dynamic and reorder quickly. From these results they coined the term DOLLOP, which stands for "dynamically ordered liquid-like oxyanion polymer." Wallace et al. (2013) later showed that in the high $\mathrm{pH}$ limit DOLLOP evolves quickly into a dense liquid phase (DLP) that is stable at lower concentrations $(\sim 15 \mathrm{mmol}$ $\mathrm{dm}^{-3}$ or less) and that first coalesces and, then, partially dehydrates to form a material whose structure is consistent with hydrated amorphous calcium carbonate. Several experimental studies have also suggested the presence of liquid calcium carbonate based on the interpretation of light scattering (Faatz et al. 2004) and cryo-electron microscopy 
data (Rieger et al. 2007; Wolf et al. 2008). These studies were unable to convincingly demonstrate that the observed particles were indeed liquid rather than amorphous and solid. However, from the biomineralization literature it is well known that organic molecules can stabilize a metastable liquid form of calcium carbonate called PILP (Polymer Induced Liquid Precursor) (Gower and Odom 2000; Jee et al. 2011; Jiang et al. 2012). It therefore seems plausible that a dense liquid phase may also form in the absence of organics, with the inorganic liquid state being presumably less stable than PILP. The possible coexistence of such a phase with a more dilute liquid suggests that under certain conditions the carbonate system could be buffered by the metastable equilibrium between the two liquid states rather than by the solubility limit of solid $\mathrm{CaCO}_{3}$ (Figure 1). The case for liquid-liquid separation is also supported in part by the recent experimental documentation of liquid-liquid coexistence in the $\mathrm{MgSO}_{4}$-water system (Wang et al. 2013), albeit at substantially higher temperatures than suggested for $\mathrm{CaCO}_{3}$, and by a nuclear magnetic resonance (NMR) study that supports the notion that liquid calcium carbonate phases can form in the absence of organic polymers (Bewernitz et al. 2012).

\section{Amorphous $\mathrm{M}^{(\mathrm{II})} \mathrm{CO}_{3}$ phases}

Amorphous phases of $\mathrm{Ca}, \mathrm{Mg}$, and $\mathrm{Fe}(\mathrm{II})$ carbonate have been characterized to varying degrees experimentally (Michel et al. 2008; Radha et al. 2012; Radha et al. 2010; Sel et al. 2012). While amorphous calcium carbonate is an important precursor phase in the formation of biogenic carbonates, the extent to which such amorphous phases may persist in abiotic environments is unknown. Modeling efforts to date have focused primarily on the structure of the calcium bearing end member, amorphous calcium carbonate (ACC). As synthesized in the laboratory, ACC contains approximately one mole of water per formula unit of $\mathrm{CaCO}_{3}$, though "anhydrous" biogenic forms have been observed with reduced water contents (Radha et al. 2010; Gong et al. 2012). Molecular dynamics simulations have demonstrated that dehydrated ACC is more dense and ordered than hydrous ACC (Saharay et al. 2013). Despite the apparent polyamorphism of ACC, the aforementioned synthetic variety remains the only non-biogenic form that has been successfully stabilized in the laboratory at ambient temperature and pressure conditions. However, the presence of a transient anhydrous phase has been inferred at high temperatures from the interpretation of Differential Scanning Calorimetry profiles (Radha

et al. 2010). ${ }^{1} \mathrm{H}$ and ${ }^{13} \mathrm{C}$ nuclear magnetic resonance spectroscopy has provided some insights into the structural and compositional characteristics of synthetic hydrated ACC (Michel et al. 2008; Nebel et al. 2008). These studies suggested a low abundance of hydroxyl moieties in the structure, as well as the presence of two populations of water molecules that are present in roughly equal proportions. On the millisecond timescale, one of these populations was immobile and the other had a somewhat restricted mobility. Additionally, two distinct populations of carbonate ions were identified that are distinguished by their proximity to immobile water molecules ( $25 \%$ close to immobile $\mathrm{H}_{2} \mathrm{O}$ at room temperature). Another study combining NMR with X-ray diffraction (XRD) reported ${ }^{13} \mathrm{C}$ spectra for amorphous "proto-calcite" and "proto-vaterite" phases (Gebauer et al. 2010); however, the alternative and more traditional interpretation of these data maintains that the observed line broadening in the NMR spectra (and XRD patterns) arises from the presence of nanocrystalline rather than amorphous material in the samples 
(Jäger et al. 2006).

The initial theoretical study of the ACC structure (Goodwin et al. 2010) utilized the Reverse Monte Carlo (RMC) approach (McGreevy and Howe 1992; McGreevy 2001), which refines the atomic positions against experimental data using Metropolis-type Monte Carlo moves to minimize the numerical differences between the observed and model data. In the case of $\mathrm{ACC}$, the $\mathrm{RMC}$ procedure was applied to the pair distribution function (PDF) of synthetic hydrated ACC as obtained from total X-ray scattering (Figure $2 \mathrm{~b}$ ). Recent work has shown that the PDF of stable biogenic ACC is essentially identical to that obtained from synthetic ACC (Reeder et al. 2013). The RMC-derived structure suggested that ACC is nanoporous and chemically heterogeneous, expressing both waterpoor $\mathrm{Ca}$-rich regions and $\mathrm{Ca}$-deficient regions that are relatively enriched in water and carbonate ions. Although this structure model has also been shown to be consistent with the results of calcium K-edge EXAFS and NMR spectroscopy (Michel et al. 2008; Goodwin et al. 2010), subsequent molecular dynamics simulations have shown that the RMC-derived structure corresponds to an unstable state, and that the system tends to become more homogeneous over time (Singer et al. 2012). The observed instability of the $\mathrm{RMC}$ structure highlights the main drawbacks of the RMC approach. While RMC modeling generally produces well-converged PDFs, the solution is not necessarily unique and a large number of candidate structures may fit the experimental data equally well; moreover, because the structure refinement is not based upon an underlying energy model, there is no guarantee that the solution will correspond to a locally stable state on the energy landscape. Despite these limitations, RMC is a valuable technique that can provide insights into the local structure of disordered materials.

As an alternative to RMC, Wallace et al. (2013) constructed a model of hydrated ACC based on the results of MD simulations of calcium carbonate nanoparticle aggregation, coalescence, and dehydration (Figure 2c). This approach utilized replicaexchange molecular dynamics (REMD) (Sugita and Okamoto 1999; Okur et al. 2006; Chaudhury et al. 2012) to first grow hydrated carbonate clusters into a size regime comparable to the coherent X-ray scattering length in synthetic ACC $(\sim 1.5 \mathrm{~nm})$ as well as to the so-called prenucleation clusters, which have an average diameter somewhat less than $1 \mathrm{~nm}$ according to cryo-TEM measurements (Pouget et al. 2009). The initial aggregate structure was obtained by randomly packing copies of a single $1.5-2 \mathrm{~nm}$ diameter $\mathrm{CaCO}_{3}\left(n \mathrm{H}_{2} \mathrm{O}\right)$ cluster into a solvent-filled cell. Subsequently, the calcium to water ratio was slowly adjusted to match that of synthetic ACC $\left(\mathrm{Ca} / \mathrm{H}_{2} \mathrm{O} \sim 1.0\right)$ over a series of constant pressure molecular dynamics simulations. At each iteration, a few solvent molecules were removed from the solvent rich volumes between the clusters. The net effect of this procedure is that the clusters were driven to coalesce without disturbing the structural water molecules that are intrinsic to their character. The model ACC structure obtained by this approach, though not as exact a match to the experimental PDF as the RMC results, is locally stable and faithfully reproduces the most salient aspects of the experimental PDF (Figure 2). Future studies of amorphous carbonate structures may benefit from a hybrid approach that integrates the beneficial aspects of the MD based approach with those of RMC. 
(a)

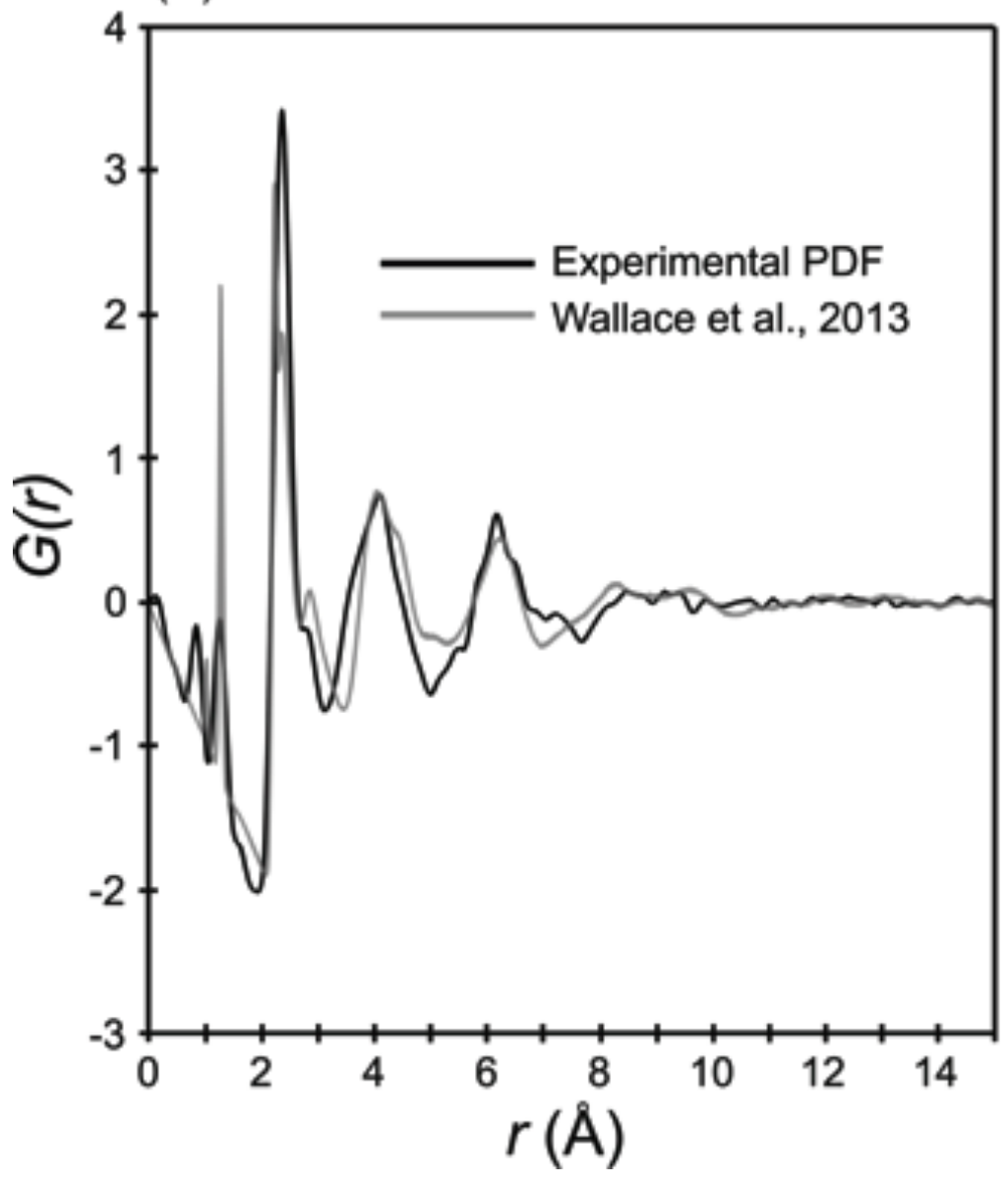

(b)

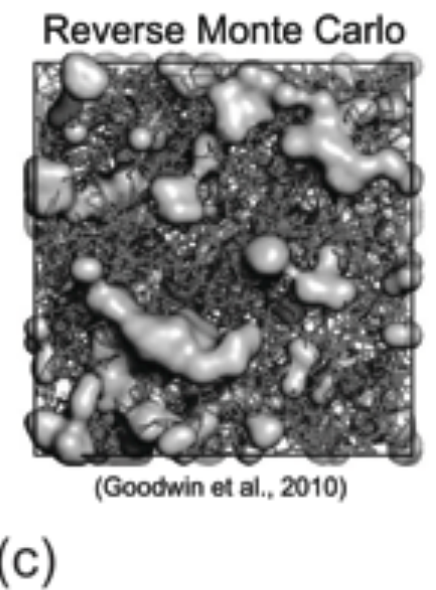

Molecular Dynamics

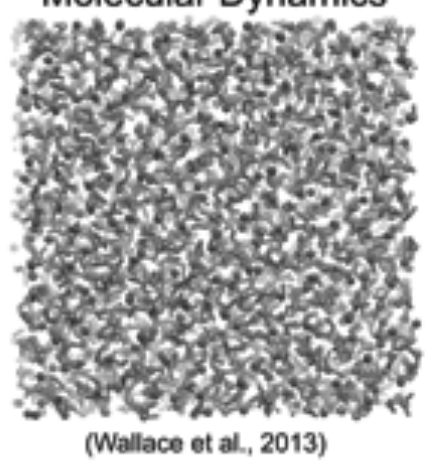

Figure 2: (a) Comparison of the experimental X-ray pair distribution function with the molecular dynamics-derived model structure of amorphous calcium carbonate (Wallace et al. 2013). (b) Snapshot of the RMC fit to the experimental PDF (Goodwin et al. 2010). (c) Model structure of amorphous calcium carbonate obtained from MD simulations of $\mathrm{CaCO}_{3}\left(\mathrm{nH}_{2} \mathrm{O}\right)$ cluster aggregation and dehydration (Wallace et al. 2013). [Figures 2a and 2c from Wallace AF et al (2013) Science 341:885-889. Reprinted with permission from AAAS. Figure $2 b$ adapted with permission from Goodwin AL et al. (2010) Chem Mater 22:3197-3205. Copyright 2010 American Chemical Society.]

Rather than modeling the experimental ACC structure, other workers have focused their efforts on characterizing the free energy landscape underlying structural transitions in anhydrous $\mathrm{CaCO}_{3}$ nanoparticles using the metadynamics approach (Laio and Gervasio 2008; Quigley and Rodger 2008, 2009; Quigley et al. 2009, 2011). The common objective of almost all of these studies has been to determine which phase of $\mathrm{CaCO}_{3}$ is thermodynamically preferred at a given nanoparticle size. The initial results of Quigley and Rodger (2008), performed at constant density for a $\sim 2 \mathrm{~nm}$ diameter particle (75 $\mathrm{CaCO}_{3}$ units), displayed two free energy minima corresponding to separate disordered and semi-ordered states, with the disordered state being overwhelmingly preferred. Later work by the same group showed that for larger particles (192 and 300 formula units) the landscape is possibly reversed, with the amorphous state being metastable with respect to 
both vaterite and calcite-like states (Freeman et al. 2010). The thermodynamic barriers associated with transforming between the disordered and semi-ordered states were predicted to be on the order of several hundred times $k_{\mathrm{B}} T$, suggesting that reordering of the particles in the solid state is unlikely. However, in their most recent work, Quigley et al. (2011) showed that in constant pressure rather than constant density simulations (i.e. in the $N P T$ versus the $N V T$ ensemble) this trend reverses for the 75 formula unit cluster and the disordered state was predicted to be metastable with respect to a partially ordered state where more than $25 \%$ of the ions occupied calcite-like environments. Additionally, in the NPT simulations the barrier between the disordered and semi-ordered states was substantially reduced to a few tens of times $k_{\mathrm{B}} T$, which suggests that some degree of ordering in the particles may be possible without partial dissolution. It was suggested that the enhanced stability of the amorphous phase at constant density arises from spatial confinement of the particle and solvent, as observed experimentally (Stephens et al. 2011). However, it is well known that synthetic and biogenic amorphous calcium carbonate contains a certain amount of water that may influence the stability of these phases; to date only anhydrous $\mathrm{CaCO}_{3}$ particles have been investigated with the metadynamics simulation technique.

\section{Crystalline carbonate phases}

Bulk Properties. Although it has been estimated that calcite and dolomite represent upwards of $90 \%$ of all naturally-formed carbonate minerals, according to Railsback (1999) there are at least 277 minerals that contain carbonate in their structure; these comprise a diverse class of materials that can contain multiple anion species including carbonate, bicarbonate, hydroxide, chloride, fluoride, sulfate, phosphate, and silicate among others. Many of these phases may yet prove to be consequential for carbon capture, storage, and utilization efforts, particularly if impurities from the injection stream are present in significant quantities (Chialvo et al., 2013a) and if the $\mathrm{pH}$ of the brine is too low to support nucleation and growth of pure carbonate phases. This exposes a gap in the theoretical literature, at least as it pertains to mineral trapping of $\mathrm{CO}_{2}$, in which the vast majority of calculations and simulations continue to be performed on phases that are naturally abundant but not necessarily very important for carbon sequestration. However, this also presents an opportunity for theoretical efforts to provide insights in the phase stability of less abundant carbonate minerals for which thermodynamic data are limited. A relatively recent report (Krupka et al. 2010) attempted for the first time to consolidate all of the available data for the whole suite of carbonate-containing phases into a single thermodynamic database.

$\mathrm{Ab}$ initio and DFT calculations are widely used to determine the structure and properties of crystalline carbonate phases at high pressures where experimental measurements are arduous or impossible (Skorodumova 2005). These methods also are valuable tools for refining and testing structure solutions for difficult phases such as vaterite, for which there is still much disagreement (Demichelis et al. 2012; Mugnaioli et al. 2012; Wang and Becker 2012). Primarily, these simulation studies have aimed to determine the elastic properties (i.e. bulk moduli) (Elstnerová et al. 2010; Brik 2011; Ungureanu et al. 2012; Carteret et al. 2013), vibrational spectra (Medeiros et al. 2007; 
Kupka et al. 2009), and thermochemical properties such as heat capacity (Ungureanu et al. 2010) that are critical for predicting phase stability. Where comparison with experimental data is possible, good agreement is generally achievable. These data are often useful for constraining empirical potential models that can be used in MD and MC simulations. Several studies have also used quantum and classical methods to investigate the substitution of M(II) cations in the calcite and dolomite structures (de Leeuw and Parker, 2000; de Leeuw et al., 2002; Austen et al., 2005; Elstnerová et al., 2010; Stashans and Chamba, 2011) and to characterize cation disorder in dolomite (Zucchini et al., 2012). Additionally, the thermodynamics of mixing [described in more detail in Radha and Navrostky (2013)] have been investigated using classical approaches for the $(\mathrm{Ca}, \mathrm{Mg}) \mathrm{CO}_{3}$ (Vinograd et al. 2007), (Ca,Mn) $\mathrm{CO}_{3}$ (Wang et al. 2011), and (Ca,Sr)CO $\mathrm{CO}_{3}$ (Kulik et al. 2010) solid solutions (Figure 3). Density functional theory calculations on transition metal carbonates, particularly iron(II) carbonate (siderite) and manganese(II) carbonate (rhodochrocite) have focused primarily on understanding the electronic band structures of these phases (Sherman 2009; Badaut et al. 2010). In the case of siderite, DFT calculations have also been applied to the analysis of the pressure induced magnetic transition from high spin to low spin iron at 40-50 GPa (Shi et al. 2008; Ming et al. 2012).
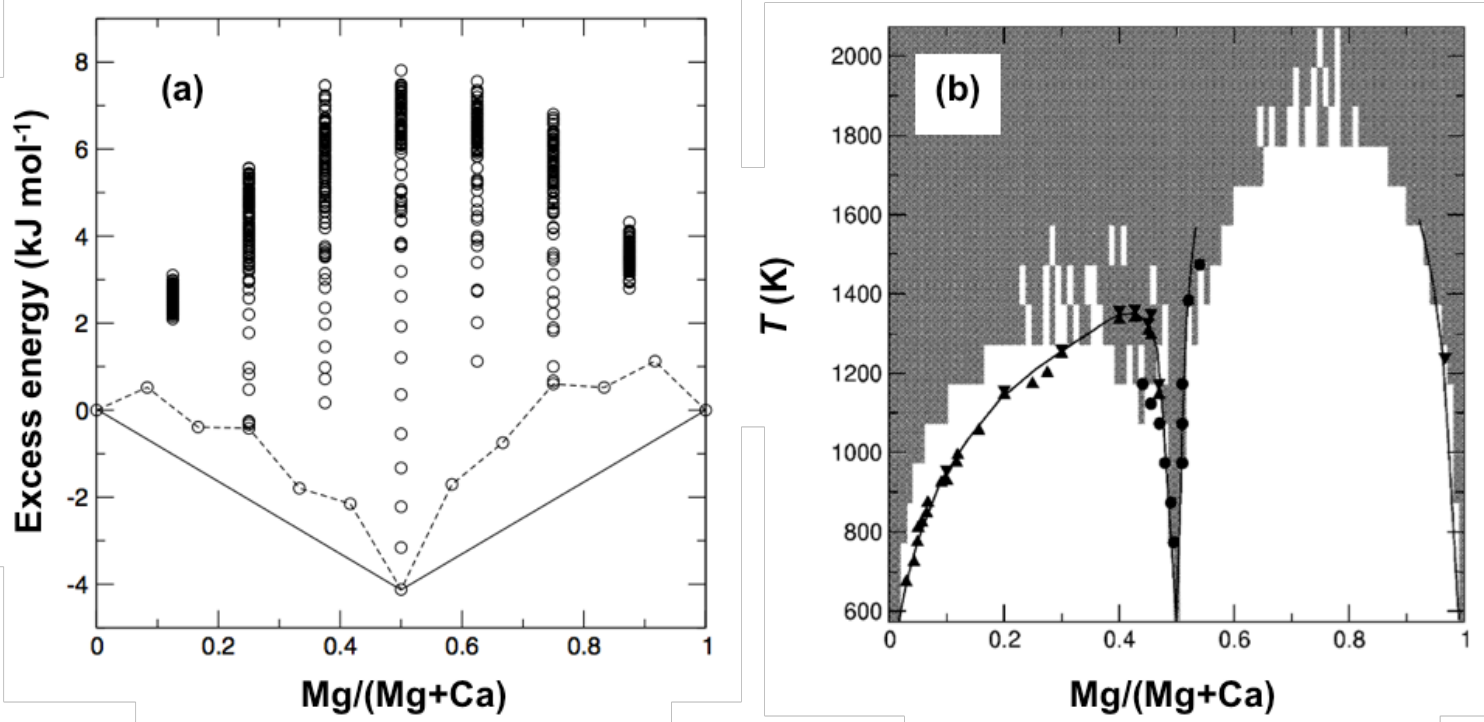

Figure 3. Prediction of the thermodynamics of mixing of the rhombohedral carbonate system $\mathrm{Ca}_{1-\mathrm{x}} \mathrm{Mg}_{\mathrm{x}} \mathrm{CO}_{3}$ based on atomistic simulations (Vinograd et al. 2007). (a) Excess static structure energies of $700 \mathrm{Ca}_{1-\mathrm{x}} \mathrm{Mg}_{\mathrm{x}} \mathrm{CO}_{3}$ structures $(4 \times 4 \times 1$ supercell with $x=0.125$ to 0.875 and different distributions of $\mathrm{Ca}$ and $\mathrm{Mg}$ atoms) predicted with an empirical model of interatomic interactions; the dashed line connects the minimum energy structures. (b) Comparison of predicted and experimental calcite-magnesite phase diagrams. The symbols and solid lines are experimental results (Goldsmith 1983); the gray and white regions indicate predictions of phase stablility and instability (or metastability). The model predictions were obtained using a coarse-grained Monte Carlo simulation $(12 \times 12 \times 4$ supercell $)$ where interactions between metal sites were described with an effective pair potential parameterized to fit the all-atom simulation results in (a). [Reprinted from Geochim Cosmochim Acta 71, Vinograd VL, Burton BP, Gale JD, Allan NL, Winkler $\mathrm{B}$, Activity-composition relations in the system $\mathrm{CaCO}_{3}-\mathrm{MgCO}_{3}$ predicted from static structure energy calculations and Monte Carlo simulations, p 974-983, Copyright 2007, with permission from Elsevier.] 
Interface with water. Compared to the number of high-precision experimental methods available to characterize the bulk structure of materials, there are relatively few scattering and spectroscopic approaches that can provide high fidelity information about interfacial structure. The only available data concerning the interfacial structure of carbonate mineral surfaces with water comes from specular and non-specular X-ray reflectivity $(\mathrm{XR})$ studies of the calcite-water interface. Specular XR provides a laterally averaged view of the interfacial structure (i.e. only information about the vertical positions of atoms relative to the interface). Non-specular XR is a complimentary technique that can provide information about both the vertical and lateral positions of atoms across the interface, but it is only sensitive to atoms that reside in well defined sites, and much more time is required to make high quality measurements relative to specular XR. On its face it appears that non-specular XR might be generally preferable because of its ability to provide three-dimensional information about the interfacial structure. However, in their recent reexamination of the calcite-water interface, Fenter and Sturchio (2012) strongly suggested that the uncertainties associated with previous studies (Geissbühler et al. 2004; Heberling et al. 2011) are substantially larger than the uncertainties in their present specular XR results due to the likely quantitative instability of the calcite surface during the course of the measurements. While Fenter and Sturchio (2012) observed that their data were inconsistent with previous combined non-specular and specular XR model fits, they reported consistency across the board with respect to the specular XR components of earlier studies (Geissbühler et al. 2004; Heberling et al., 2011). These specular XR results show the presence of at least two structured water layers adjacent to the $\{10-14\}$ surface, and indicate that the calcite surface is relaxed (to a depth of up to 4 to 6 unit cells) relative to the bulk structure of calcite (Fenter and Sturchio 2012).

The structure of the calcite-water interface has been studied by molecular orbital calculations (Lardge et al. 2009; Villegas-Jiménez et al. 2009) and classical molecular dynamics (Spagnoli et al. 2006; Cooke and Elliott 2007; Aschauer et al. 2010; Cooke et al. 2010; Miyake and Kawano 2010; Doudou et al. 2012; Wolthers et al. 2012). While ab initio and DFT approaches are appealing due to the robust treatment of interatomic forces, their applicability to the calcite-water interface is challenging because the interfacial region is thick, spanning several unit cell depths of the calcite surface and extending a nanometer or more into the bulk solution. Handling such a large system is not readily tractable for electronic structure methods; therefore, investigations of this kind have been limited to the study of small portions of the calcite surface in contact with very few water molecules; these system sizes may or may not be sufficient to constitute an adequate representation of the interfacial region. Conversely, MD simulations can easily handle large systems due to their more empirical treatment of interatomic forces, but their results can be very sensitive to the parameterization of the forcefield. In a recent study, Fenter et al. (2013) compared experimental specular XR model fits to the results of four different MD simulations that used empirical potentials with different functional forms (nonpolarizable, polarizable, reactive). Quantitative agreement between the measured and predicted XR spectra was found to be poor in each case, primarily because the MD models did not correctly predict the relaxation of the calcite structure in the vicinity of 
the interface (Figure 4). Remarkably, the two most simple force fields (non-polarizable, non-reactive empirical pair potentials) tested by Fenter et al. (2013) predicted interfacial water structures that were consistent with the XR data, whereas the more complex (polarizable or reactive) force fields did not.
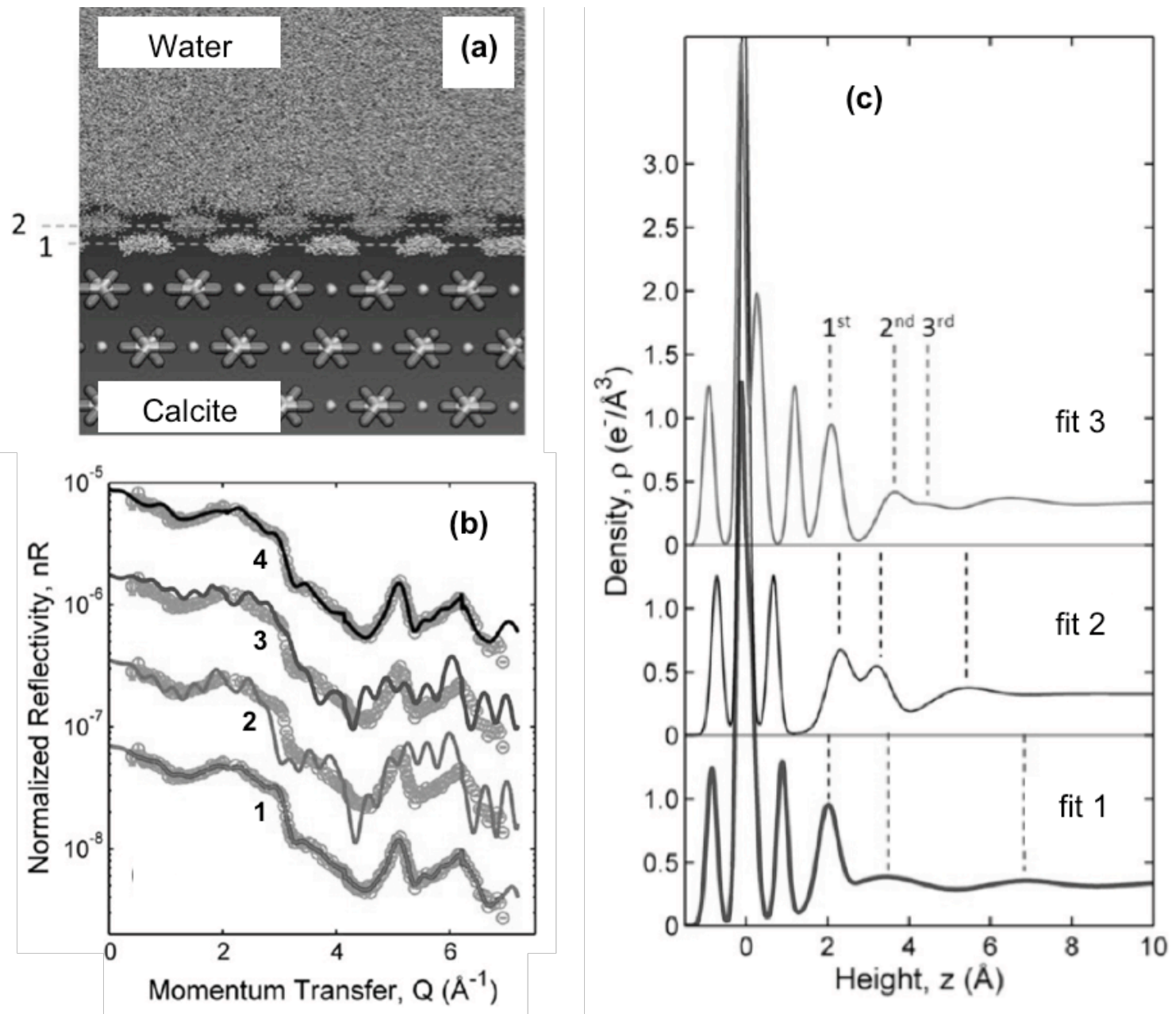

Figure 4. Examination of the structure of water and calcite on terraces of the $\{10-14\}$ calcite surface using a combination of X-ray reflectivity (XR) data and MD simulation results (Fenter et al. 2013). (a) MD simulation prediction of water structure on the calcite surface. The lower part of the figure shows the average position of the calcite atoms during the simulation (spheres: $\mathrm{Ca}$ atoms; sticks: $\mathrm{C}$ and $\mathrm{O}$ atoms). The upper part of the figure shows the range of positions of water $\mathrm{O}$ atoms during the simulation $(\mathrm{O}$ atoms shown as points, with coordinates taken from 500 frames sampled at regular intervals during the simulation). The planes of $\mathrm{O}$ atoms coordinated to surface $\mathrm{Ca}$ and $\mathrm{CO}_{3}$ groups are labeled 1 and 2. (b) Comparison of the normalized XR data (circles) with four different fitting schemes (lines): (1) direct fit to the XR data, (2) direct comparison of the full MD data with the XR data, (3) hybrid scheme in which only the interfacial calcite structure was taken from the MD results, and (4) hybrid scheme in which only the interfacial water structure was taken from the MD results. (c) Total electron density profile in the direction normal to the interface ( $z=0$ at the location of the plane of surface $\mathrm{Ca}$ atoms) calculated by direct fit to the XR data (fit 1 ) or by using a fitting procedure that was informed by two different MD models (fits 2 and 3). All three fits described the XR data equally well. [Adapted with permission from Fenter P et al. (2013) J Phys Chem C 117:5028-5042. Copyright 2013 American Chemical Society.] 
Molecular dynamics simulations and ab initio calculations have also been used to assess the acidity of various sites on the $\{10-14\}$ surface (defects, terraces, acute and obtuse ledges, kinks, and corner sites). On defect-free terraces, water is favored to adsorb associatively (Kerisit et al. 2003; Lardge et al. 2009). However, defect and edge sites can promote water dissociation (Kerisit et al. 2003). From X-ray photoelectron spectroscopy (XPS) there is evidence of $\mathrm{H}-\mathrm{CO}_{3}$ and $\mathrm{Ca}-\mathrm{OH}$ type bonding environments being present on the calcite surface (Stipp and Hochella 1991). Two recent studies (Andersson and Stipp 2012; Wolthers et al. 2012) concluded also that the acidity of surface sites depends strongly on the nature of the local water structure and that dissociative adsorption is promoted to varying degrees at edge, kink, and corner sites, with dissociation being generally most favored at kink and corner sites and along acute step edges. These findings reinforce the experimental observation that obtuse and acute steps behave differently, particularly with respect to their interactions with impurities (Davis et al. 2000, 2004; Wasylenki et al. 2005a, 2005c). Additional insights into the behavior of impurity ions at the calcite-water interface may be gained by revisiting previous studies (de Leeuw and Parker 2000; de Leeuw 2002; de Leeuw et al. 2002; de Leeuw and Cooper 2004) with reactive empirical potentials that can account for variations in surface speciation.

\section{Geochemical kinetics at $\mathrm{M}^{(\mathrm{II})} \mathrm{CO}_{3}$-water interfaces}

Formation of carbonate minerals. To date, modeling studies of carbonate mineral formation from solution have focused predominantly on the calcite-water system. Typically it is assumed that mineral precipitation occurs by nucleation, which is a specific mechanism of phase-separation by which the free energy of a metastable system is reduced by overcoming a free energy barrier opposing the formation of a new phase (De Yoreo et al. 2013; Radha and Navrotsky 2013). Physically, nucleation occurs as thermally driven fluctuations induce the assembly of unstable clusters, which grow ionby-ion against a free energy barrier until a critical size threshold is surpassed. Beyond the critical size the clusters are stable with respect to dissolution, and unstable with respect to continued growth of the new phase. However, because the height of the free energy barrier opposing nucleation is inversely proportional to supersaturation, the free energy barrier opposing nucleation vanishes if the chemical driving force for precipitation becomes large enough. When the free energy barrier disappears, the phase-separation mechanism changes from nucleation to spinodal decomposition. At the spinodal line, the same fluctuations that in the case of nucleation form clusters that are unstable with respect to dissolution instead produce clusters that are unstable with respect to growth. Furthermore, once the system enters the spinodal regime, the assumption of ion-by-ion growth that is implicit in the classical kinetic treatment of nucleation (Nielsen 1964) no longer applies in a strict sense and phase separation may proceed by cluster coalescence as well as by single ion addition.

The mechanism of phase-separation in $\mathrm{CaCO}_{3}$-water systems is challenging to discern largely because the many varied observations concerning the early stages of

mineral formation are difficult to reconcile within a single theoretical framework. It is 
likely, especially given recent suggestion that there may be a liquid-liquid binodal in the system (Wallace et al. 2013), that much of the observed variability may arise from the particular relationship of a given set of experimental conditions to the supposed liquidliquid coexistence line. At low driving force, direct nucleation of the solid phases may be the only accessible mechanism. If the system approaches the binodal (and, beyond that, the spinodal) it may also become possible to form a dense liquid phase by nucleation and spinodal decomposition.

Theorists have the potential to quantify free energy landscapes of early stage carbonate mineral formation, although the rarity of nucleation events makes the simulation of systems comparable to experimental conditions difficult for suitably long timescales. Additionally, the ability of potential-based simulation methods to elucidate phase separation processes depends on the development of force fields that accurately describe both solid and aqueous phases. The force field for the $\mathrm{CaCO}_{3}$-water system developed by Raiteri et al. (2010) is a promising step towards the goal of simulating $\mathrm{CaCO}_{3}$ precipitation events as it accurately reproduces free energies of component ions in solution as well as the energy difference for the calcite to aragonite phase transition. The use of non-reactive potentials, however, prevents direct description of carbonate speciation and limits its applicability for studying nucleation events because carbonatebicarbonate conversion occurs during $\mathrm{CaCO}_{3}$ nucleation at $\mathrm{pH}$ levels relevant to natural systems. Development of reactive carbonate models, like the one recently proposed by Gale et al. (2011) for the aqueous calcium carbonate system, will help future simulation efforts better study carbonate formation processes.

At present, most simulations pertinent to $\mathrm{CaCO}_{3}$ nucleation have utilized MD simulations (Martin et al. 2006; Raiteri and Gale 2010; Demichelis et al. 2011; Finney and Rodger 2012) and enhanced sampling methods including umbrella sampling (Tribello et al. 2009; Demichelis et al. 2011) and metadynamics (Quigley and Rodger 2008) in an attempt to identify $\mathrm{CaCO}_{3}$ species that act as intermediates between ions in solution and post-nucleation amorphous or crystalline $\mathrm{CaCO}_{3}$ phases. Di Tommaso and de Leeuw $(2008,2009)$ have examined $\mathrm{Ca}-\mathrm{CO}_{3}$ ion pair formation as a first step towards modeling homogeneous nucleation from solution. Such simulations have repeatedly shown that cluster aggregation and ion or cluster addition to amorphous nanoparticles in solution is essentially barrier-less (Figure 5), unlike ion or cluster addition to ordered $\mathrm{CaCO}_{3}$ phases (Martin et al. 2006; Tribello et al. 2009; Raiteri and Gale 2010). 
(a)
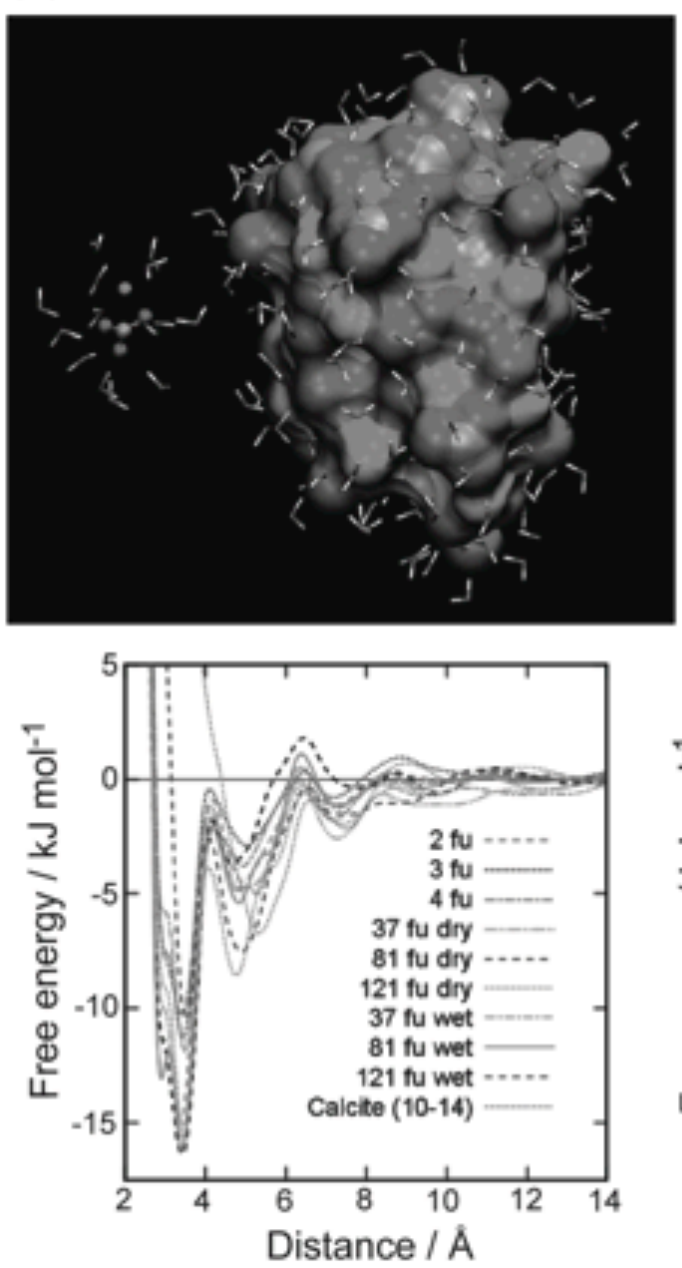

(b)
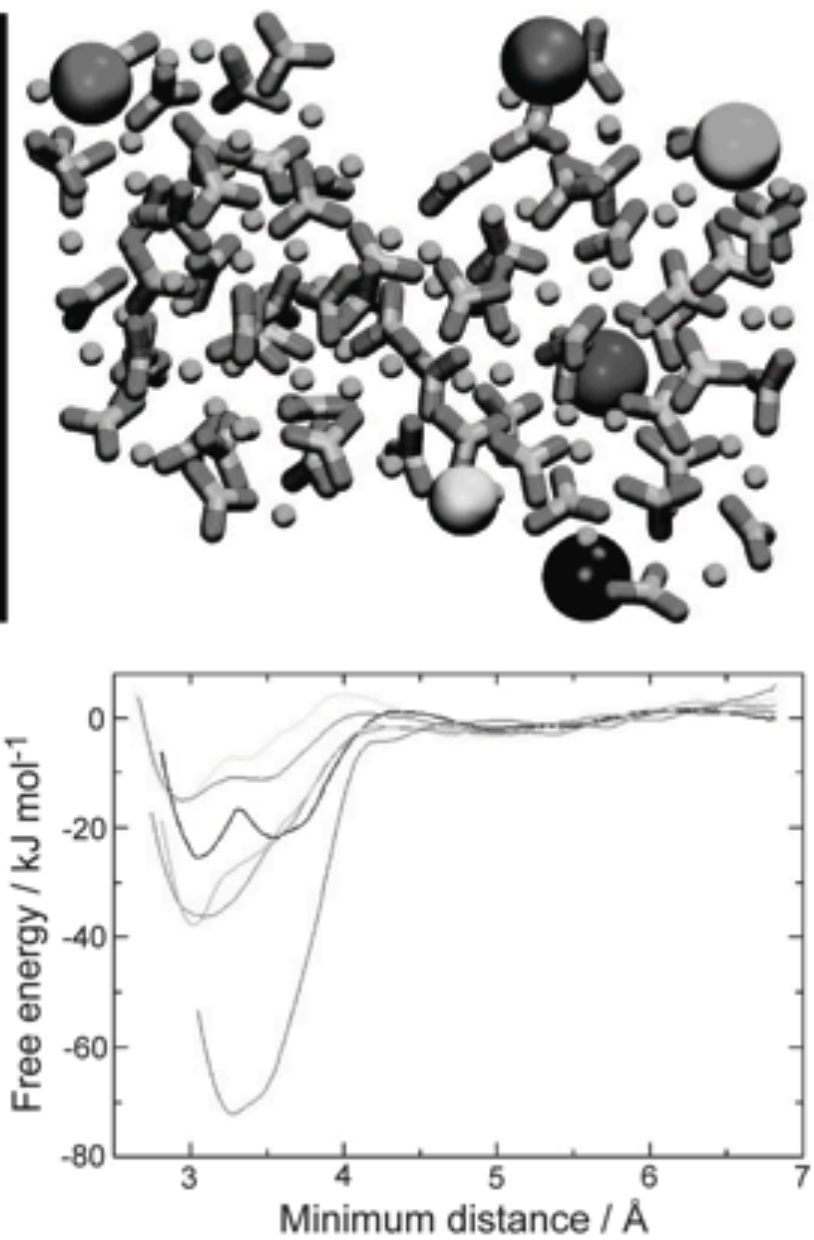

Figure 5: Atomistic scale calculations with model ACC clusters demonstrate that calcium ion and $\mathrm{CaCO}_{3}$ ion pair addition to ACC are energetically favorable processes. (a) Illustration of a $\mathrm{CaCO}_{3}$ ion pair (visible on the left with water molecules in its first solvation shell) being added to a model ACC cluster (the large structure on the right, also shown with its neighboring water molecules) and free energy profiles for the addition of a $\mathrm{CaCO}_{3}$ ion pair to ACC clusters of varying size (formula units, fu) and hydration state (Raiteri and Gale 2010). The equivalent profile for addition to the (10-14) surface of calcite (light gray line with an overall minimum at $\sim 5 \AA$ instead of $\sim 3 \AA$ ) is shown for comparison. (b) Model ACC cluster with potential calcium ion addition sites (shown as large spheres) and free energy profiles for the addition of $\mathrm{Ca}^{2+}$ at the different sites (Tribello et al. 2009). [Adapted with permission from Raiteri P and Gale JD (2013) J Am Chem Soc 132:17623-17634, Copyright 2010 American Chemical Society, and Tribello GA et al. (2009) J Phys Chem B 113:11680-11687, Copyright 2009 American Chemical Society.]

An interplay between calcium - carbonate coordination number and ion hydration has been invoked to explain differences in cluster stability based on size (Finney and Rodger 2012), although no specific cluster size or makeup has been identified as a likely candidate for the stable prenucleation clusters. Hydration effects also are influential in modulating the energetic barriers to cluster aggregation and growth - the disorder of 
water layers at unstructured $\mathrm{CaCO}_{3}$ nanoparticles may explain the low energy barrier to forming and growing these species compared to crystalline particles, which exert stronger ordering on the surrounding water molecules (Tribello et al. 2009; Raiteri and Gale 2010). Additional simulations of heterogeneous nucleation on self-assembled monolayers have examined the roles of monolayer ionization, epitaxial matching, and headgroup orientation on nucleating $\mathrm{CaCO}_{3}$ (Freeman et al. 2008), and successfully predicted the orientations of calcite crystallization on carboxylic-acid terminated surfaces (Quigley et al. 2009).

It should be noted that the majority of these simulations describe high $\mathrm{pH}$ and high supersaturation regimes, where $\mathrm{CO}_{3}{ }^{2-}$ is the dominant carbonate species and cluster growth and aggregation can be observed on time scales accessible by simulation. Both of these limitations are problematic because the dominant species in most natural systems is $\mathrm{HCO}_{3}{ }^{-}$and because the mechanism of phase separation depends upon supersaturation. Thus, high concentration simulations may only probe those mechanisms, such as spinodal decomposition, that are active at high driving forces.

Ion attachment and detachment at carbonate step edges. The flat $\{10-14\}$ surface of calcite is by far the most stable face and dominates the morphology of the mineral. From atomic force microscopy (AFM) experiments, growth and dissolution on these surfaces is known to occur at steps (Gratz et al. 1993) and spiral dislocations (Hillner et al. 1993). Early simulations of ion detachment at steps include a kinetic Monte Carlo model that reproduces AFM data for calcite dissolution (McCoy and LaFemina 1997) and MD simulations that predicted $\mathrm{CaCO}_{3}$ unit removal to be more energetically favorable from the obtuse step compared to the acute step (de Leeuw et al. 1999), as seen experimentally. Subsequent MD calculations of free energy profiles (Spagnoli et al. 2006) and energy minimizations (Kerisit et al. 2003) concluded that ion detachment occurs preferentially at step edges compared to the flat surface, and identified the reaction of water with edge $\mathrm{CO}_{3}$ groups as the first step in the detachment process. In the case of $\mathrm{BaSO}_{4}$, a potential analog for $\mathrm{CaCO}_{3}$, metadynamics and umbrella sampling calculations showed that metal detachment from step edges is a multi-step process as described in Figure 6 (Stack et al. 2012). Metal detachment from calcite step edges may be equally complex.

Simulations of ion attachment at carbonate step edges have been carried out for $\mathrm{MCO}_{3}$ (where $\mathrm{M}=\mathrm{Ca}^{2+}, \mathrm{Mg}^{2+}, \mathrm{Fe}^{2+}, \mathrm{Sr}^{2+}$, or $\mathrm{Cd}^{2+}$ ) growth on the calcite $\{10-14\}$ surface (de Leeuw 2002). As for attachment of $\mathrm{Ca}^{2+}$ ions, the initial incorporation of impurity ions is more exothermic at the obtuse step, with free energies of attachment 44 to $86 \mathrm{~kJ}$ $\mathrm{mol}^{-1}$ more negative than at the acute step, depending on the cation. The calculated free energies indicate that impurity incorporation competes effectively with calcite formation for a single row of growth, but becomes increasingly endothermic for subsequent rows due to the mismatch with the underlying calcite lattice. Thus, subsequent growth becomes unfavorable (Davis et al. 2000) and growth is poisoned, as seen experimentally (Wasylenki et al. 2005b; Nielsen et al. 2013). The development of a new force field for MD simulations of hydrated calcium carbonate (Raiteri et al. 2010) highlights a few differences from previous models (Jackson and Price, 1992; Pavese et al. 1992, 1996) 
with implications for step growth. Namely, inner-sphere complexation of $\mathrm{Ca}^{2+}$ at the flat $\{10-14\}$ surface is unfavorable and $\mathrm{CO}_{3}{ }^{2-}$ is only weakly attracted to the interface. Thus, the traditional view of growth wherein ions adsorb to the surface and, then, diffuse to growth sites may be unrealistic for the calcite $\{10-14\}$ surface, as ions prefer to diffuse via solution. Continued development of force field parameters that accurately describe the energetics of both aqueous and solid phases will aid in future simulations of carbonate growth mechanisms.
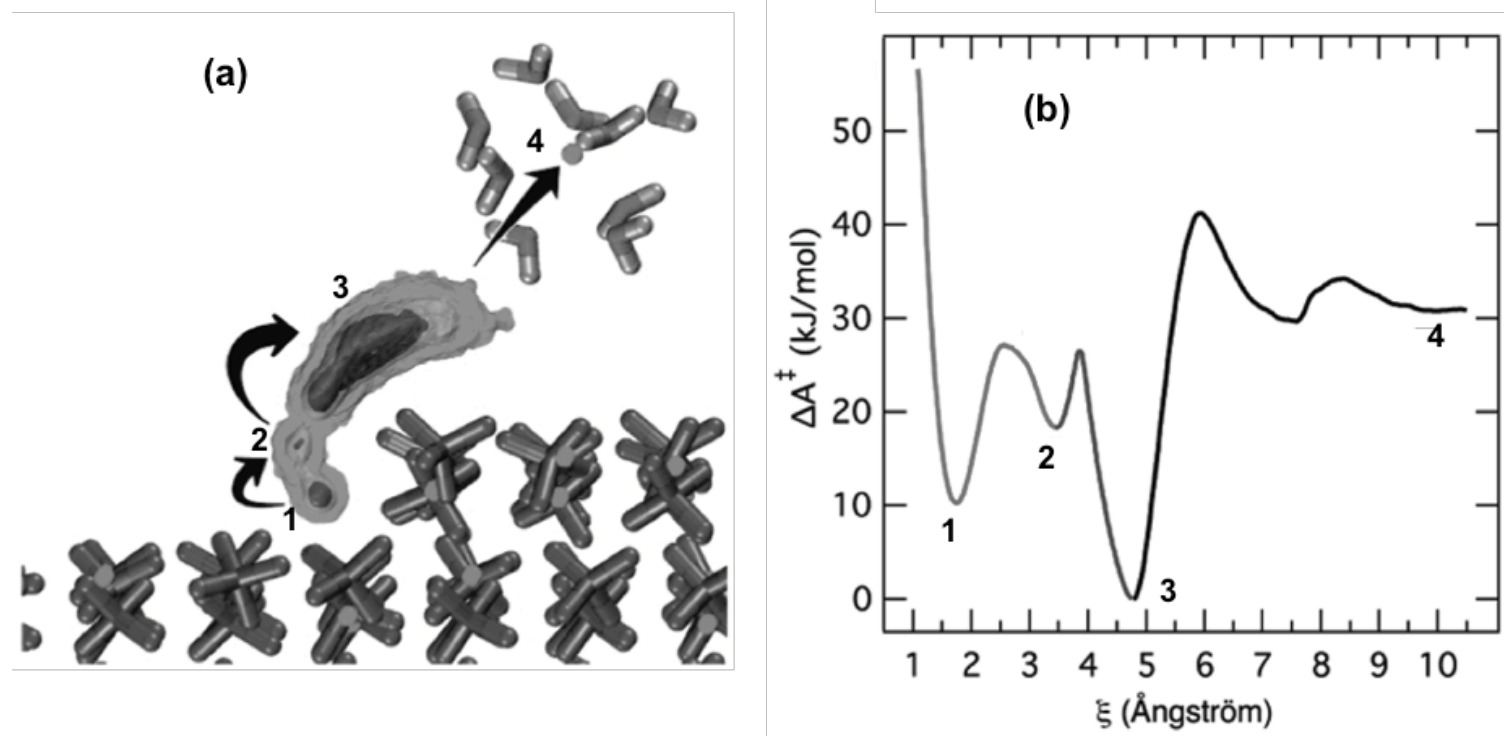

Figure 6: Metadynamics and umbrella sampling calculations reveal that the attachment of $\mathrm{Ba}^{2+}$ on a $\mathrm{BaSO}_{4}$ step edge involves several stable states: (1) Ba at the step edge, (2) Ba slightly detached from the step edge, (3) Ba forming an inner-sphere surface complex above the step edge, and (4) Ba in solution (Stack et al. 2012). The different stable states are shown in (a) a twodimensional map of the potential energy landscape calculated with the metadynamics method, and (b) a plot of the free energy profile along the minimum free energy path as calculated with the umbrella sampling technique (this technique shows a fifth stable state at $\xi \approx 7.5 \AA$ where $\mathrm{Ba}$ forms an outer-sphere surface complex). The potential energy landscape associated with $\mathrm{Ca}^{2+}$ attachment to a $\mathrm{CaCO}_{3}$ kink site is likely to be similarly complex. [Adapted with permission from Stack AG et al. (2012) J Am Chem Soc 134:11-14. Copyright 2012 American Chemical Society.]

Influence of organic species on carbonate formation and growth. Organic additives have long been known to modify calcium carbonate growth rate (Addadi and Weiner 1985), morphology (Wada et al. 1999), and nucleating phase (Falini et al. 1996). With recent developments in understanding the early stages of $\mathrm{CaCO}_{3}$ crystallization, more attention is being paid to how organic molecules affect the formation, evolution, and stability of amorphous $\mathrm{CaCO}_{3}$ phases and prenucleation species. While the motivation for these studies often lies in understanding biomineralization, organic species are ubiquitous in most environments and are likely to also influence non-biogenic carbonate formation. The specific functions of organic additives and the mechanisms by which they act, however, remain difficult to discern because of their chemical complexity and the fact that a single organic molecule can have multiple roles, and these roles can change depending on concentration and other conditions. Titration work in the presence 
of organic molecules by Gebauer et al. (2009) constitutes a first effort at developing a framework to categorize additives based on their effects on all stages of $\mathrm{CaCO}_{3}$ formation. Organic species are divided into classes based on their interaction with calcium ions, soluble clusters, nanoparticles, amorphous intermediates, and nucleated crystals.

In an attempt to examine how acetate, aspartate and citrate influence prenucleation clusters of $\mathrm{CaCO}_{3}$ within the context of these categories, the MD simulation study by Raiteri et al. (2012) highlights the complexity of organic- $\mathrm{CaCO}_{3}$ interactions and the difficulty in identifying individual roles and mechanisms. Both aspartate and citrate are classified as nucleation inhibitors from titration data, yet only citrate binds strongly enough to $\mathrm{Ca}^{2+}$ in solution to inhibit nucleation through the lowering of supersaturation. The simulations indicate that aspartate, which is also classified as a stabilizer of amorphous intermediates, has a moderate binding affinity for both clusters and amorphous nanoparticles (a weaker affinity than citrate, which is classified as a stabilizer of prenucleation clusters but not of amorphous intermediates). This moderate affinity of aspartate for amorphous nanoparticles presumably allows stabilization of the intermediate phase, as seen in the experimental formation of polymerinduced liquid precursor (PILP) in the presence of polyaspartate (Gower and Odom 2000) and in agreement with other MD simulation work (Finney and Rodger 2012). Additionally, the strong interaction of citrate with all $\mathrm{CaCO}_{3}$ species except basal calcite surfaces may help explain the experimentally observed bias towards calcite in systems containing citrate. Results from the metadynamics work of Freeman et al. (2010) suggest a similar mechanism at work in the case of eggshell protein OC-17; the protein is proposed to bind to ACC nanoparticles, facilitate the transformation to calcite and, then, desorb from the crystal surface as the mineral begins to grow.

Other computational studies have focused on understanding the mechanisms that underlie experimentally observed effects of organics on $\mathrm{CaCO}_{3}$ step growth kinetics. Atomistic energy minimizations of phosphonates indicate that these molecules bind more strongly to steps than to the flat $\{10-14\}$ surface, confirming results of AFM growth experiments (Nancollas et al. 1981; Gratz et al. 1993). More recent MD simulation work again confirms the preference of organic species (in this case polyaspartate and polyacrylic acid) for steps over flat surfaces, and further speculates that the inhibitory ability depends on an interplay between surface/step binding affinity and affinity for ions in solution (Aschauer et al. 2010). Experimental studies demonstrate that impurities, including organic molecules (peptides and peptoids), influence calcite growth differently depending on their concentration: at low concentrations they accelerate calcite step velocities and growth rates, whereas at high concentrations they inhibit calcite growth (Elhadj et al. 2006a; Chen et al. 2011). The organic concentration at which growth is inhibited is related to the effectiveness of the organic as a growth accelerator (more effective growth promotion corresponds to a lower inhibitory concentration). Elhadj et al. (2006b) modeled polyaspartate $\left(\mathrm{Asp}_{\mathrm{n}}\right)$ attachment at calcite steps with a quantum mechanics method and determined that binding strength increases with Asp chain length, reducing the $\mathrm{Asp}_{\mathrm{n}}$ concentration required to block step growth. Results from molecular simulations have also suggested that enhancements in step growth rate may be explained by the ability of organic molecules to lower dehydration barriers, either of ions (Hamm et 
al. 2010; Piana et al. 2007) or of the mineral surface (Piana et al. 2006), both of which represent significant barriers to step growth. Lastly, organic self-assembled monolayers, commonly used experimentally as templates for heterogeneous $\mathrm{CaCO}_{3}$ nucleation (Aizenberg et al., 1999; De Yoreo et al., 2013), also have been studied computationally to understand their interaction with nucleating $\mathrm{CaCO}_{3}$ minerals. This work (Quigley et al., 2009) demonstrated that the formation of oriented crystals on self-assembled monolayers does not arise as a consequence of epitaxy, but rather by the cooperative reorganization of both the mineral phase and the organic layer.
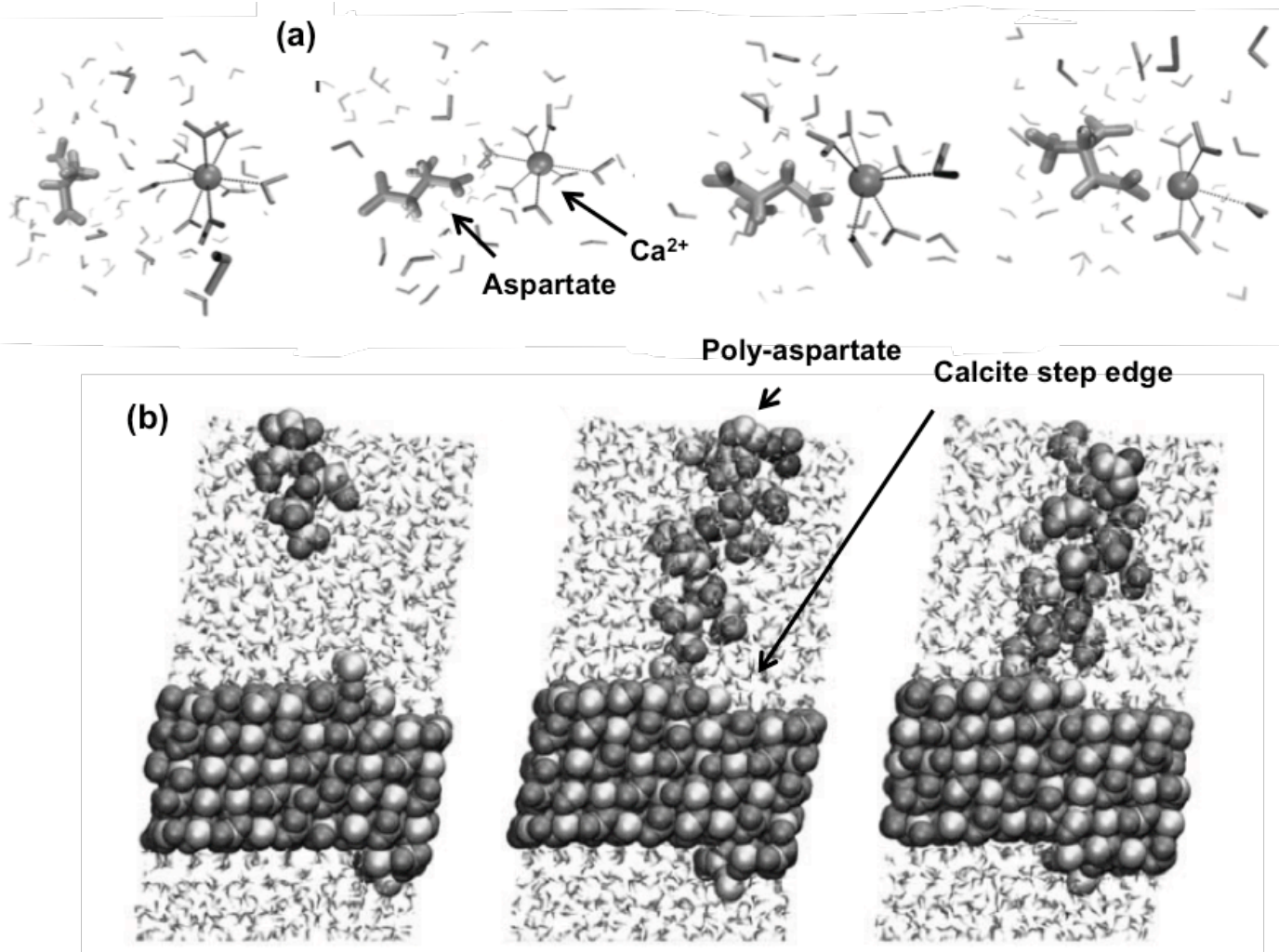

Figure 7: Organic acids may influence calcite growth rates either by (a) interacting with $\mathrm{Ca}^{2+}$ in solution, of (b) interacting with growth (kink) sites on the calcite surface. (a) Molecular dynamics simulations show that Asp binding to $\mathrm{Ca}^{2+}$ in bulk liquid water strongly disrupts the solvation shell of calcium; in particular, the number of water molecules coordinating $\mathrm{Ca}$ decreases from 8 to 5 as Asp approaches $\mathrm{Ca}$ (Hamm et al. 2010). (b) Molecular dynamics simulations show that $\mathrm{n}$ Asp spontaneously adsorbs on negatively charged kink sites, but not on the uncharged flat surface of calcite (Aschauer et al. 2010). [Figure 7a adapted with permission from Hamm LM et al. (2010) J Phys Chem B 114:10488-10495, Copyright 2010 American Chemical Society; Figure 7b reprinted from J Colloid Interface Sci 346, Aschauer U, Spagnoli D, Bowen P, Parker SC, Growth modification of seeded calcite using carboxylic acids: atomistic simulations, $\mathrm{p}$ 226-231, Copyright 2010, with permission from Elsevier.]

\section{CO$_{2}$-BRINE-MINERAL SYSTEMS}

\section{$\mathrm{CO}_{2}$-brine two-phase systems}


Equation of state. In order to predict the fate of $\mathrm{CO}_{2}$ in geologic carbon sequestration, it is essential to consider the phase behavior of $\mathrm{CO}_{2}$ when placed in contact with the geological medium (DePaolo and Cole, 2013). A molecular model used for that purpose should correctly describe the thermodynamic properties of mixtures of $\mathrm{CO}_{2}$ with brine as a function of thermodynamic conditions: pressure $(P)$ or density $(\rho)$, temperature $(T)$, and composition (nature of the ions and their concentrations) in the aqueous phase.

Several force fields have been proposed in the literature to investigate, using various approaches [the most common being the Grand Canonical Monte Carlo (GCMC) simulation technique], the phase behavior of pure $\mathrm{CO}_{2}$ and its mixture with pure and salty water.

The most popular force field for $\mathrm{CO}_{2}$, the EPM2 model, was introduced by Harris and Yung (1995). This simple 3-site model, in which $\mathrm{C}$ and $\mathrm{O}$ atoms interact via pairwise additive Lennard-Jones (LJ) and Coulomb (with point charges) potentials, is able to correctly capture the Liquid-Vapor equilibrium (LVE) and the critical properties of pure $\mathrm{CO}_{2}$ in the $(\rho, T)$ plane. Accounting for flexibility in this model does not appreciably change the phase boundaries, and simulations with the EPM2 model usually treat the $\mathrm{CO}_{2}$ molecule as a rigid entity. The similar Exp-6 and TraPPE (Transferable Potential for Phase Equilibria) models are also able to describe the LVE of pure $\mathrm{CO}_{2}$ (Potoff et al. 1999; Potoff 2001). Zhang and Duan (2005) optimized parameters of a similar force field for the prediction of the LVE and critical properties. Other force fields have been proposed, either with increased complexity to refine the prediction of $\mathrm{CO}_{2}$ properties (such as the composition of the coexisting phases or the critical behavior) or with simplified interactions to increase computational efficiency. Examples of the latter type include several 1-site models that differ according to their treatment of electrostatic [point quadrupole (Vrabec et al. 2001), thermally averaged quadrupole (Mognetti et al. 2008) or without explicit electrostatics (Avendano et al. 2011)] and non-electrostatic interactions [isotropic (Mognetti et al. 2008; Vrabec et al. 2001) or anisotropic LJ (Persson 2011), with Lorentz-Berthelot combining rules for interactions between atoms of different type or more elaborate ones (Schacht et al. 2011)]. A 3-site model with LJ interactions and a point quadrupole, optimized for LVE, has also been proposed (Merker et al. 2010). These simpler models are usually parameterized to reproduce the experimental LVE and/or critical properties or analytical equations of state such as the Statistical Associating Fluid Theory (SAFT) model (Avendano et al. 2011; Schacht et al. 2011). In the opposite direction, refined models have been proposed that introduce flexibility (Zhu et al. 2009; Cygan et al 2012) or polarization effects using distributed point polarizabilities (Wang et al. 2012a). Finally, ab initio calculations have enabled the direct investigation of the effect of dispersion on the properties of supercritical $\mathrm{CO}_{2}\left(\mathrm{scCO}_{2}\right)($ Balasubramanian et al. 2009) and the development of improved force fields accounting for non-additive interactions (Oakley and Wheatley 2009) or based on a rigorous energy decomposition and Symmetry Adapted Perturbation Theory (Yu et al. 2011).

Some studies have been devoted to the properties of a single phase, such as the effect of density on the structure of $\mathrm{scCO}_{2}$ along an isotherm (Ishii et al. 1996), the structure of liquid $\mathrm{CO}_{2}$ (Neuefeind et al. 2009) or more rarely dynamical properties (In Het Panhuis et al., 1998; Nieto-Draghi et al. 2007; Garcia-Ratés et al. 2012). In all cases, 
comparison with experimental data provides a critical test of the accuracy of the force fields. For example, Nieto-Draghi et al. (2007) found that the EPM2 model reasonably describes the shear viscosity and thermal conductivity under sub-critical conditions, except for the thermal conductivity at low density. Such a good prediction of dynamical properties by EPM2 is remarkable, since this force field was calibrated to reproduce only thermodynamic properties, and suggests that the interactions between $\mathrm{CO}_{2}$ molecules are relatively well described on the microscopic level.

The phase equilibria of pure $\mathrm{CO}_{2}$ have been investigated in many simulation studies, not only for their interest per se and their relevance for practical applications, but also as a critical test of molecular models, in particular as a first step towards predicting the phase behavior of mixtures containing $\mathrm{CO}_{2}$. For example, Errington et al. (1998) used GCMC simulations to predict the LVE of pure $\mathrm{CO}_{2}$ with the EPM2 model and its binary mixture with water. The same model was investigated by Vorholz et al. (2000) using GCMC simulations in the NVT and NPT ensembles (Figure 8a). These studies, together with the above-mentioned ones, confirm the ability of EPM2 to correctly describe the LVE and critical properties of pure $\mathrm{CO}_{2}$. The Fluid-Solid equilibria (FSE) have attracted less attention, but have also provided interesting insights. Albo and Müller (2003) discussed the relevance of simulation methods and the choice of force field for the prediction of these equilibria. More recently, Péréz-Sanchez et al. (2013) analyzed the role of the quadrupole moment on the melting curve of dry ice up to $1000 \mathrm{MPa}$ by comparing several popular force fields. They found that, firstly, while the models were all able to reproduce the experimental LVE, their prediction of the melting curve differed significantly; secondly, of all the models tested, the TraPPE force field yielded the best predictions for melting curve and triple point properties and; thirdly, a large quadrupole moment is required to correctly describe the properties of the solid phase. From the dynamical point of view, molecular simulations have been used by Leyssale et al. (2005) to investigate homogeneous crystal nucleation in supercooled $\mathrm{CO}_{2}$.

Several groups have built upon the promising results on the thermodynamic properties of pure $\mathrm{CO}_{2}$ by combining the EPM2 or TraPPE models with popular force fields for water to predict the phase behavior of their binary mixtures. For example, Errington et al. (1998) and Vorholz et al. (2000) investigated the SPC and TIP4P water models. They found that the use of standard combining rules for the LJ parameters of the pure components yielded very good results for the LVE between EPM2 and both SPC or TIP4P, for temperatures of 348 to $393 \mathrm{~K}$ and pressures up to $20 \mathrm{MPa}$. Among several combinations of force fields for the solubility of $\mathrm{CO}_{2}$ in water over a wide range of thermodynamic conditions, the Exp-6 model of Errington and Panagiotopoulos (Errington and Panagiotopoulos, 1998; Potoff et al., 1999) gives the best agreement with experimental data (Lísal et al. 2005). The most comprehensive comparison of force fields for mixtures of water and $\mathrm{CO}_{2}$, over a wide range of $P$ ( 0 to $1000 \mathrm{bar}$ ) and $T$ (323 to 623 $\mathrm{K})$ was carried out by Liu et al. (2011). While none of the models could reproduce the experimental data over the whole range of thermodynamic conditions, it was found that, firstly, below $523 \mathrm{~K}$, i.e. away from the critical region of water, the Exp- 6 model gives the best predictions for the $\mathrm{CO}_{2}$-rich phase, whereas the TraPPE/TIP4P2005 combination is more accurate for the $\mathrm{H}_{2} \mathrm{O}$-rich phase (Figure $8 \mathrm{~b}$ ); secondly, near the critical region 
( 523 to $623 \mathrm{~K}$ ) none of the models correctly predicts the critical behavior, even though the Exp-6 model gives the correct qualitative features and; thirdly, modified LorentzBerthelot combining rules provide only minor improvements. This extensive study highlights the need for improving the force fields for the prediction of binary mixture properties. To achieve this goal, it might be useful to consider in the parameterization process the dynamical properties, which have been only rarely investigated for mixtures (Fernández et al. 2005; Nieto-Draghi et al. 2007; Garcia-Ratés et al. 2012). An alternative approach consists in designing modified Lorentz-Berthelot combining rules for the $\mathrm{CO}_{2}$ water interaction that are fitted to the mutual solubility of water and $\mathrm{CO}_{2}$, but with the mole fraction of water in $\mathrm{CO}_{2}$ corrected to account for the polarization change associated with water evaporation (Vlcek et al. 2011; Chialvo et al. 2013a). This approach follows naturally from the fact that non-polarizable water models will necessarily underestimate the enthalpy of vaporization of water because they inherently cannot account for the different dipole moments of water in $\mathrm{scCO}_{2}$ and in liquid water.

Finally, a few studies have considered the more complex mixtures of $\mathrm{CO}_{2}$ with brine. Vorholz et al. (2004) tested the ability of the SPC and TIP4P (for water) and EPM2 (for $\mathrm{CO}_{2}$ ) models, with various potentials for sodium and chloride ions, to reproduce the solubility of $\mathrm{CO}_{2}$ in $\mathrm{NaCl}$ aqueous solutions, for temperatures of 373 to $433 \mathrm{~K}$ and pressures up to $10 \mathrm{MPa}$. Several salt molalities, including above the solubility limit, were simulated. While the "salting-out" effect observed in experiments was qualitatively reproduced, the decrease in $\mathrm{CO}_{2}$ solubility in the presence of salt was overestimated. Improvements can be obtained by introducing modified combining rules for the interactions between unlike species. Molecular dynamics simulations further provided data on the diffusion and electric conductivity of $\mathrm{CO}_{2}$-brine mixtures, for which few experimental results are available, as well as molecular scale information, such as rotational relaxation times. Garcia-Ratés et al. (2012) investigated these properties with the SPC/E and EPM2 models for water and $\mathrm{CO}_{2}$ and two models for the ions. Finally, the solvation of cations in $\mathrm{scCO}_{2}$-water mixtures at $300 \mathrm{~K}$ was studied by Criscenti and Cygan (2013). This study investigated the partitioning of alkali and alkaline-earth metals between the liquid aqueous and supercritical $\mathrm{CO}_{2}$-rich phases. Although ions consistently prefer the aqueous phase, the partitioning of cations into $\mathrm{CO}_{2}$ increases with ion size, because of the inverse relation between ion size and solvation energy. When both phases are in contact, cations can be found in the $\mathrm{CO}_{2}$ phase as partially (e.g., $\mathrm{K}^{+}$or $\left.\mathrm{Cs}^{+}\right)$or fully $\left(\mathrm{Sr}^{2+}\right)$ hydrated complexes. 

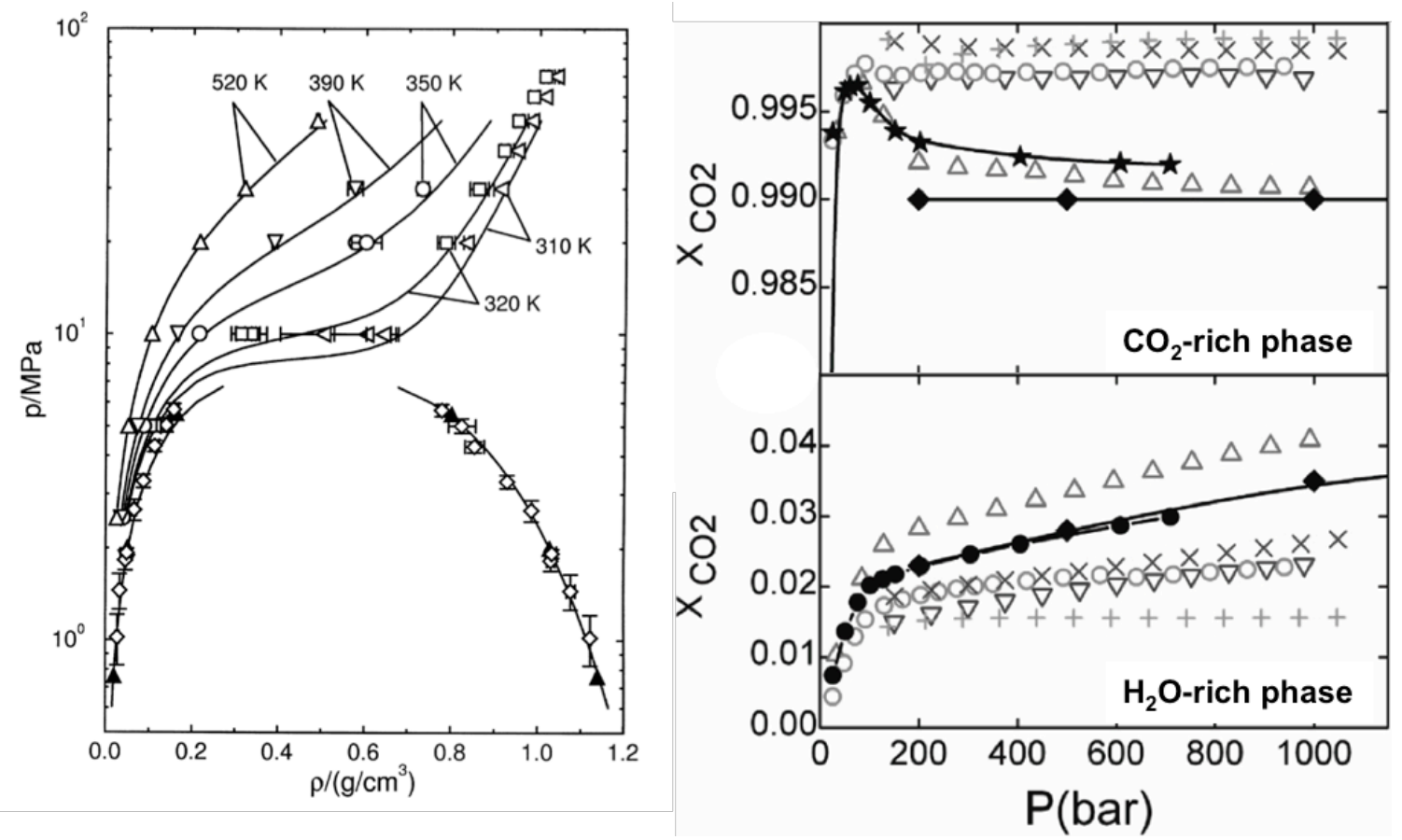

Figure 8: Model predictions of the phase properties of pure $\mathrm{CO}_{2}$ (left) and $\mathrm{CO}_{2}$-water mixtures (right). (a) Pressure-density relation of pure $\mathrm{CO}_{2}$ calculated with the equation of state of Bender (1970) (solid line) or predicted using GCMC simulation with the EPM2 $\mathrm{CO}_{2}$ model (open symbols) at $T=290$ to $520 \mathrm{~K}$ (Vorholz et al. 2000). (b) Pressure-composition relation of $\mathrm{CO}_{2}$ water two-phase mixtures predicted using GCMC simulation (Liu et al. 2011) with different models of water and $\mathrm{CO}_{2}$ [Exp-6 water and $\mathrm{CO}_{2}(\Delta), \mathrm{EPM} 2+\mathrm{TIP} 4 \mathrm{P} / 2005(+)$, TraPPE+TIP4P2005 (×), EPM2+SPC (o), EPM2+TIP4P $(\nabla)]$. The filled symbols are experimental data from Wiebe and Gaddy (1939) (circles), Wiebe (1941) (stars), and Takenouchi and Kennedy (1964) (diamonds). [Figure 8a reprinted from Fluid Phase Equil 226, Vorholz J, Harismiadis VI, Panagiotopoulos AZ, Rumpf B, Maurer G, Molecular simulation of the solubility of carbon dioxide in aqueous solutions of sodium chloride, p 237-250, Copyright 2004, with permission from Elsevier; Figure 8b reproduced with permission from Liu Y et al. (2011) J Phys Chem B 115:6629-6635, Copyright 2011 American Chemical Society.]

Interfacial tension. Once the composition of the co-existing fluid phases is known under given thermodynamic conditions, molecular simulations allow computing another important property in the context of $\mathrm{CO}_{2}$ sequestration, namely the interfacial tension between the two phases, and interpreting its microscopic origin. Such simulations usually involve slabs of fluids and the determination of the normal and tangential components of the local pressure tensor: the interfacial tension (IFT) is then given by the integral of the difference between these components across the interface. In fact, these interfacial components are also related to the bulk phase stability. Kraska et al. (2009) exploited this connection to the LVE of $\mathrm{CO}_{2}$ in order to predict the spinodal (limit of metastability) and the equation of state in the unstable region. The interface between pure water and $\mathrm{scCO}_{2}$ was investigated with the SPC and EPM2 models by Zhao et al. (2011). By analyzing the relative contribution of the water-water, $\mathrm{CO}_{2}-\mathrm{CO}_{2}$ and water- $\mathrm{CO}_{2}$ interactions to the IFT, they showed that the overall IFT is dominated by the water "self" contribution (consistently with the very large IFT for the water liquid-vapor interface) and that the 
$\mathrm{CO}_{2}$-water interactions contribute negatively, i.e., they lower the IFT. The decomposition of the IFT according to the various terms of the force field (electrostatic, bond stretching, angle bending, $\mathrm{LJ}$ ) indicated that only the $\mathrm{LJ}$ interactions contribute favorably to the surface tension. Nevertheless, one should keep in mind that such a decomposition in the design of a force field is not without its ambiguities and, therefore, the last point should be considered with caution. Finally, the authors considered the orientation of interfacial molecules and found that both water and $\mathrm{CO}_{2}$ are aligned nearly parallel to the Gibbs Dividing Surface. The brine-water interface was also investigated by Zhao et al. (2011) who considered a $2.7 \mathrm{M} \mathrm{CaCl}_{2}$ aqueous solution. They predicted that IFT increases with salinity, as observed experimentally, and they suggested that this salinity-dependence results from a change in the orientation of interfacial water caused by the ions.

The most comprehensive molecular simulation study of the water- $\mathrm{CO}_{2}$ IFT was performed by Nielsen et al. (2012). They assessed the ability of several force fields to predict the IFT at pressure and temperature conditions relevant to GCS (Figure 9). The combinations of three $\mathrm{CO}_{2}$ models and two water models all predicted the same qualitative trends: at fixed $T$, the IFT decreases strongly with increasing $P$ below the critical $\mathrm{CO}_{2}$ pressure, then levels off, while it depends only slightly on $T$ at fixed $P$, as observed experimentally. Quantitative differences were observed between the different force fields, mainly due to variations in the description of short-range interactions that dominate the overall value of the IFT. The PPL $\mathrm{CO}_{2}$ model (In Het Panhuis et al. 1998) combined with the TIP4P/2005 $\mathrm{CO}_{2}$ model (Abascal and Vega 2005) provided the best agreement with experimental data over the whole 5-45 MPa range at $383 \mathrm{~K}$. The PPL model combined with the SPC/E water model underestimated the IFT by $\sim 10 \mathrm{mN} / \mathrm{m}$, i.e. the amount by which SPC/E underestimates the IFT of pure liquid water. The simulation results of Nielsen et al. (2012) showed that the $P$-dependence of IFT is consistent with the Gibbs adsorption equation $\left[\mathrm{d} \gamma_{\mathrm{wg}}=-\Gamma_{\mathrm{CO} 2}{ }^{(\mathrm{H} 2 \mathrm{O})} \mathrm{d} \mu_{\mathrm{CO} 2}\right.$, where $\gamma_{\mathrm{wg}}$ is the $\mathrm{CO}_{2}$-water IFT, $\mu_{\mathrm{CO} 2}$ is the chemical potential of $\mathrm{CO}_{2}$, and $\Gamma_{\mathrm{CO} 2}{ }^{(\mathrm{H} 2 \mathrm{O})}$ is the surface excess of $\mathrm{CO}_{2}$ at the interface (calculated using water as a reference phase)]. The difference between the IFT values predicted with different $\mathrm{CO}_{2}$ models was shown to result from differences in the $\mathrm{CO}_{2}$-water $\mathrm{LJ}$ interaction predicted by different models: the PPL model predicts a stronger short-range $\mathrm{CO}_{2}$-water attraction, hence more $\mathrm{CO}_{2}$ adsorption on the water surface and a larger $P$-dependence of IFT, in agreement with experimental data. 

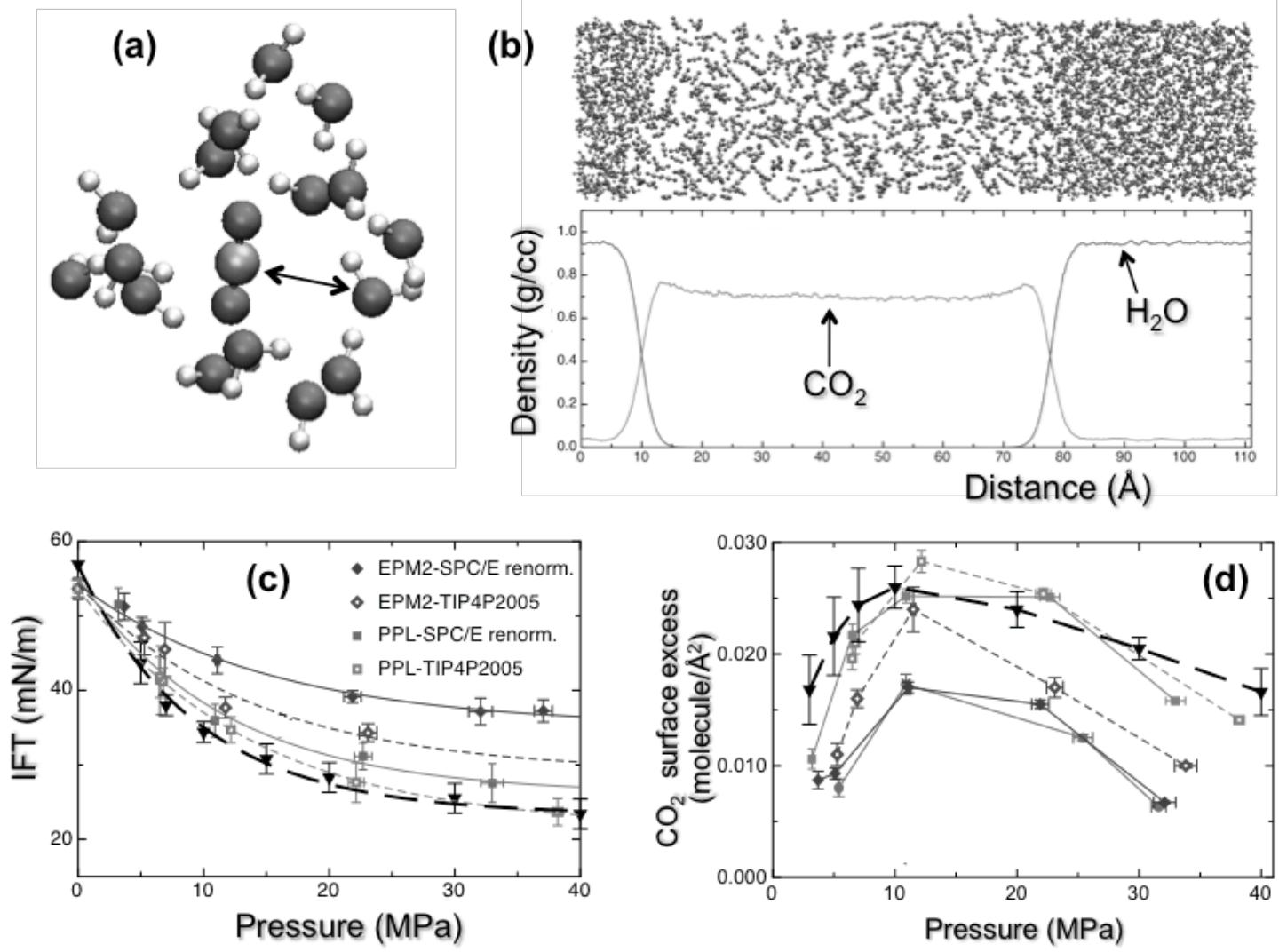

Figure 9: Molecular dynamics simulation prediction of $\mathrm{CO}_{2}$-water IFT and $\mathrm{CO}_{2}$ adsorption on the surface of liquid water (Nielsen et al. 2012). (a) Snapshot of a single $\mathrm{CO}_{2}$ molecule and the water molecules in its first solvation shell. (b) Snapshot of a MD simulation cell containing two coexisting fluid phases (liquid water and $\mathrm{scCO}_{2}$ ) and two parallel interfaces; the graph shows the density profile of water and $\mathrm{CO}_{2}$ molecules in the direction normal to the $\mathrm{CO}_{2}$-water interfaces; adsorption of $\mathrm{CO}_{2}$ on the water surface is evidenced by the small enhancement in $\mathrm{CO}_{2}$ density near the interface. (c) Experimental data on IFT vs. $P$ at $383 \mathrm{~K}$ [black triangles and dashed line (Chiquet et al. 2007a)] compared with MD simulation predictions obtained with different combinations of water (SPC/E, TIP4P/2005) and $\mathrm{CO}_{2}$ (EPM2, PPL) models (gray symbols and lines). Simulation results with the SPC/E water model were renormalized to the surface tension of TIP4P2005 water by adding $8.4 \mathrm{mN} \mathrm{m}^{-1}$ to the predicted IFT values. (d) Experimental data and MD simulation predictions of $\mathrm{CO}_{2}$ surface excess $\Gamma_{\mathrm{CO} 2}{ }^{(\mathrm{H} 2)}$ vs. $P$. The experimental values were calculated from the experimental data on IFT vs. $P$ in (c) using the Gibbs adsorption equation. [Figure modified from Geochim Cosmochim Acta 81, Nielsen LC, Bourg IC, Sposito G, Predicting $\mathrm{CO}_{2}$-water interfacial tension under pressure and temperature conditions of geologic $\mathrm{CO}_{2}$ storage, $\mathrm{p} 28-38$, Copyright 2012, with permission from Elsevier.]

As mentioned above, IFT results from various contributions, whose subtle balance depends on the arrangement of the interfacial molecules. Willard and Chandler (2010) demonstrated that the interfacial structure cannot be understood properly by considering only the Gibbs Dividing Surface (GDS), which is smeared out by capillary fluctuations. Rather, they introduced the notion of an instantaneous interface that fluctuates in time and showed that when the structure of molecules is analyzed with respect to this interface one recovers a layered structure that is progressively damped over a few molecular layers, 
as in the vicinity of a solid object. Zhang and Singer (2011) re-examined the structure of the interface between water and sub-critical $\mathrm{CO}_{2}$ using this concept. Under these conditions, they observed, as in experiments, the adsorption of a $\mathrm{CO}_{2}$ layer on the water surface (which is at the origin of the decrease in IFT compared to pure water, as noted above). In addition, the density profile decays almost exponentially from the interface, with a characteristic length that diverges with increasing pressure according to an inverse power law. No effect of $\mathrm{CO}_{2}$ adsorption on the orientation of interfacial water molecules was observed.

\section{$\mathrm{CO}_{2}$-brine-mineral systems with a single fluid phase}

Clay interlayer nanopores. Much of the atomistic simulation research on $\mathrm{CO}_{2}$ near mineral surfaces has used clay minerals, a well-characterized nanoporous medium (Rotenberg et al. 2007; Bourg and Sposito 2010; Ferrage et al. 2011; Marry et al. 2011) of relevance to the geochemistry of clayshale and mudstone caprocks of GCS sites (Carey, 2013; Kaszuba et al., 2013). The adsorption of $\mathrm{CO}_{2}$ in clay nanopores has been mainly considered in the absence of water. Experimentally, the incorporation of $\mathrm{CO}_{2}$ in pyrophyllite during dehydroxylation has been observed by infrared spectroscopy (Wang et al. 2003) and X-ray diffraction has allowed following the intercalation of $\mathrm{CO}_{2}$ in $\mathrm{Na}$ fluorohectorite near ambient conditions: the expansion in basal spacing is similar to that obtained during intercalation with water, but it occurs at a rate that is several orders of magnitude slower (Hemmen et al. 2012). The density of $\mathrm{CO}_{2}$ confined in Namontmorillonite with a sub-single hydration layer depends on the bulk $\mathrm{scCO}_{2}$ density (Rother et al. 2013). Yang and Zhang (2005) used MD simulations to investigate the structure and diffusion of $\mathrm{CO}_{2}$ in clay-like slit pores, finding in particular a decrease in the diffusion coefficient under confinement. Cole et al. (2010) carried out MD simulations of dry $\mathrm{scCO}_{2}$ in mica interlayers and observed, in line with the behavior of water, a layering of the fluid and a decrease in mobility compared to bulk $\mathrm{scCO}_{2}$. It would be interesting to investigate how some of the observed features, such as the formation of hydrogen bonds between $\mathrm{CO}_{2}$ oxygens and surface hydroxyl groups, are affected by the presence of water. The swelling of Na-montmorillonite in contact with $\mathrm{CO}_{2}$ was studied by Yang and Yang (2011) using GCMC simulations. Whereas swelling is thermodynamically favorable under supercritical conditions $(10 \mathrm{MPa}$ and $318.15 \mathrm{~K})$, it is unfavorable at lower $\mathrm{CO}_{2}$ pressure $(0.1 \mathrm{MPa})$. In the former case, it was found that $\mathrm{Na}^{+}$ counterions were not well solvated by $\mathrm{CO}_{2}$ and remained close to the surface. The swelling of organoclays, where inorganic counterions are replaced by alkylammonium chains, by $\mathrm{scCO}_{2}$ has also been simulated by Yu and Yang (2011).

More relevant in the context of geological sequestration is the case where clay is in contact with both $\mathrm{CO}_{2}$ and water. Recent experiments have shown that the uptake of $\mathrm{CO}_{2}$ depends on the initial water content - hence also on the nature of the counterion (Giesting et al., 2012; Schaef et al., 2012). Botan et al. (2010) used molecular simulations to investigate the thermodynamics, structure and transport in Na-montmorillonite in contact with water and $\mathrm{CO}_{2}$ (Figure 10). They considered clay interlayer nanopores in equilibrium with a reservoir at $348 \mathrm{~K}$ and two pressures in which two bulk phases coexist: an $\mathrm{H}_{2} \mathrm{O}$-rich liquid phase and a $\mathrm{CO}_{2}$-rich gas (at 25 bars) or supercritical fluid (at 125 bar). 
This bulk phase coexistence determines the chemical potentials of water and $\mathrm{CO}_{2}$ used in GCMC simulations, with the rigid SPC and EPM2 models, to determine the swelling free energy curves and composition of the metastable states. The bihydrated state, which is the most stable in the absence of $\mathrm{CO}_{2}$ under the investigated conditions, remains the most stable in the presence of $\mathrm{CO}_{2}$, i.e., no swelling (by $\mathrm{CO}_{2}$ uptake) or shrinkage (by water removal) was predicted if the clay remains in contact with the water reservoir. The $\mathrm{CO}_{2}$ uptake is limited to its dissolution in interlayer water without dramatic changes in the overall fluid density and the water structure. The $\mathrm{CO}_{2}$ molecules tend to stay close to the clay surface, oriented so as to partially enter the hexagonal cavities. The diffusion coefficient of $\mathrm{CO}_{2}$ is reduced compared to its value in bulk liquid water by a factor 50 and 5 in the mono- and bihydrated states, respectively. The presence of $\mathrm{CO}_{2}$ also slows down the diffusion of interlayer water and cations.
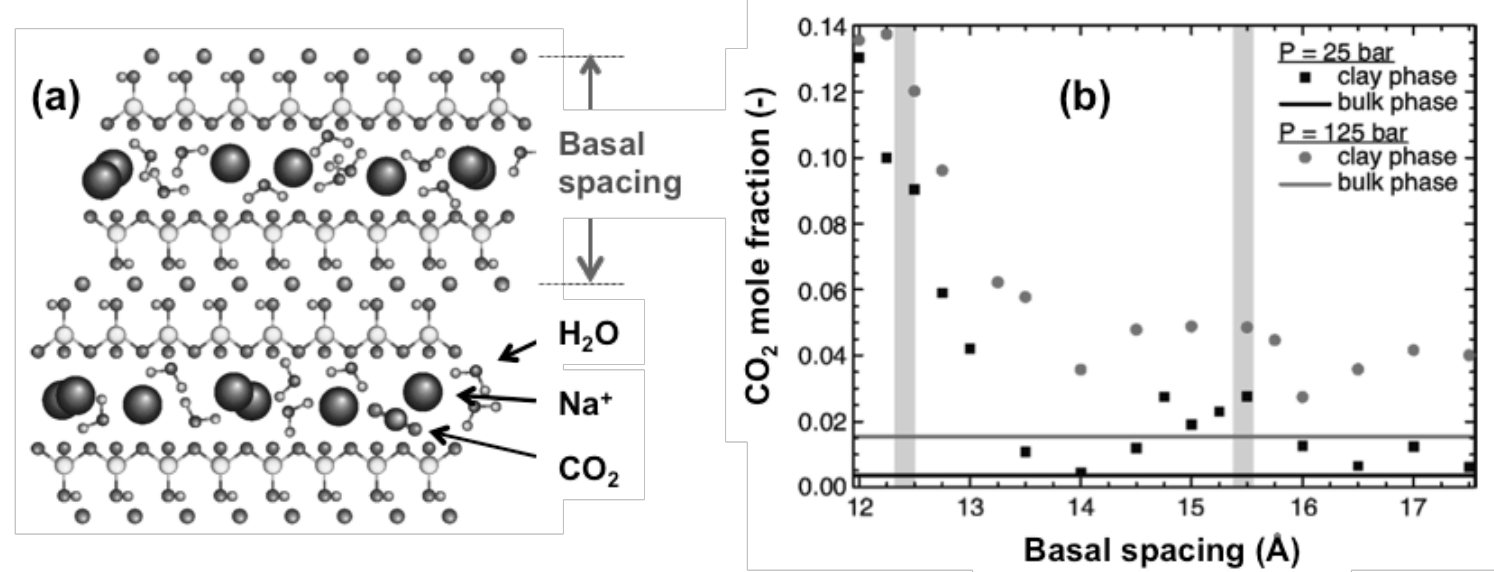

Figure 10: Grand Canonical Monte Carlo prediction of the solubility of $\mathrm{CO}_{2}$ in water-filled smectite clay interlayer nanopores at $348 \mathrm{~K}$ and 25 or 125 bar as a function of clay basal spacing (Botan et al. 2010). (a) Schematic view of the simulated system containing stacked smectite lamellae and interlayer nanopores filled with water, $\mathrm{Na}^{+}$, and $\mathrm{CO}_{2(\mathrm{aq})}$. (b) Predictions of the solubility of $\mathrm{CO}_{2}$ in nanopore water as a function of clay basal spacing (black and gray squares at 25 and 125 bar, respectively). The solubility of $\mathrm{CO}_{2}$ in bulk liquid water at 25 and 125 bar is shown by the horizontal black and gray lines. The vertical shaded bars indicate the stable swelling states of the clay mineral (the one- and two-layer hydrates). The results show that $\mathrm{CO}_{2}$ is more soluble in clay interlayer water than in bulk liquid water. [Figure modified with permission from Botan A et al. (2010) J Phys Chem C 114:14962-14969. Copyright 2010 American Chemical Society.]

Cygan et al. (2012) recently developed a fully flexible $\mathrm{CO}_{2}$ model for the simulation of $\mathrm{CO}_{2}$ and water in clays. This model better reproduces the vibrational properties of bulk $\mathrm{CO}_{2}$ than earlier flexible force fields and, when used in conjunction with the flexible SPC or TIP4P water models, more accurately predicts the diffusion coefficient of $\mathrm{CO}_{2}$ in bulk water at $0.1 \mathrm{MPa}$ compared to its rigid counterparts (which overestimate it). In simulations of a hydrated Na-montmorillonite clay, the addition of two $\mathrm{CO}_{2}$ molecules per unit cell in the interlayer space was predicted to cause an increase in the interlayer distance (i.e., swelling) for all considered water contents. This finding does not contradict the results of Botan et al. (2010), because Cygan et al. (2012) simulated systems with a fixed number of interlayer water and $\mathrm{CO}_{2}$ molecules, whereas 
Botan et al. (2010) simulated systems with fixed chemical potential. Flexibility of water and $\mathrm{CO}_{2}$ does not have a large impact on the structure of the interlayer fluid but is obviously essential for the prediction of vibrational properties. In particular, Cygan et al. (2012) predicted that the bending motion of $\mathrm{CO}_{2}$ is blue-shifted by 10 to $15 \mathrm{~cm}^{-1}$ in the clay interlayer while the asymmetric stretch mode is virtually unaffected by confinement, in qualitative agreement with their diffuse-reflectance infrared spectroscopy results.

Nanoporous silica and zeolites. A significant body of atomistic simulation research exists on the adsorption of $\mathrm{CO}_{2}$ in nanoporous silica and zeolites at relatively low pressures and in the absence of water, because of the potential utility of these materials in carbon capture. These studies show that $\mathrm{CO}_{2}$ has a significant affinity for silica surfaces that is strongly dependent on the details of the pore structure and the presence of surface charge sites (Kim et al. 2013). At conditions more relevant to GCS (high $P$ and $T$, presence of water), few atomistic simulation studies have been carried out. Gravimetric and neutron scattering data show that confinement in silica nanopores can promote the formation of a dense adsorbed phase even in pores as large as $35 \mathrm{~nm}$ (Melnichenko et al 2009; Cole et al., 2010; Rother et al 2012) but this has never been tested by atomistic simulation, to our knowledge. Molecular dynamics simulations described elsewhere in this volume show that the solubility of $\mathrm{CO}_{2}$ in water-filled silica nanopores is highly sensivity to nanopore size and the hydrophilicity of the silica surface (Chialvo et al. 2013a,b).

\section{$\mathrm{CO}_{2}$-brine-mineral systems with two fluid phases}

Thin films of adsorbed water at $\mathrm{CO}_{2}$-mineral interfaces. Hydrophilic mineral surfaces (such as silica, mica, and carbonates), when exposed to humid air, are well known to adsorb thin films of liquid water (up to hundreds of nanometers thick) with a chemical potential lower than that of bulk liquid water (Pashley and Kitchener 1979; Balmer et al. 2008; Asay et al. 2009; Salmeron et al. 2009; Tokunaga 2009, 2012; Bohr et al. 2010; Rubasinghege and Grassian 2013). These adsorbed water films influence the hydrogeology of unsaturated porous media (Tokunaga 2009; Diaz et al. 2010) and the geochemistry of mineral-air interfaces (Kendall and Martin 2005; Rubasinghege and Grassian 2013). On quartz and silica surfaces at low relative vapor pressures $\left(p / p_{\text {sat }} \leq 0.8\right)$, the thickness of these films ranges from zero to about two statistical water monolayers (Asay et al. 2009; Tokunaga 2009, 2012). These two water monolayers are strongly adsorbed as measured by their isosteric heat of adsorption (Asay et al. 2009). Beyond the first two water monolayers, water is much more weakly adsorbed (Pashley 1980; Asay et al. 2009); nevertheless, water film thickness continues to increase with relative vapor pressure and reaches tens to hundreds of nanometers at $p / p_{\text {sat }}>0.975$ (Pashley and Kitchener 1979; Tokunaga 2012). Mica surfaces are somewhat less hydrophilic than silica and they carry only one water monolayer at $p / p_{\text {sat }} \approx 0.65$ (Balmer et al. 2008).

In geological $\mathrm{CO}_{2}$ storage formations, adsorbed water films may play important roles by mediating the interaction of humid $\mathrm{scCO}_{2}$ with mineral surfaces (McGrail et al. 2009; Kwak et al. 2011; Loring et al. 2011; Shao et al. 2011; Tokunaga and Wan 2013). At present, however, the properties of adsorbed water films at mineral- $\mathrm{CO}_{2}$ interfaces 
remain poorly understood. Loring et al. (2011) roughly estimated the thickness of water films at forsterite-scCO $\mathrm{CO}_{2}$ interfaces by infrared spectroscopy as $0.1,0.2,1.0$ and $2.0 \mathrm{~nm}$ at $p / p_{\text {sat }}=0.47,0.81,0.95$ and 1.36 , respectively (for comparison, a single water monolayer has a thickness of about $0.3 \mathrm{~nm}$ ). Kim et al. (2012) probed water films at silica-scCO interfaces at low capillary pressures $\left(P_{\mathrm{c}}=0.18\right.$ to $3.7 \mathrm{kPa}$, equivalent to $\left.p / p_{\text {sat }} \sim 0.99999\right)$ using X-ray synchrotron fluorescence. At the conditions of their study, water film thickness was less than $2 \mathrm{~nm}$, but a more precise quantification of adsorbed film thickness was prevented by capillary condensation on surface roughness features.

Molecular dynamics and Monte Carlo simulations have been used to study adsorbed water films in the absence of $\mathrm{CO}_{2}$, for example on silica (Wensink et al. 2000; RomeroVargas Castrillón et al. 2011), calcite (Stöckelmann and Hentschke 1999; Rahaman et al. 2008), mica (Malani and Ayappa 2009), and talc surfaces (Rotenberg et al. 2011). In these studies, plots of the average water density as a function of distance from the surface showed that up to two water monolayers are structured by the surface. In the presence of $\mathrm{CO}_{2}$, to our knowledge, only two atomistic simulations have probed adsorbed water films, on forsterite (Kerisit et al. 2012) and quartz (Bagherzadeh et al. 2012). In atomistic simulations, film thickness can be controlled by imposing the vapor pressure of water in the gas phase (Stöckelmann and Hentschke 1999; Rahaman et al. 2008; Malani and Ayappa 2009), the total number of water molecules in the simulation cell (RomeroVargas Castrillón et al. 2011; Kerisit et al. 2012), or the radius of curvature $r_{\mathrm{m}}$ of a water vapor or $\mathrm{CO}_{2}$ bubble in the simulated system (Wensink et al. 2000; Bagherzadeh et al. 2012). This last property is related to the relative vapor pressure $p / p_{\text {sat }}$ through the Kelvin equation (Wensink et al. 2000):

$$
\frac{p}{p_{s: 1}}=e^{\frac{\gamma_{s p} \gamma_{m 1}}{K J} r_{m}}
$$

where $\gamma_{\mathrm{wg}}$ is the interfacial tension between liquid water and the non-wetting phase $\left(\mathrm{CO}_{2}\right.$ or water vapor) and $v_{\mathrm{m}}$ is the molar volume of water. Overall, atomistic simulations show that, in both mineral-water-air and mineral-water- $\mathrm{CO}_{2}$ systems, water molecules located in the first one or two monolayers on hydrophilic mineral surfaces have a large isosteric heat of adsorption (in agreement with experimental results) and a low diffusivity relative to bulk liquid water (Wensink et al. 2000; Rahaman et al. 2008; Malani and Ayappa 2009; Kerisit et al. 2012). These distinct properties of the first one or two water monolayers result from the participation of interfacial water in the solvation of adsorbed (Malani and Ayappa 2009) or structural (Rahaman et al. 2008; Kerisit et al. 2012) surface metal cations (Figure 11a) and in hydrogen bonding with surface $\mathrm{O}$ atoms and $\mathrm{OH}$ groups (Rahaman et al. 2008; Romero-Vargas Castrillón et al. 2011). Water molecules located beyond the first two monolayers behave essentially as bulk water (Kerisit et al. 2012).

Grand Canonical Monte Carlo simulation predictions of water film thickness vs. $p / p_{\text {sat }}$ on silica (Leroch and Wendland 2012), mica (Malani and Ayappa 2009), and calcite surfaces (Rahaman et al. 2008) in mineral-water-vapor systems predict that these surfaces have similar hydration properties at $p / p_{\text {sat }}$ values up to 0.7 , where they carry a single statistical water monolayer (Figure 11b). The apparent discrepancy between the 
monolayer coverage of silica at $p / p_{\text {sat }} \sim 0.7$ predicted by GCMC simulation (Leroch and Wendland 2012) and the bilayer coverage observed experimentally at the same relative vapor pressure (Asay et al. 2009) may arise from the $\mathrm{pH}$-dependence of silica surface charge: at near-neutral $\mathrm{pH}$ values, silica has a negative surface charge density because of the deprotonation of silanol groups $\left[>\mathrm{Si}-\mathrm{OH}=>\mathrm{Si}_{-}-\mathrm{O}^{-}+\mathrm{H}^{+}\right.$, with $\mathrm{pK}_{\mathrm{a}}=7.0 \pm 0.6$ (Sonnefeld et al. 2001; Carroll et al. 2002; Dove and Craven 2005)]. The uncharged silica surface (with fully protonated silanol groups) simulated by Leroch and Wendland (2012) is representative of acidic conditions, the point of zero net charge of silica being located near $\mathrm{pH} 3$ (Wang et al. 2012b). Figure 11b includes data obtained in systems where $p / p_{\text {sat }}$ $<1$ was imposed by placing a bubble of water vapor (Wensink et al. 2000; Bagherzadeh et al. 2012) or $\mathrm{CO}_{2}$ (Bagherzadeh et al. 2012) in contact with the adsorbed water film. Experimental and simulation results show that at $p / p_{\text {sat }} \sim 0.7$, pristine (negatively charged) silica surfaces carry two water monolayers (Asay et al. 2009), uncharged silica surfaces (representative of $\mathrm{pH} \sim 3$ ) carry one water monolayer (Leroch and Wendland 2012), and uncharged silica surfaces exposed to a bulk $\mathrm{CO}_{2}$ fluid carry zero water monolayers (Bagherzadeh et al. 2012).
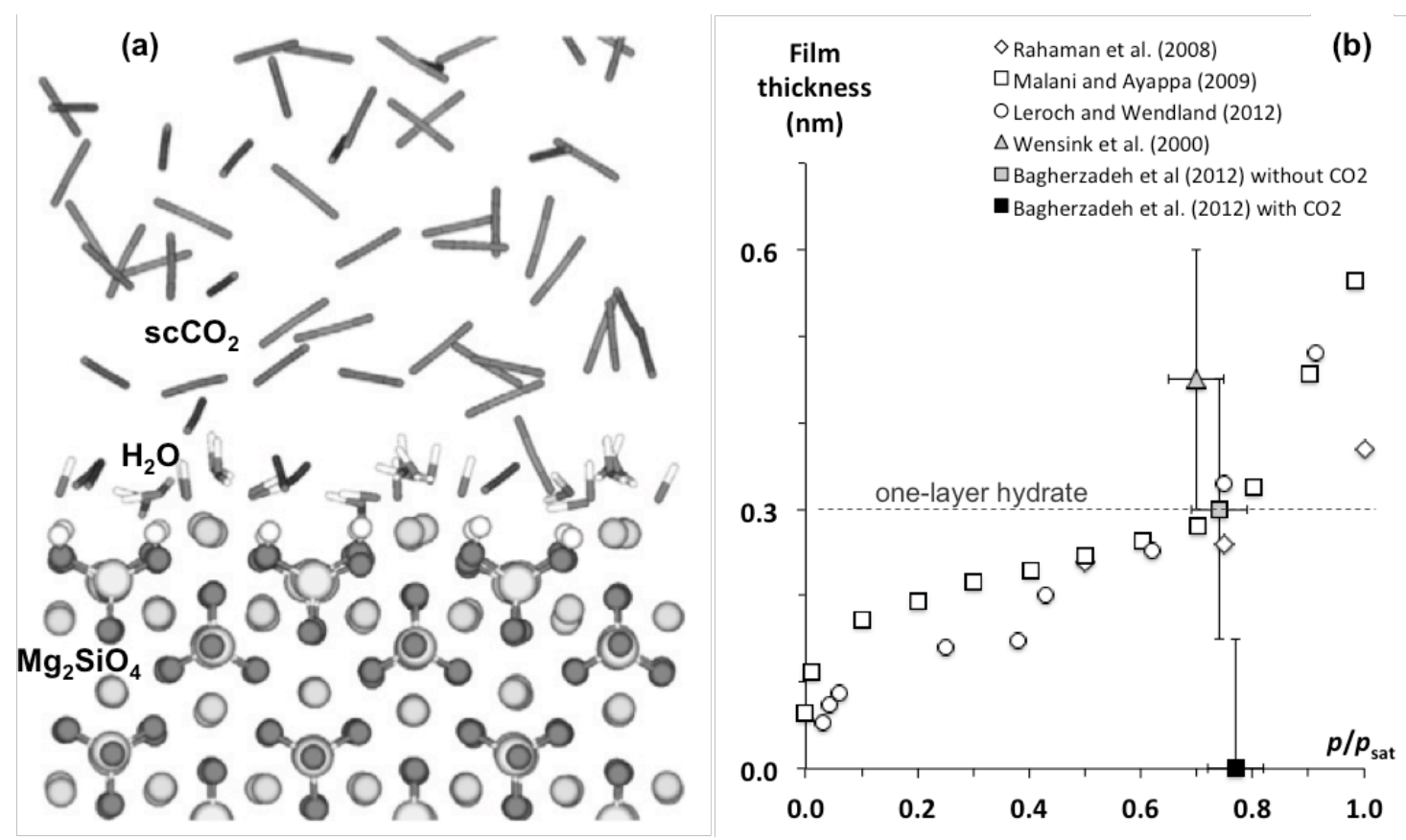

Figure 11: (a) Molecular dynamics simulation snapshot of a sub-monolayer adsorbed water film at the forsterite- $\mathrm{scCO}_{2}$ interface (Kerisit et al. 2012). The figure shows that adsorbed water molecules are attracted to the forsterite surface because of their affinity for structural $\mathrm{Mg}^{2+}$ ions (light gray spheres). (b) Compilation of MD and GCMC simulation predictions of the thickness of adsorbed water films on flat mineral surfaces at $T=298$ to $300 \mathrm{~K}$ on silica (Bagherzadeh et al. 2012; Leroch and Wendland 2012; Wensink et al. 2000), calcite (Rahaman et al. 2008), and mica (Malani and Ayappa 2009). Values of film thickness and $p / p_{\text {sat }}$ in the simulations of Wensink et al. (2000) and Bagherzadeh et al. (2012) were estimated by visual inspection of MD simulation snapshots and by applying Eq. 1 with $\gamma_{\mathrm{gw}}=54.7 \mathrm{mN} \mathrm{m}^{-1}$ and $r_{\mathrm{m}}=1.1 \pm 0.2 \mathrm{~nm}$ (Wensink et al. 2000 ) or with $\gamma_{\mathrm{gw}}=80.1$ or $70.1 \mathrm{mN} \mathrm{m}^{-1}$ (in the absence or presence of $\mathrm{CO}_{2}$, respectively) and $r_{\mathrm{m}}$ $=1.93 \pm 0.4 \mathrm{~nm}$ (Bagherzadeh et al. 2012) $\left[\gamma_{\mathrm{gw}}\right.$ values were roughly estimated from the results of 
Vega and deMiguel (2007) and Nielsen et al. (2012)]. [Figure 11a reprinted from Geochim Cosmochim Acta 84, Kerisit S, Weare JH, Felmy AR, Structure and dynamics of forsterite$\mathrm{scCO}_{2} / \mathrm{H}_{2} \mathrm{O}$ interfaces as a function of water content, $\mathrm{p}$ 137-151, Copyright 2012, with permission from Elsevier.]

$\mathrm{CO}_{2}$-brine-mineral wetting angles. The wettability of mineral surfaces by brine vs. $\mathrm{CO}_{2}$ - characterized by the mineral-brine- $\mathrm{CO}_{2}$ wetting angle $\theta$ - is an important property of rock formations used in GCS (Tokunaga and Wan 2013). Knowledge of $\theta$ is required to convert mercury intrusion porosimetry data into a $\mathrm{CO}_{2}$-brine capillary pressuresaturation relation (Espinoza and Santamarina 2010; Pini et al. 2012), to predict the maximum column height of $\mathrm{CO}_{2}$ that can be immobilized under a seal formation (Chiquet et al. 2007b; Chalbaud et al. 2009; Iglauer et al. 2012b), and to derive correlations for the residual $\mathrm{CO}_{2}$ saturation $S_{\mathrm{g}, \mathrm{r}}$ (Spiteri et al. 2008; Iglauer et al. 2012a). These relationships arise from the well-known Young-Laplace equation $\left(P_{\mathrm{c}}=\gamma_{\mathrm{wg}} / r_{\mathrm{m}}\right)$, where $r_{\mathrm{m}}$ is the radius of curvature of the $\mathrm{CO}_{2}$-brine interface. If $r_{\mathrm{m}}$ is expressed as a function of the wetting angle and pore aperture, this yields for a cylindrical pore of radius $r_{\mathrm{p}}$ :

$$
P_{c}=\frac{2 \gamma_{w g} \cos \theta}{r_{p}}
$$

Despite their importance, the $\theta$ values of mineral surfaces in GCS-relevant conditions are poorly characterized. Experimental results obtained at the most widely studied conditions (silica surfaces, $T \sim 298 \mathrm{~K}$, low salinity) show significant discrepancies in both the magnitude of $\theta$ and its pressure dependence (Figure 12a). Experimental studies also disagree on the influence of salinity [ $\theta$ either increases (Espinoza and Santamarina 2010; Jung and Wan 2012; Farokhpoor et al. 2013) or decreases with $\mathrm{NaCl}$ concentration (Chiquet et al. 2007b; Wang et al. 2012b)] and on the hysteresis of measured $\theta$ values [reported as either negligible (Bikkina 2011; Jung and Wan 2012) or up to $20^{\circ}$ (Dickson et al. 2006; Chiquet et al. 2007b; Broseta et al. 2012)]. The influence of $\mathrm{pH}$ is almost entirely unexamined (Wang et al. 2012) and few studies have measured the $\theta$ values of minerals other than silica, with the exception of calcite (Espinoza and Santamarina 2010; Bikkina 2011; Wang et al. 2012b; Farokhpoor et al. 2013) and phyllosilicates (Chiquet et al. 2007b; Wang et al. 2012b; Farokhpoor et al. 2013). Figure 12 shows that $\theta=21 \pm 11^{\circ}$ in silica-water- $\mathrm{CO}_{2}$ systems at low $P$ (Chiquet et al. 2007b; Espinoza and Santamarina 2010; Bikkina 2011; Jung and Wan 2012; Wang et al. 2012b; Farokhpoor et al. 2013). For comparison, $\theta=0^{\circ}$ in silica-water-air systems (Lamb and Furlong 1982). This difference suggests that the presence of $\mathrm{CO}_{2}$ decreases the hydrophilicity of silica, perhaps because it causes the $\mathrm{pH}$ to approach the point of zero net charge of silica (Chiquet et al. 2007b; Wang et al. 2012b).

The range of behaviors shown in Figure 12a illustrates the difficulty of accurately characterizing $\theta$. Experimental measurements of $\theta$ are highly sensitive to trace levels of impurities that can accumulate at interfaces (Pashley and Kitchener 1979; Lamb and Furlong 1982; Stipp and Hochella 1991). Another experimental difficulty is the hysteresis between wetting angles measured during imbibition $\left(\theta_{\mathrm{i}}\right)$ and drainage $\left(\theta_{\mathrm{d}}<\theta_{\mathrm{i}}\right)$. This hysteresis may be enhanced by surface roughness (Dickson et al. 2006; Chiquet et al. 
2007b; Broseta et al. 2012), but it can also occur on atomically smooth surfaces (Diaz et al. 2010). The few studies that measured a wetting angle hysteresis reported drainage wetting angles $\theta_{\mathrm{d}}$ (Dickson et al. 2006; Chiquet et al. 2007b; Farokhpoor et al. 2013), but some studies may have reported $\theta$ values that are intermediate between $\theta_{\mathrm{d}}$ and $\theta_{\mathrm{i}}$. Finally, the $\theta$-values themselves may be influenced by surface roughness, a poorly controlled parameter that may evolve upon exposure to $\mathrm{CO}_{2}$ (Espinoza and Santamarina 2010).
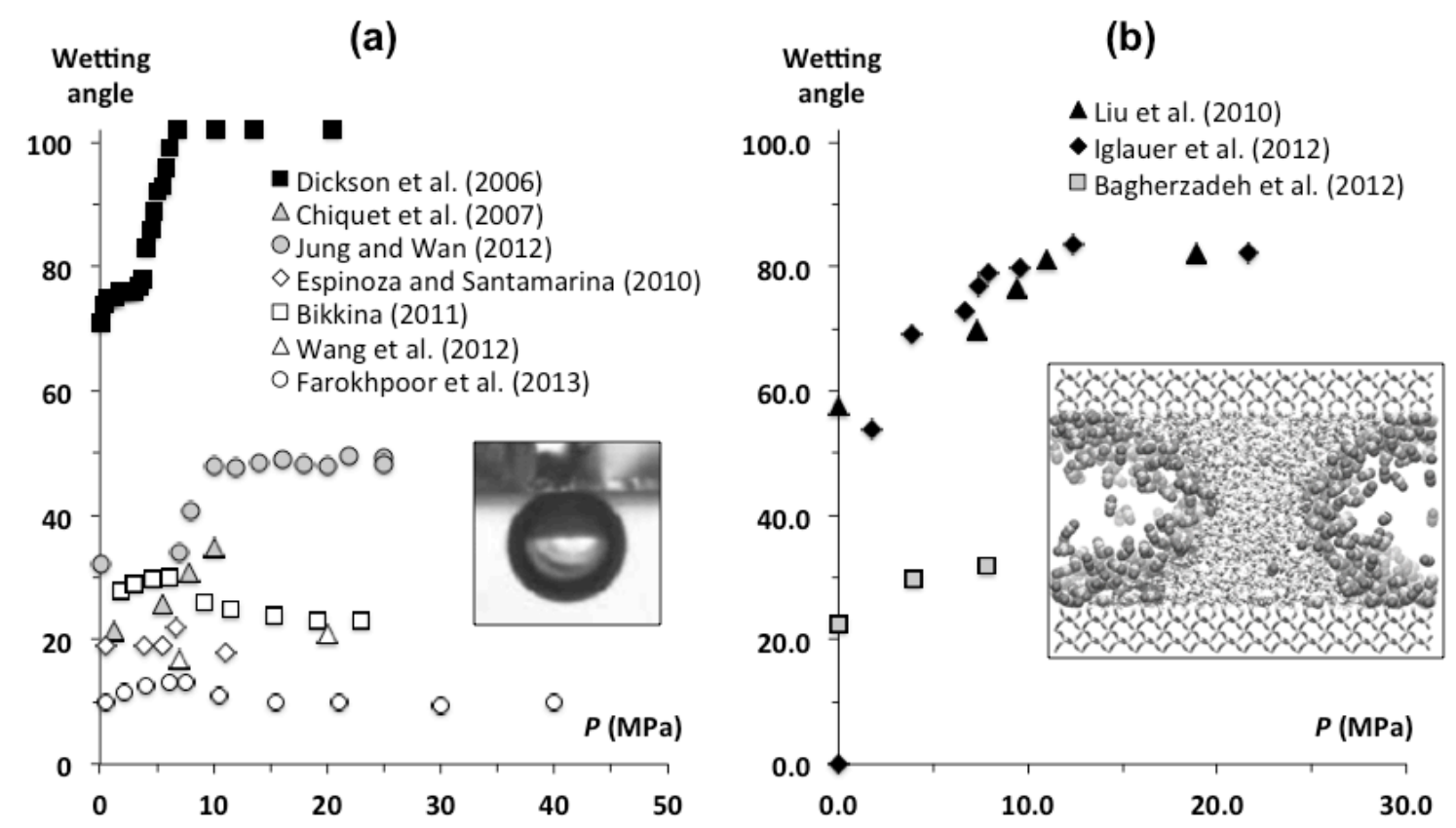

Figure 12: Compilation of (a) measurements and (b) MD simulations of the mineral-water- $\mathrm{CO}_{2}$ wetting angle $\theta$ on silica surfaces at low ionic strengths $(I \leq 0.2 \mathrm{M} \mathrm{NaCl})$ as a function of pressure. The inset images show a photograph of a $\mathrm{CO}_{2}$ droplet on a quartz surface in water during a goniometric contact angle experiment (Wang et al. 2012) and a MD simulation cell containing a $\mathrm{CO}_{2}$ bubble confined in an otherwise water-filled pore between quartz surfaces (Bagherzadeh et al. 2012). All studies used pristine quartz surfaces and $T=293$ to $309 \mathrm{~K}$ unless otherwise noted. Dickson et al. (2006) used a reduced-hydrophilicity silica surface treated by silanization to remove $63 \%$ of silanol groups. Wang et al. (2012b) used $T=303 \mathrm{~K}$ at $7 \mathrm{MPa}, 323 \mathrm{~K}$ at $20 \mathrm{MPa}$. Jung and Wan (2012) used $T=318 \mathrm{~K}$ and an amorphous silica surface. Liu et al. (2010) used $T=$ $318 \mathrm{~K}$ and a crystobalite surface with $\sim 35 \%$ of the hydroxyl site density of a pristine silica surface. Iglauer et al. (2012b) used a dehydroxylated quartz surface with no silanol surface functional groups. Pressure in the simulations of Liu et al. (2010) was estimated from the reported $\mathrm{CO}_{2}$ densities using National Institute of Standards and Technology (NIST) data on the pressuredensity relation of pure $\mathrm{CO}_{2}$ at $318 \mathrm{~K}$. Pressure in the simulations of Bagherzadeh et al. (2012) was roughly estimated as the average value of the diagonal pressure tensor components in directions parallel to the silica surfaces (calculated by the authors for the entire simulation cell), renormalized such that $P=0$ in the absence of $\mathrm{CO}_{2}$. [Figure 12a inset reproduced with permission from Wang S et al. (2012) Environ Sci Technol 47:234-241. Copyright 2012 American Chemical Society. Figure 12b inset reproduced with permission from Bagherzadeh SA et al (2012) J Phys Chem C 116:24907-24915. Copyright 2012 American Chemical Society.]

Atomistic simulations can readily predict the wetting angle $\theta$ and its dependence on 
pressure and salinity and provide insight into the molecular-scale phenomena that control $\theta$. To our knowledge, only three such simulation studies have been carried out (Figure $12 \mathrm{~b}$ ). A probable cause of the range of predicted $\theta$-values is that the studies in Figure $12 \mathrm{~b}$ used very different models of the silica surface structure: Liu et al. (2010) simulated a surface with bare $\mathrm{Si}$ atoms and a few protonated silanol $(>\mathrm{Si}-\mathrm{OH})$ functional groups; Iglauer et al. (2012b) simulated a surface with only siloxane $(>\mathrm{Si}-\mathrm{O}-\mathrm{Si}<)$ functional groups; and Bagherzadeh et al. (2012) simulated a surface with only silanol functional groups. The first two types of surfaces should be quite different from the pristine silica surfaces probed experimentally, because the formation of silanol sites on silica surfaces is highly favorable (Lamb and Furlong 1982; Du and de Leeuw 2006; Salmeron et al. 2009), but they may be analogous to the synthetically dehydroxylated silica surface studied by Dickson et al. (2006).

A notable difficulty in predicting $\theta$ from atomistic simulations is the lack of a set of inter-atomic potential parameters known to accurately predict the solid-water $\left(\gamma_{\mathrm{sw}}\right)$, solid$\mathrm{CO}_{2}\left(\gamma_{\mathrm{sg}}\right)$, and water- $\mathrm{CO}_{2}\left(\gamma_{\mathrm{wg}}\right)$ interfacial tensions. These interfacial tensions determine the wetting angle through the well-known Young equation:

$\cos \theta=\frac{\gamma_{\mathrm{sg}}-\gamma_{\mathrm{sw}}}{\gamma_{\mathrm{wg}}}$

In the absence of a well-tested set of force fields for $\mathrm{CO}_{2}$-water-mineral wettability studies, Iglauer et al. (2012b) used $\mathrm{CO}_{2}$ and water models (EPM2, TIP4P/2005) that predicts $\gamma_{\mathrm{wg}}$ within $\sim 10 \mathrm{mN} \mathrm{m}^{-1}$ (Nielsen et al., 2012), but they selected a silica-water interaction model (van Beest et al., 1990) that overestimates the strength of the silicawater interaction [in the absence of $\mathrm{CO}_{2}$, they predicted $\theta=0^{\circ}$ for water on a silica surface that carries only siloxane functional groups, whereas the experimental value for a fully dehydroxylated silica surface is about $42^{\circ}$ (Lamb and Furlong 1982)]. Bagherzadeh et al. (2012) used a water model (TIP4P/Ice) that significantly overestimates the surface tension of liquid water (Vega and de Miguel 2007) and a silica-water interaction model (Lopes et al. 2006) that was not designed for use with the TIP4P/Ice water model and that performs less than optimally when used with at least one other water model (Skelton et al. 2011). In recent years, the CLAYFF model (Cygan et al. 2004b) has emerged as a remarkably accurate model of the interaction between silicate minerals and liquid water (Bourg and Sposito 2010; Ferrage et al. 2011; Marry et al. 2011; Skelton et al. 2011; Bourg and Steefel 2012; Leroch and Wendland 2012), but this model has been exclusively used with two water models [the SPC and SPC/E water models (Berendsen et al. 1981, 1987)] that underestimate the surface tension of liquid water (Vega and de Miguel 2007; Nielsen et al. 2012). When used with the SPC water model, the CLAYFF model underestimates the adhesive energy caused by a water meniscus between silica surfaces in humid air ( $p / p_{\text {sat }}=0.3$ to 0.8$)$ by 5 to $22 \%$ (Leroch and Wendland 2012).

Another notable difficulty associated with atomistic simulation predictions of $\theta$ is that systems larger than $\sim 10^{5}$ atoms are difficult to model at a reasonable computational cost for the durations (tens of nanoseconds) required to probe wetting angles. Therefore, atomistic simulations of wetting phenomena necessarily probe very small $\mathrm{CO}_{2}$ bubbles or 
water droplets (with diameters on the order of $5 \mathrm{~nm}$ ) that may have distinct properties from those of macroscopic bubbles and drops. For example, pressure may be difficult to define in nanoscale bubbles that are too small to contain a bulk-fluid-like region (Cosden and Lukes 2011). Furthermore, interfacial energies are sensitive to long-range interactions; therefore, they may be influenced by interfacial curvature (Cosden and Lukes 2011; Rezaei Nejad et al. 2011) and by the choice of approximations used in evaluating long-range van der Waals interactions (Wensink et al. 2000; Biscay et al. 2009; Cosden and Lukes 2011).

The $\theta$ values of Si oxide surfaces reported in Figure 12 can be grouped into two distinct datasets. The first set includes all studies of partly or completely de-hydroxylated silica surfaces (Dickson et al. 2006; Liu et al. 2010; Iglauer et al. 2012b). These surfaces are weakly hydrophilic in the absence of $\mathrm{CO}_{2}$ and they show a strong wettability alteration with increasing $\mathrm{CO}_{2}$ pressure. The second set includes all studies of pristine silica surfaces (Chiquet et al. 2007b; Espinoza and Santamarina 2010; Bikkina 2011; Jung and Wan 2012; Wang et al. 2012b). The density of silanol functional groups determines whether a silica surface belongs to one or the other group. Within the second dataset, the MD simulation results of Bagherzadeh et al. (2012) are most closely consistent with the experimental results of Chiquet et al. (2007b). The origin of the difference between studies that show a $P$-dependence of $\theta$ (Chiquet et al. 2007b; Bagherzadeh et al. 2012; Jung and Wan 2012) and those that do not (Espinoza and Santamarina 2010; Bikkina 2011; Wang et al. 2012b) is not known. This question should lend itself readily to an atomistic scale analysis of the $P$-dependence of the interfacial energies $\gamma_{\mathrm{gs}}, \gamma_{\mathrm{gw}}$, and $\gamma_{\mathrm{ws}}$ (Iglauer et al. 2012b).

\section{$\mathrm{CO}_{2}$ clathrate hydrates}

Gas clathrate hydrates (Figure 13a) play important roles in certain GCS concepts, such as carbon sequestration in deep ocean sediments (House et al. 2006; Tohidi et al. 2010) and $\mathrm{CO}_{2}-\mathrm{CH}_{4}$ substitution in natural methane hydrate formations (Ota et al. 2005; Park et al. 2006; Espinoza and Santamarina 2011). The potential usefulness of gas hydrates as a $\mathrm{CO}_{2}$ storage medium is illustrated by the fact that the molecular $\mathrm{CO}_{2}: \mathrm{H}_{2} \mathrm{O}$ ratio in these hydrates can be as high as 1:5.75, about 300 times the solubility of $\mathrm{CO}_{2}$ in water at ambient conditions. A substantial fraction of the molecular modeling research on $\mathrm{CO}_{2}-\mathrm{H}_{2} \mathrm{O}$ systems has focused on $\mathrm{CO}_{2}$ hydrates [their bulk properties (Chialvo et al. 2002; Ota and Ferdows 2005; Geng et al. 2009; Jiang and Jordan 2010), their nucleation (Radhakrishnan and Trout 2002), growth (Tung et al. 2011a), and dissolution (Sarupria and Debenedetti 2011), their stability near mineral surfaces (Bai et al. 2011), and the conversion from $\mathrm{CH}_{4}$ to $\mathrm{CO}_{2}$ hydrates (Geng et al. 2009; Tung et al. 2011b)].

From a technical point of view, atomistic simulations of $\mathrm{CO}_{2}$ hydrates benefit from the existence of well-tested force fields that are known to predict the properties of these crystals with reasonable accuracy (Jiang and Jordan 2010; Sarupria and Debenedetti 2011; Tung et al. 2011a). In particular, the combination of the TIP4P/Ew water model (Horn et al. 2004), the EPM2 $\mathrm{CO}_{2}$ model (Harris and Yung 1995), and the $\mathrm{CO}_{2}$-water interaction parameters of Sun and Duan (2005) [parameterized to fit the quantum mechanical 
calculations of Sadlej et al. (1998)] yields a remarkably good prediction of $\mathrm{CO}_{2}$ hydrate melting temperature (Figure 13b; Tung et al. 2011a). One complicating aspect of the atomistic modeling of $\mathrm{CO}_{2}$ hydrates is that the cage occupancy of real $\mathrm{CO}_{2}$ hydrates is lower than one $\mathrm{CO}_{2}$ molecule per cage: it ranges from 0.8 to 1.0 and depends on cage size [the large cages of the gas hydrate sI structure are almost fully occupied, the small cages are partly occupied (Circone et al. 2003; Sun and Duan 2005; Takeya et al. 2010)]. Molecular simulation studies have almost always probed the condition of full cage occupancy (Jiang and Jordan 2010; Tung et al. 2011a). In a rare study of $\mathrm{CO}_{2}$ hydrates with partial cage occupancy, Sarupria and Debenedetti (2011) showed that the melting temperature of $\mathrm{CO}_{2}$ clathrate hydrate decreases by 2 to $4 \mathrm{~K}$ as cage occupancy decreases from 1.0 to 0.87 and that this destabilization is greater if $\mathrm{CO}_{2}$ is removed from the larger cages of the clathrate structure.

Atomistic simulations of bulk $\mathrm{CO}_{2}$ hydrates and their interfaces with liquid water have yielded several insights into the nano-scale properties of $\mathrm{CO}_{2}$ hydrates. For example, simulations of bulk $\mathrm{CO}_{2}$ hydrates revealed that their thermal conductivity is $\sim 20 \%$ smaller than that of $\mathrm{CH}_{4}$ hydrates (Jiang and Jordan 2010), a difference that could have important implications for the process of storing $\mathrm{CO}_{2}$ in $\mathrm{CH}_{4}$ hydrate formations. Simulations of $\mathrm{CO}_{2}$ hydrate growth showed that the growth rate is on the order of 0.10 to $0.16 \mathrm{~m} \mathrm{~s}^{-1}$, with little pressure-dependence, and that growth proceeds through the formation of a transient amorphous phase that contains more large cages and fewer small cages than the bulk $\mathrm{CO}_{2}$ hydrate (Tung et al. 2011a), a finding consistent with simulations showing that the binding energy of $\mathrm{CO}_{2}$ is about $4.0 \mathrm{~kJ} \mathrm{~mol}^{-1}$ greater in the large cages than in the small cages (Jiang and Jordan 2010). Simulations of the dissolution of $\mathrm{CO}_{2}$ hydrates show that dissolution is a collective phenomenon with an activation energy of 62 to $70 \mathrm{~kJ} \mathrm{~mol}^{-1}$ (consistent with the breaking of 3-5 hydrogen bonds) and a rate that increases as cage occupancy decreases (Sarupria and Debenedetti 2011). Simulations of $\mathrm{CO}_{2}$ hydrate dissolution and growth (Figure 13c) have not detected the formation of transient ice-like structures (Sarupria and Debenedetti 2011; Tung et al. 2011a). Finally, simulations show that the replacement of $\mathrm{CH}_{4}$ by $\mathrm{CO}_{2}$ in clathrate hydrate crystals can occur in the absence of clathrate melting (Tung et al. 2011b) and that the $\mathrm{CH}_{4}-\mathrm{CO}_{2}$ mixed hydrate, with $\mathrm{CH}_{4}$ occupying the small clathrate cages, is more stable than either the $\mathrm{CH}_{4}$ or the $\mathrm{CO}_{2}$ hydrates (Geng et al. 2009), in agreement with experimental evidence that $\mathrm{CO}_{2}$ displaces $\mathrm{CH}_{4}$ much more readily from large cages than from small cages (Ota et al. 2005).

An emerging research area in the simulation of gas hydrates is the influence of mineral surfaces on hydrate nucleation, growth, and dissolution. Experimental studies suggest that mineral surfaces influence the kinetics and thermodynamics of methane hydrate growth in porous media (Cha et al. 1988; Uchida et al. 2004; Koster van Groos and Guggenheim 2009), but the details of this effect are not well established (Park and Sposito 2003; Cygan et al. 2004a) and its existence in the case of $\mathrm{CO}_{2}$ hydrates is unknown. To our knowledge, only two atomistic-scale simulation studies have studied $\mathrm{CO}_{2}$ or $\mathrm{CH}_{4}$ hydrate crystals near mineral surfaces (Bai et al. 2011; Liang et al. 2011). Both studies simulated uncharged silica surfaces and found that a thin water film $(0.5$ to $1.0 \mathrm{~nm}$ thick) separates the gas hydrate from the mineral surface (Bai et al. 2011; Liang et 
al. 2011). This finding is consistent with the well-established observation that a 0.4 to 0.6 $\mathrm{nm}$ thick layer of surface water in silica nanopores freezes at a much lower temperature than bulk liquid water and does not form a crystalline ice phase (Hansen et al. 1996; Schreiber et al. 2001) and with the strong adsorption of one or two water monolayers on flat silica surfaces (discussed in the section on adsorbed water films). The simulation study by Liang et al. (2011) provides tantalizing evidence that MD simulations may allow evaluating the silica-water-gas hydrate wetting angle.
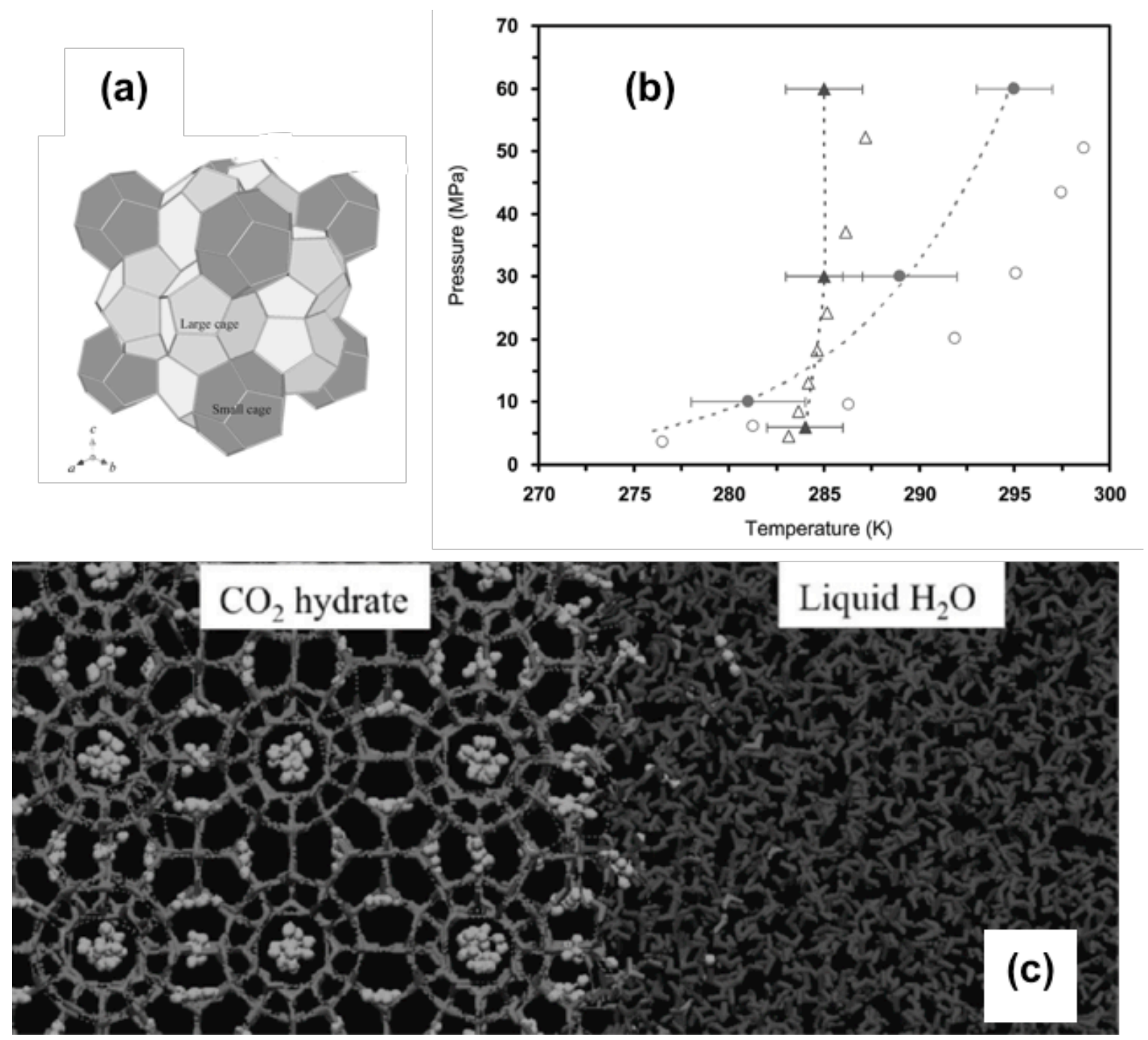

Figure 13: Prediction of the properties of $\mathrm{CO}_{2}$ hydrates in contact with bulk liquid water. (a) Structure of the host lattice in the sI clathrate hydrate; the large and small cages are shown in light and dark gray, respectively (Hoshikawa et al. 2006). (b) Comparison of experimental measurements [open symbols (Takenouchi and Kennedy 1965; Jager and Sloan 2001; Yang et al. 2001)] and MD simulation predictions [filled symbols (Tung et al. 2010, 2011a)] of the threephase coexistence conditions of $\mathrm{CO}_{2}$ and $\mathrm{CH}_{4}$ hydrates (triangles and circles, respectively) (Tung et al. 2011b). (c) Interface between $\mathrm{CO}_{2}$ hydrate and bulk liquid water during a simulation of $\mathrm{CO}_{2}$ hydrate dissociation; water molecules are displayed in lighter or darker gray depending on whether their local coordination is more clathrate-like or liquid-like (Sarupria and Debenedetti 2011). [Figure 13a reprinted with permission from Hoshikawa A et al (2006) J Chem Phys 
125:034505. Copyright 2006, AIP Publishing LLC. Figure 13b reproduced with permission from Tung Y-T et al (2011) J Phys Chem B 115:15295-15302. Copyright 2011 American Chemical Society. Figure 13c reproduced with permission from Sarupria S and Debenedetti PG (2011) J Phys Chem A 115:6102-6111. Copyright 2011 American Chemical Society.]

\section{FUTURE RESEARCH OPPORTUNITIES}

Atomistic simulations can play an important role in helping to improve thermodynamic models of mineral-brine- $\mathrm{CO}_{2}$ systems, one of the poorly constrained inputs of current GCS models (Xu et al., 2007). In particular, MD simulation techniques can probe the stability of metal carbonate/bicarbonate ion species in solution that are larger than ion pairs (Fosbøl et al. 2010; Marcus and Hefter 2006) and the thermodynamics of $\mathrm{CO}_{2}$ impurities such as $\mathrm{H}_{2} \mathrm{~S}$ and $\mathrm{SO}_{2}$ (Chialvo et al., 2013a). Classical or quantum mechanical calculations also could be used to inform thermodynamic models of aqueous Al species (Gaus et al., 2005).

Continued development of force field parameters that accurately describe the energetics of both aqueous and solid phases will aid in future simulations of carbonate growth mechanisms. Comparisons of experimental and atomistic simulation results will continue to play a central role in this effort as shown by recent XR data on the structure of the calcite-water interface (Fenter et al., 2013). Ab initio and DFT predictions of calcite-water interfaces can play an important role in constraining new force fields. Development of reactive carbonate models, like the one proposed by Gale et al. (2011) for the aqueous-calcium carbonate system, could also play an important role in this effort because of the possible importance of water dissociation at calcite kink sites.

Investigations of synthetic and biogenic ACC should elucidate the water content of these phases and its influence on their stability. For example, the metadynamics technique (so far been applied only to anhydrous $\mathrm{CaCO}_{3}$ particles) should be applied to hydrated ACC.

Simulations of the interplay between organic and inorganic species in solution during mineralization remain challenging because the mechanisms of $\mathrm{CaCO}_{3}$ crystallization are still not fully understood. In a simpler crystallization system like urea, for which MD and kinetic Monte Carlo modeling has successfully described the mechanisms of crystal growth and dissolution (Piana and Gale 2005), simulation is able to predicts growth rates and morphologies in the presence of organic species in good agreement with experiment (Salvalaglio et al. 2012). For carbonates, the information gained from simulations of additive effects during the early stages of crystallization will be much less complicated to interpret once the pathways to mineral formation are known.

Atomistic simulations are barely beginning to be applied to the study of wetting properties (behavior of adsorbed water, wetting angles) in mineral-brine- $\mathrm{CO}_{2}$ systems. Carefully designed simulations can provide information on the dependence of these properties on the type of mineral surface, and the influence of solutes such as electrolyte ions, dissolved organic molecules, or $\mathrm{CO}_{2}$ impurities $\left(\mathrm{H}_{2} \mathrm{~S}, \mathrm{SO}_{2}\right)$. Advances in this area will require the identification of a set of force fields that can accurately predict the 
interfacial energies of mineral-water, mineral- $\mathrm{CO}_{2}$, and water- $\mathrm{CO}_{2}$ interfaces. Future simulations should determine the origin of the difference between studies that show a $P$ dependence of $\theta$ in silica-water- $\mathrm{CO}_{2}$ systems (Chiquet et al. 2007b; Bagherzadeh et al. 2012; Jung and Wan 2012) and those that do not (Espinoza and Santamarina 2010; Bikkina 2011; Wang et al. 2012b).

\section{ACKNOWLEDGMENTS}

This material was prepared by $\mathrm{LMH}, \mathrm{AFW}$, and ICB with support from the Center for Nanoscale Control of Geologic $\mathrm{CO}_{2}$ (NCGC), an Energy Frontiers Research Center funded by the U.S. Department of Energy, Office of Science, Office of Basic Energy Sciences under Award Number DE-AC02-05CH11231.

\section{REFERENCES}

Abascal JLF, Vega C (2005) A general purpose model for the condensed phases of water: TIP4P/2005. J Chem Phys 123:234505

Addadi L, Weiner S (1985) Interactions between acidic proteins and crystals: stereochemical requirements in biomineralization. Proc Nat Acad Sci USA 82:4110-4114

Aizenberg J, Black AJ, Whitesides GM (1999) Control of crystal nucleation by patterned self-assembled monolayers. Nature 398:495-498

Albo S, Müller EA (2003) On the calculation of supercritical fluid-solid equilibria by molecular simulation. J Phys Chem B 107:1672-1678

Allen MP, Tildesley DJ (1987) Computer simulation of liquids. Oxford University Press, Oxford, $385 \mathrm{p}$

Andersson MP, Stipp SLS (2012) How acidic is water on calcite? J Phys Chem C 116:18779-18787

Asay DB, Barnette AL, Kim SH (2009) Effects of surface chemistry on structure and thermodynamics of water layers at solid-vapor interfaces. J Phys Chem C 113:2128-2133

Aschauer U, Spagnoli D, Bowen P, Parker SC (2010) Growth modification of seeded calcite using carboxylic acids: atomistic simulations. J Colloid Interface Sci 346:226-231

Austen KF, Wright K, Gale JD (2005) The interaction of dolomite surfaces with metal impurities: a computer simulation study. Phys Chem Chem Phys 7:4150-4156

Avendaño C, Lafitte T, Galindo A, Adjiman CS, Jackson G, Müller EA (2011) SAFTgamma force field for the simulation of molecular fluids. 1. A single-site coarse grained model of carbon dioxide. J Phys Chem B 115:11154-69

Badaut V, Zeller P, Dorado B, Schlegel ML (2010) Influence of exchange correlation on the symmetry and properties of siderite according to density-functional theory. Phys Rev B 82:205121

Bagherzadeh SA, Englezos P, Alavi S, Ripmeester JA (2012) Influence of hydrated silica surfaces on interfacial water in the presence of clathrate hydrate forming gases. J Phys Chem C 116:24907-24915

Bai D, Chen G, Zhang X, Wang W (2011) Microsecond molecular dynamics simulations 
of the kinetic pathways of gas hydrate formation from solid surfaces. Langmuir 27:5961-7

Balasubramanian S, Kohlmeyer A, Klein ML (2009) Ab initio molecular dynamics study of supercritical carbon dioxide including dispersion corrections. J Chem Phys 131:144506

Balmer TE, Christenson HK, Spencer ND, Heuberger M (2008) The effect of surface ions on water adsorption to mica. Langmuir 24:1566-1569

Bender E (1970) Equations of state exactly representing the phase behavior of pure substances. In: Proceedings of the $5^{\text {th }}$ Symposium on Thermophysical Properties. The American Chemical Society of Mechanical Engineers, Columbia, p 227

Berendsen HJC, Grigera JR, Straatsma TP (1987) The missing term in effective pair potentials. J Phys Chem 91:6269-6271

Berendsen HJC, Postma JPM, van Gunsteren WF, Hermans J (1981). Interaction models for water in relation to protein hydration. In: Intermolecular Forces. Pullman B (ed) Reidel Publishing, Amsterdam, p 331-342

Bewernitz MA, Gebauer D, Long J, Cölfen H, Gower LB (2012) A metastable liquid precursor phase of calcium carbonate and its interactions with polyaspartate. Farad Discuss 159:291.

Bickmore BR, Rosso KM, Brown ID, Kerisit S (2009) Bond-valence constraints on liquid water structure. J Phys Chem A 113:1847-1857

Bikkina PK (2011) Contact angle measurements of CO2-water-quartz/calcite systems in the perspective of carbon sequestration. Int J Greenhouse Gas Control 5:12591271

Binder K, Fratzl P (2005) Spinodal decomposition. In: Phase Transformations in Materials. Kostorz G (ed) Wiley-VCH Verlag GmbH \& Co. KGaA, Weinheim, p 409-480

Biscay F, Ghoufi A, Lachet V, Malfreyt P (2009) Monte Carlo simulations of the pressure dependence of the water-acid gas interfacial tensions. J Phys Chem B 113:14277-14290

Bohr J, Wogelius RA, Morris PM, Stipp SLS (2010) Thickness and structure of the water film deposited from vapour on calcite surfaces. Geochim Cosmochim Acta 74:5985-5999

Botan A, Rotenberg B, Marry V, Turq P, Noetinger B (2010) Carbon dioxide in montmorillonite clay hydrates: thermodynamics, structure, and transport from molecular simulation. J Phys Chem C 114:14962-14969

Bourg IC, Sposito G (2010) Connecting the molecular scale to the continuum scale for diffusion processes in smectite-rich porous media. Environ Sci Technol 44:20852091

Bourg IC, Steefel CI (2012) Molecular dynamics simulations of water structure and diffusion in silica nanopores. J Phys Chem C 116:11556-11564

Brik MG (2011) First-principles calculations of structural, electronic, optical and elastic properties of magnesite $\mathrm{MgCO}_{3}$ and calcite $\mathrm{CaCO}_{3}$. Physica B: Condens Matter 406:1004-1012

Broseta D, Tonnet N, Shah V (2012) Are rocks still water-wet in the presence of dense $\mathrm{CO} 2$ or H2S? Geofluids 12: 280-294

Carey JW (2013) Geochemistry of wellbore integrity in $\mathrm{CO}_{2}$ sequestration: Portland 
cement-steel-brine- $\mathrm{CO}_{2}$ interactions. this volume

Carroll SA, Maxwell RS, Bourcier W, Martin S, Hulsey S (2002) Evaluation of silicawater surface chemistry using NMR spectroscopy. Geochim Cosmochim Acta 66:913-926

Carteret C, De La Pierre M, Dossot M, Pascale F, Erba A, Dovesi R (2013) The vibrational spectrum of $\mathrm{CaCO}_{3}$ aragonite: a combined experimental and quantummechanical investigation. J Chem Phys 138:014201

Cha SB, Ouar H, Wildeman TR, Sloan ED (1988) A third-surface effect on hydrate formation. J Phys Chem 92:6492-6494

Chalbaud C, Robin M, Lombarad J-M, Martin F, Egermann P, Bertin H (2009) Interfacial tension measurements and wettability evaluation for geological $\mathrm{CO}_{2}$ storage. Adv Water Resour 32:98-109

Chaudhury S, Olson Ma, Tawa G, Wallqvist A, Lee MS (2012) Efficient conformational sampling in explicit solvent using a hybrid replica exchange molecular dynamics method. J Chem Theory Comput 8:677-687

Chen CL, Qi J, Zuckermann RN, De Yoreo JJ (2011) Engineered biomimetic polymers as tunable agents for controlling $\mathrm{CaCO}_{3}$ mineralization. J Am Chem Soc 133:52145217

Chialvo AA, Houssa M, Cummings PT (2002) Molecular Dynamics Study of the Structure and Thermophysical Properties of Model sI Clathrate Hydrates. J Phys Chem B 106:442-451

Chialvo AA, Vlcek L, Cole DR (2013a) Acid gases in $\mathrm{CO}_{2}$-rich subsurface geologic environments. this volume

Chialvo AA, Vlcek L, Cole DR (2013b) Aqueous $\mathrm{CO}_{2}$ solutions at silica surfaces and within nanopore environments. Insights from isobaric-isothermal molecular dynamics. J Phys Chem C 116:13904-13916

Chiquet P, Daridon J-L, Broseta D, Thibeau S (2007a) $\mathrm{CO}_{2} /$ water interfacial tensions under pressure and temperature conditions of $\mathrm{CO}_{2}$ geological storage. Energy Convers Manage 48:736-744

Chiquet P, Broseta D, Thibeau S (2007b) Wettability alteration of caprock minerals by carbon dioxide. Geofluids 7:112-122

Circone S, Stern LA, Kirby SH, Durham WB, Chakoumakos BC, Rawn CJ, Rondinone AJ, Ishii Y (2003). $\mathrm{CO}_{2}$ hydrate: synthesis, composition, structure, dissociation behavior, and a comparison to structure $\mathrm{I} \mathrm{CH}_{4}$ hydrate. J Phys Chem B 107:55295539

Cole DR, Chialvo AA, Rother G, Vlcek L, Cummings PT (2010) Supercritical fluid behavior at nanoscale interfaces: Implications for $\mathrm{CO}_{2}$ sequestration in geologic formations. Phil Mag 90:2339-2363

Cooke DJ, Elliott JA (2007) Atomistic simulations of calcite nanoparticles and their interaction with water. J Chem Phys 127:104706

Cooke DJ, Gray RJ, Sand KK, Stipp SLS, Elliott JA (2010) Interaction of ethanol and water with the $\{1014\}$ surface of calcite. Langmuir 26:14520-14529

Cosden LA, Lukes JR (2011) Effect of cutoff radius on the surface tension of nanoscale bubbles. J Heat Transfer 113:101501

Criscenti LJ, Cygan RT (2013) Molecular simulations of carbon dioxide and water: cation solvation. Environ Sci Technol 47:87-94 
Cygan RT, Guggenheim S, Koster van Groos AF (2004a) Molecular models for the intercalation of methane hydrate complexes in montmorillonite clay. J Phys Chem B 108:15141-15149

Cygan RT, Liang J-J, Kalinichev AG (2004b) Molecular models of hydroxide, oxyhydroxide, and clay phases and the development of a general force field. $\mathrm{J}$ Phys Chem B 108:1255-1266

Cygan RT, Romanov VN, Myshakin EM (2012) Molecular simulation of carbon dioxide capture by montmorillonite using an accurate and flexible force field. J Phys Chem C 116:13079-13091

Davies CW (1962) Ion Association. Butterworths, London, $190 \mathrm{p}$

Davis KJ, Dove PM, De Yoreo JJ (2000) The role of $\mathrm{Mg}^{2+}$ as an impurity in calcite growth. Science 290:1134-1137

Davis KJ, Dove PM, Wasylenki LE, De Yoreo JJ (2004) Morphological consequences of differential $\mathrm{M}^{\mathrm{g} 2+}$ incorporation at structurally distinct steps on calcite. Geochim Cosmochim Acta 89:714-720

de Leeuw NH (2002) Molecular dynamics simulations of the growth inhibiting effect of $\mathrm{Fe}^{2+}, \mathrm{Mg}^{2+}, \mathrm{Cd}^{2+}$, and $\mathrm{Sr}^{2+}$ on calcite crystal growth. J Phys Chem B 106:52415249

de Leeuw NH, Cooper TG (2004) A computer modeling study of the inhibiting effect of organic adsorbates on calcite crystal growth. Cryst Growth Des 4:123-133

de Leeuw NH, Harding JH, Parker SC (2002) Molecular dynamics simulations of the incorporation of $\mathrm{Mg}^{2+}, \mathrm{Cd}^{2+}$ and $\mathrm{Sr}^{2+}$ at calcite growth steps: Introduction of a $\mathrm{SrCO}_{3}$ potential model. Mol Simul 28:573-589

de Leeuw NH, Parker SC (2000) Modeling absorption and segregation of magnesium and cadmium ions to calcite surfaces: introducing $\mathrm{MgCO}_{3}$ and $\mathrm{CdCO}_{3}$ potential models. J Chem Phys 112:4326

de Leeuw NH, Parker SC, Harding JH (1999) Molecular dynamics simulation of crystal dissolution from calcite steps. Phys Rev B 60:13792-13799

De Yoreo JJ, Waychunas GA, Jun Y-S, Fernandez-Martinez A (2013) In situ investigations of carbonate nucleation on mineral and organic surfaces. this volume

Debye P, Hückel E (1923) Zur Theorie der Elektrolyte. I. Gefrierpunktserniedrigung und verwandte Erscheinungentle. Physik Z 24:185-206

Demichelis R, Raiteri P, Gale JD, Dovesi R (2012) A new structural model for disorder in vaterite from first-principles calculations. CrystEngComm 14:44-47

Demichelis R, Raiteri P, Gale JD, Quigley D, Gebauer D (2011) Stable prenucleation mineral clusters are liquid-like ionic polymers. Nature Commun 2:590

DePaolo DJ, Cole DR (2013) Geochemistry of geologic carbon sequestration: An overview. this volume

Di Tommaso D, de Leeuw NH (2008) The onset of calcium carbonate nucleation: a density functional theory molecular dynamics and hybrid microsolvation/continuum study. J Phys Chem B 112:6965-6975

Di Tommaso D, de Leeuw NH (2009) Theoretical study of the dimerization of calcium carbonate in aqueous solution under natural water conditions. Geochim Cosmochim Acta 73:5394-5405

Diaz ME, Fuentes J, Cerro RL, Savage MD (2010) Hysteresis during contact angles 
measurement. J Colloid Interface Sci 343:574-583

Dickson JL, Gupta G, Horozov TS, Binks BP, Johnston KP (2006) Wetting phenomena at the $\mathrm{CO} 2 /$ water/glass interface. Langmuir 22:2161-2170

Doudou S, Vaughan DJ, Livens FR, Burton NA (2012) Atomistic simulations of calcium uranyl(VI) carbonate adsorption on calcite and stepped-calcite surfaces. Environ Sci Technol 46:7587-7594

Dove PM, Craven CM (2005) Surface charge density on silica in alkali and alkaline earth chloride electrolyte solutions Geochim Cosmochim Acta, 69:4963-4970

Du Z, de Leeuw NH (2006) Molecular dynamics simulations of hydration, dissolution and nucleation processes at the alpha-quartz (0001) surface in liquid water. Dalton Trans:2623-2634

Elhadj S, De Yoreo JJ, Hoyer JR, Dove PM (2006a) Role of molecular charge and hydrophilicity in regulating the kinetics of crystal growth. Proc Natl Acad Sci USA, 103:19237-19242

Elhadj S, Salter EA, Wierzbicki A, De Yoreo JJ, Han N, Dove PM (2006b) Peptide controls on calcite mineralization: Polyaspartate chain length affects growth kinetics and acts as a stereochemical switch on morphology. Cryst Growth Des 6:197-201

Elstnerová P, Friák M, Fabritius HO, Lymperakis L, Hickel T (2010) Ab initio study of thermodynamic, structural, and elastic properties of Mg-substituted crystalline calcite. Acta biomater 6:4506-4512

Errington JR, Panagiotopoulos AZ (1998) A fixed point charge model for water optimized to the vapor-liquid coexistence properties. J Phys Chem B 102:74707475

Errington JR, Kiyohara K, Gubbins KE, Panagiotopoulos AZ (1998) Monte Carlo simulation of high-pressure phase equilibria in aqueous systems. Fluid Phase Equil 150-151:33-40

Espinoza DN, Santamarina JC (2010) Water- $\mathrm{CO}_{2}$-mineral systems: Interfacial tension, contact angle, and diffusion-Implications to $\mathrm{CO}_{2}$ geological storage. Water Resour Res 46:537-547

Espinoza DN, Santamarina JC (2011) P-wave monitoring of hydrate-bearing sand during $\mathrm{CH}_{4}-\mathrm{CO}_{2}$ replacement. Int J Greenhouse Gas Control 5:1031-1038

Faatz M, Gröhn F, Wegner G (2004) Amorphous calcium carbonate: synthesis and potential intermediate in biomineralization. Adv Mater 16:996-1000

Falini G, Albeck S, Weiner S, Addadi L (1996) Control of aragonite or calcite polymorphism by mollusk shell macromolecules. Science 271:67-69

Farokhpoor R, Bjørkvik BJA, Lindeberg E, Torsæter O (2013) Wettability behaviour of $\mathrm{CO}_{2}$ at storage conditions. Int $\mathrm{J}$ Greenhouse Gas Control 12:18-25

Fenter P, Kerisit S, Raiteri P, Gale JD (2013) Is the calcite-water interface understood? direct comparisons of molecular dynamics simulations with specular X-ray reflectivity data. J Phys Chem C 117:5028-5042

Fenter P, Sturchio NC (2012) Calcite (104)-water interface structure, revisited. Geochim Cosmochim Acta 97:58-69

Fernández GA, Vrabec J, Hasse H (2005) Self-diffusion and binary Maxwell-Stefan diffusion coefficients of quadrupolar real fluids from molecular simulation. Int $\mathbf{J}$ Thermophys 26:1389-1407 
Ferrage E, Sakharov BA, Michot LJ, Delville A, Bauer A, Lanson B, Grangeon S, Frapper G, Jiménez-Ruiz M, Cuello GJ (2011) Hydration properties and interlayer organization of water and ions in synthetic Na-smectite with tetrahedral layer charge. Part 2. Toward a precise coupling between molecular simulations and diffraction data. J Phys Chem C 115:1867-1881

Finney AR, Rodger PM (2012) Probing the structure and stability of calcium carbonate pre-nucleation clusters. Farad Discuss 159:47-60

Fosbøl PL, Thomsen K, Stenby EH (2010) Review and recommended thermodynamic properties of $\mathrm{FeCO}_{3}$. Corros Eng Sci Technol 45:115-135

Freeman CL, Harding JH, Duffy DM (2008) Simulations of calcite crystallization on selfassembled monolayers. Langmuir 24:9607-9615

Freeman CL, Harding JH, Quigley D, Rodger PM (2010) Structural control of crystal nuclei by an eggshell protein. Angew Chem Int Ed 49:5135-5137

Frenkel D, Smit B (2001) Understanding molecular simulation: From algorithms to applications. Academic Press, San Diego, 638 p

Gale JD, Raiteri P, van Duin AC (2011) A reactive force field for aqueous-calcium carbonate systems. Phys Chem Chem Phys 13:16666-16679

Garcia-Ratés M, de Hemptinne J-C, Avalos JB, Nieto-Draghi C (2012) Molecular modeling of diffusion coefficient and ionic conductivity of $\mathrm{CO}_{2}$ in aqueous ionic solutions. J Phys Chem B 116:2787-2800

Gaus I, Azaroual M, Czernichowski-Lauriol I (2005) Reactive transport modeling of the impact of $\mathrm{CO}_{2}$ injection on the clayey cap rock at Sleipner (North Sea) Chem Geol 217:319-337

Gebauer D, Coelfen H (2011) Prenucleation clusters and non-classical nucleation. Nano Today 6:564-584

Gebauer D, Colfen H, Verch A, Antonietti M (2009) The multiple roles of additives in $\mathrm{CaCO}_{3}$ crystallization: A quantitative case study. Adv Mater 21:435-439

Gebauer D, Gunawidjaja PN, Ko JYP, Bacsik Z, Aziz B, Liu L, Hu Y, Bergström L, Tai C-W, Sham T-K, Edén M, Hedin N (2010) Proto-valcite and proto-vaterite in amorphous calcium carbonates. Agnew Chem 122:9073-9075

Gebauer D, Voelkel A, Coelfen H (2008) Stable prenucleation calcium carbonate clusters. Science 322:1819-1822

Geissbühler P, Fenter P, DiMasi E, Srajer G, Sorensen LB, Sturchio NC (2004) Threedimensional structure of the calcite-water interface by surface X-ray scattering. Surf Sci 573:191-203

Geng CY, Wen H, Zhou H (2009) Molecular simulation of the potential of methane reoccupation during the replacement of methane hydrate by $\mathrm{CO}_{2}$. J Phys Chem A 113:5463-5469

Giesting P, Guggenheim S, Koster van Groos AF, Busch A (2012) Interaction of carbon dioxide with Na-exchanged montmorillonite at pressures to 640 bars: Implications for $\mathrm{CO}_{2}$ sequestration. Int J Greenhouse Gas Control 8:73-81

Goldsmith JR (1983) Phase relations of rhombohedral carbonates. In: Reviews in Mineralogy, Vol 11. Reeder RJ (ed), Mineralogical Society of America, p 49-76

Gong YUT, Killian CE, Olson IC, Appathurai NP, Amasino AL, Martin MC, Holt LJ, Wilt FH, Gulbert PUPA (2012) Phase transitions in biogenic amorphous calcium carbonate. Proc Nat Acad Sci USA 109:6088-6093 
Goodwin AL, Michel FM, Phillips BL, Keen DA, Dove MT, Reeder RJ (2010)

Nanoporous structure and medium-range order in synthetic amorphous calcium carbonate. Chem Mater 22:3197-3205

Gower LB, Odom DJ (2000) Deposition of calcium carbonate films by a polymerinduced liquid-precursor (PILP) process. J Cryst Growth 210:719-734

Gratz AJ, Hillner PE, Hansma PK (1993) Step dynamics and spiral growth on calcite. Geochim Cosmochim Acta 57:491-495

Hamm LM, Wallace AF, Dove PM (2010) Molecular dynamics of ion hydration in the presence of small carboxylated molecules and implications for calcification. $\mathrm{J}$ Phys Chem B 114:10488-10495

Hansen EW, Stöcker M, Schmidt R (1996) Low-temperature phase transition of water confined in mesopores probed by NMR. Influence on pore size distribution. J Phys Chem 100:2195-2200

Harris JG, Yung KH (1995) Carbon dioxide's liquid-vapor coexistence curve and critical properties as predicted by a simple molecular model. J Phys Chem 99:1202112024

Heberling F, Trainor TP, Lützenkirchen J, Eng P, Denecke MA, Bosbach D (2011) Structure and reactivity of the calcite-water interface. J Colloid Interface Sci 354:843-857

Hemmen H, Rolseth EG, Fonseca DM, Hansen EL, Fossum JO, Plivelic TS (2012) X-ray studies of carbon dioxide intercalation in Na-fluorohectorite clay at near-ambient conditions. Langmuir 28:1678-1682

Hillner PE, Manne S, Hansma PK, Gratz AJ (1993) Atomic force microscope: a new tool for imaging crystal growth processes. Farad Discuss 95:191-197

Hofmann AE, Bourg IC, DePaolo DJ (2012) Ion desolvation as a mechanism for kinetic isotope fractionation in aqueous systems. Proc Natl Acad Sci USA 109:1868918694

Horn HW, Swope WC, Pitera JW, Madura JD, Dick TJ, Hura GL, Head-Gordon T (2004) Development of an improved four-site water model for biomolecular simulations: TIP4P-Ew. J Chem Phys 120:9665-9678

Hoshikawa A, Igawa N, Yamauchi H, Ishii Y (2006) Observation of hydrogen in deuterated methane hydrate by maximum entropy method with neutron powder diffraction. J Chem Phys 125:034505

House KZ, Schrag DP, Harvey CF, Lackner KS (2006) Permanent carbon dioxide storage in deep-sea sediments. Proc Natl Acad Sci USA 103:12291-12295

Hura G, Russo D, Glaeser RM, Head-Gordon T, Krack M, Parrinello M (2003). Water structure as a function of temperature from X-ray scattering experiments and $a b$ initio molecular dynamics. Phys Chem Chem Phys 5:1981-1991

Iglauer S, Ferno MA, Shearing P, Blunt MJ (2012a) Comparison of residual oil cluster size distribution, morphology and saturation in oil-wet and water-wet sandstone. $\mathrm{J}$ Colloid Interface Sci 375:187-192

Iglauer S, Mathew MS, Bresme F (2012b) Molecular dynamics computations of brine$\mathrm{CO}_{2}$ interfacial tensions and brine- $\mathrm{CO}_{2}$-quartz contact angles and their effects on structural and residual trapping mechanisms in carbon geo-sequestration. J

Colloid Interface Sci 386:405-414

In Het Panhuis M, Patterson CH, Lynden-Bell RM (1998) A molecular dynamics study 
of carbon dioxide in water: diffusion, structure and thermodynamics. Mol Phys 94: 963-972

Ishii R, Okazaki S, Okada I, Furusaka M, Watanabe N, Misawa M, Fukunaga T (1996) Density dependence of structure of supercritical carbon dioxide along an isotherm J Chem Phys 105:7011

Jackson RA, Price GD (1992) A transferable interatomic potential for calcium carbonate. Mol Simul 9:175-177

Jager MD, Sloan ED (2001) The effect of pressure on methane hydration in pure water and sodium chloride solutions. Fluid Phase Equil 185:89-99

Jäger C, Welzel T, Meyer-Zaika W, Epple M (2006) A solid-state NMR investigation of the structure of nanocrystalline hydroxyapatite. Magn Reson Chem 44:573-580

Jee SS, Kasinath RK, DiMasi E, Kim Y-Y, Gower L (2011) Oriented hydroxyapatite in turkey tendon mineralized via the polymer-induced liquid-precursor (PILP) process. CrystEngComm 13:2077-2083

Jiang H, Jordan KD (2010) Comparison of the properties of xenon, methane, and carbon dioxide hydrates from equilibrium and nonequilibrium molecular dynamics simulations. J Phys Chem C 114:5555-5564

Jiang Y, Gower L, Volkmer D, Cölfen H (2012) The existence region and composition of a polymer-induced liquid precursor phase for DL-glutamic acid crystals. Phys Chem Chem Phys 14:914-919

Jorgensen WL, Chandrasekhar J, Madura JD, Impey RW, Klein ML (1983) Comparison of simple potential functions for simulating liquid water. J Chem Phys 79:926-935

Jung J-W, Wan J (2012) Supercritical $\mathrm{CO}_{2}$ and ionic strength effects on wettability of silica surfaces: equilibrium contact angle measurements. Energy Fuels 26:60536059

Kaszuba J, Yardley B, Andreani M (2013) Experimental perspectives of mineral dissolution and precipitation due to carbon dioxide-water-rock interactions. this volume

Kendall TA, Martin ST (2005) Mobile ions on carbonate surfaces. Geochim Cosmochim Acta 69:3257-3263

Kerisit S, Liu C (2010) Molecular simulation of the diffusion of uranyl carbonate species in aqueous solution. Geochim Cosmochim Acta 74:4937-4952

Kerisit S, Parker SC, Harding JH (2003) Atomistic simulation of the dissociative adsorption of water on calcite surfaces. J Phys Chem B 107:7676-7682

Kerisit S, Weare JH, Felmy AR (2012) Structure and dynamics of forsterite- $\mathrm{scCO}_{2} / \mathrm{H}_{2} \mathrm{O}$ interfaces as a function of water content. Geochim Cosmochim Acta 84:137-151

Kim J, Lin L-C, Swisher JA, Haranczyk M, Smit B (2013) Predicting large $\mathrm{CO}_{2}$ adsorption in aluminosilicate zeolites for postcombustion carbon dioxide capture. J Am Chem Soc 134:18940-18943

Kim TW, Tokunaga TK, Shuman DB, Sutton SR, Newville M, Lanzirotti A (2012). Thickness measurements of nanoscale brine films on silica surfaces under geologic $\mathrm{CO}_{2}$ sequestration conditions using synchrotron $\mathrm{X}$-ray fluorescence. Water Resour Res 48:W09558

Koster van Groos AF, Guggenheim S (2009) The stability of methane hydrate intercalates of montmorillonite and nontronite: Implications for carbon storage in ocean-floor environments. Am Miner 94:372-379 
Kraska T, Romer F, Imre AR (2009) The relation of interface properties and bulk phase stability: molecular dynamics simulations of carbon dioxide. J Phys Chem B 113: 4688-4697

Krupka KM, Cantrell KJ, McGrail PB 2010. Thermodynamic data for geochemical modeling of carbonate reactions associated with $\mathrm{CO}_{2}$ sequestration - literature review, Pacific Northwest National Laboratory, Richland, WA, $135 \mathrm{p}$

Kulik DA, Vinograd VL, Paulsen N, Winkler B (2010) $(\mathrm{Ca}, \mathrm{Sr}) \mathrm{CO}_{3}$ aqueous-solid solution systems: From atomistic simulations to thermodynamic modelling. Phys Chem Earth 35:217-232

Kupka T, Lin HM, Stobinski L, Chen C-H, Liou W-J, Wrzalik R, Flisak Z (2009) Experimental and theoretical studies on corals. I. Toward understanding the origin of color in precious red corals from Raman and IR spectroscopies and DFT calculations. J Raman Spec 41:651-658

Kwak JH, Hu JZ, Turcu RVF, Rosso KM, Ilton ES, Wang C, Sears JA, Engelhard MH, Felmy AR, Hoyt DW (2011) The role of $\mathrm{H}_{2} \mathrm{O}$ in the carbonation of forsterite in supercritical $\mathrm{CO}_{2}$. Int J Greenhouse Gas Control 5:1081-1092

Laio A, Gervasio FL (2008) Metadynamics: a method to simulate rare events and reconstruct the free energy in biophysics, chemistry and material science. Rep Prog Phys 71:126601

Lamb RN, Furlong DN (1982). Controlled wettability of quartz surfaces. J Chem Soc Faraday Trans 1 78:61-73

Lardge JS, Duffy DM, Gillan MJ (2009) Investigation of the interaction of water with the calcite (10.4) surface using ab initio aimulation. J Phys Chem C 113:7207-7212.

Leroch S, Wendland M (2012) Simulation of forces between humid amorphous silica surfaces: A comparison of empirical atomistic force fields. J Phys Chem C 116:26247-26261

Leyssale JM, Delhommelle J, Millot C (2005) Molecular simulation of the homogeneous crystal nucleation of carbon dioxide. J Chem Phys 122: 184518

Liang S, Rozmanov D, Kusalik PG (2011) Crystal growth simulations of methane hydrates in the presence of silica surfaces. Phys Chem Chem Phys 13: 1985619864

Lísal M, Smith,WR, Aim K (2005) Analysis of Henry's constant for carbon dioxide in water via Monte Carlo simulation. Fluid Phase Equil 228-229:345-356

Liu S, Yang X, Qin Y (2010) Molecular dynamics simulation of wetting behavior at $\mathrm{CO}_{2} /$ water/solid interfaces. Chin Sci Bull 55:2252-2257

Liu Y, Panagiotopoulos AZ, Debenedetti PG (2011) Monte Carlo simulations of highpressure phase equilibria of $\mathrm{CO}_{2}-\mathrm{H}_{2} \mathrm{O}$ mixtures. J Phys Chem B 115:6629-6635

Lopes PE, Murashov V, Tazi M, Demchuk E, Mackerell AD Jr. (2006) Development of an empirical force field for silica. Application to the quartz-water interface. J Phys Chem B 110: 2782-2792

Loring JS, Thompson CJ, Wang Z, Joly AG, Sklarew DS, Schaef HT, Ilton ES, Rosso KM, Felmy AR (2011) In situ infrared spectroscopic study of forsterite carbonation in wet supercritical $\mathrm{CO}_{2}$. Environ Sci Technol 45:6204-6210

Malani A, Ayappa KG (2009) Adsorption isotherms of water on mica: redistribution and film growth. J Phys Chem B 113:1058-67

Marcus Y, Hefter G (2006) Ion pairing. Chem Rev 106:4585-4621 
Markov IV (2004) Crystal Growth for Beginners: Fundamentals of Nucleation, Crystal Growth and Epitaxy. World Scientific, Singapore, $546 \mathrm{p}$

Marry V, Dubois E, Malikova N, Durand-Vidal S, Longeville S, Breu J (2011) Water dynamics in hectorite clays: influence of temperature studied by coupling neutron spin echo and molecular dynamics. Environ Sci Technol 45:2850-2855

Martin P, Spagnoli D, Marmier A, Parker SC, Sayle DC, Watson G (2006) Application of molecular dynamics DL_POLY codes to interfaces of inorganic materials. Mol Simul 32:1079-1093

McCoy JM, LaFemina JP (1997) Kinetic Monte Carlo investigation of pit formation at the $\mathrm{CaCO}_{3}$ (1014) surface-water interface. Surf Sci 373:288-299

McGrail BP, Schaef HT, Glezakou V-A, Dang LX, Owen AT (2009) Water reactivity in the liquid and supercritical $\mathrm{CO}_{2}$ phase: Has half the story been neglected? Energy Procedia 1:3415-3419

McGreevy RL (2001) Reverse Monte Carlo modelling. J Phys: Condens Matter 13:R877R913

McGreevy RL, Howe MA (1992). RMC : modeling disordered structures. Ann Rev Mat Sci 22:217-242

Medeiros SK, Albuquerque EL, Maia FF, Caetano EWS, Freire VN (2007) Firstprinciples calculations of structural, electronic, and optical absorption properties of $\mathrm{CaCO}_{3}$ vaterite. Chem Phys Lett 435:59-64

Melnichenko YB, Mayama H, Cheng G, Blach T (2009) Monitoring phase behavior of sub- and supercritical $\mathrm{CO}_{2}$ confined in porous fractal silica with $85 \%$ porosity. Langmuir 26:6374-6379

Merker T, Engin C, Vrabec J, Hasse H (2010) Molecular model for carbon dioxide optimized to vapor-liquid equilibria. J Chem Phys 132:234512

Michel FM, MacDonald J, Feng J, Phillips BL, Ehm L, Tarabrella C, Parise JB, Reeder RJ (2008) Structural characteristics of synthetic amorphous calcium carbonate. Chem Mater 20:4720-4728

Ming X, Wang X-L, Du F, Yin J-W, Wang C-Z, Chen G (2012) First-principles study of pressure-induced magnetic transition in siderite $\mathrm{FeCO}_{3}$. J Alloys Compd 510:L1L4

Miyake A, Kawano J (2010) High-temperature molecular dynamics simulation of aragonite. J Phys: Condens Matter 22:225402

Mognetti BM, Yelash L, Virnau P, Paul W, Binder K, Müller M, MacDowell LG (2008) Efficient prediction of thermodynamic properties of quadrupolar fluids from simulation of a coarse-grained model: The case of carbon dioxide. J Chem Phys, 128:104501

Mugnaioli E, Andrusenko I, Schüler T, Loges N, Dinnebier RE, Panthöfer M, Tremel W, Kolb U (2012) Ab Initio structure determination of vaterite by automated electron diffraction. Angew Chem Int Ed 51:7041-7045

Nancollas GH, Kazmierczak TF, Schuttringer E (1981) A controlled composition study of calcium carbonate crystal growth: The influence of scale inhibitors. Corrosion 37:76-81

Nebel H, Neumann M, Mayer C, Epple M (2008) On the structure of amorphous calcium carbonate--a detailed study by solid-state NMR spectroscopy. Inorg Chem 47:7874-7879 
Neuefeind J, Fisher HE, Simonson JM, Idrissi A, Schöps A, Honkimäki V (2009) The structure of liquid carbon dioxide and carbon disulfide. J Chem Phys 130:174503

Nielsen AE (1964) Kinetics of precipitation. International Series of Monographs on Analytical Chemistry, Vol. 18. Pergamon Press limited, Oxford, $153 \mathrm{p}$

Nielsen LC, Bourg IC, Sposito G (2012) Predicting $\mathrm{CO}_{2}$-water interfacial tension under pressure and temperature conditions of geologic $\mathrm{CO}_{2}$ storage. Geochim Cosmochim Acta 81:28-38

Nielsen LC, De Yoreo JJ, DePaolo DJ (2013) General model for calcite growth kinetics in the presence of impurity ions. Geochim Cosmochim Acta 115:100-114

Nieto-Draghi C, de Bruin T, Perez-Pellitero J, Bonet Avalos J, Mackie AD (2007) Thermodynamic and transport properties of carbon dioxide from molecular simulation. J Chem Phys 126:064509

Oakley MT, Wheatley RJ (2009) Additive and nonadditive models of vapor-liquid equilibrium in CO2 from first principles. J Chem Phys 130:034110

Okur A, Wickstrom L, Layten M, Geney R, Song K, Hornak V, Simmerling C (2006) Improved efficiency of replica exchange simulations through use of a hybrid explicit/implicit solvation model. J Chem Theory Comput 2:420-433

Ota M, Ferdows M (2005) Monte Carlo approach to structure and thermodynamic property of $\mathrm{CO}_{2}$ hydrate. JSME Int J, Ser A, 48:802-809

Ota M, Morohashi K, Abe Y, Watanabe M, Smith RL Jr, Inomata H (2005) Replacement of $\mathrm{CH}_{4}$ in the hydrate by use of liquid $\mathrm{CO}_{2}$. Energy Convers Manage 46:16801691

Park S-H, Sposito G (2003) Do montmorillonite surfaces promote methane hydrate formation? Monte Carlo and molecular dynamics simulations. J Phys Chem B 107:2281-2290

Park Y, Kim D-Y, Lee J-W, Huh D-G, Park K-P, Lee J, Lee H (2006). Sequestering carbon dioxide into complex structures of naturally occurring gas hydrates. Proc Natl Acad Sci USA 103:12690-12694

Pashley RM (1980) Multilayer adsorption of water on silica: An analysis of experimental results. J Colloid Interface Sci 78:246-248

Pashley RM, Kitchener JA (1979) Surface forces in adsorbed multilayers of water on quartz. J Colloid Interface Sci 71:491-500

Pavese A, Catti M, Parker SC, Wall A (1996) Modelling of the thermal dependence of structural and elastic properties of calcite, $\mathrm{CaCO}_{3}$. Phys Chem Min 23:89-93

Pavese A, Catti M, Price GD, Jackson RA (1992) Interatomic potentials for $\mathrm{CaCO}_{3}$ polymorphs (calcite and aragonite), fitted to elastic and vibrational data. Phys Chem Min 19:80-87

Perez-Sanchez G, Gonzalez-Salgado D, Pineiro MM, Vega C (2013) Fluid-solid equilibrium of carbon dioxide as obtained from computer simulations of several popular potential models: the role of the quadrupole. J Chem Phys 138:084506

Persson RA (2011) Simple one-center model for linear molecules: application to carbon dioxide. J Phys Chem B 115:10073-10078

Piana S, Gale JD (2005) Understanding the barriers to crystal growth: dynamical simulation of the dissolution and growth of urea from aqueous solution. J Am Chem Soc 127: 1975-1982

Piana S, Jones F, Gale JD (2006) Assisted desolvation as a key kinetic step for crystal 
growth. J Am Chem Soc 128:13568-13574

Piana S, Jones F, Gale JD (2007) Aspartic acid as a crystal growth catalyst. CrystEngComm 9:1187-1191

Pini R, Krevor SCM, Benson SM (2012) Capillary pressure and heterogeneity for the $\mathrm{CO} 2 /$ water system in sandstone rocks at reservoir conditions. Adv Water Res 38:48-59

Pitzer KS (1973) Thermodynamics of electrolytes. I. Theoretical basis and general equations. J Phys Chem 77:268-277

Potoff JJ (2001) Vapor-liquid equilibria of mixtures containing alkanes, carbon dioxide, and nitrogen. AIChE J 47:1676-1682

Potoff JJ, Errington JR, Panagiotopoulos AZ (1999) Molecular simulation of phase equilibria for mixtures of polar and non-polar components. Mol Phys 97:10731083

Pouget EM, Bomans PHH, Goos JACM, Frederik PM, de With G, Sommerdijk NAJM (2009) The initial stages of template-controlled $\mathrm{CaCO}_{3}$ formation revealed by cryo-TEM. Science 323:1455-1458

Quigley D, Freeman CL, Harding JH, Rodger PM (2011) Sampling the structure of calcium carbonate nanoparticles with metadynamics. Journal Chem Phys 134:044703

Quigley D, Rodger PM (2008) Free energy and structure of calcium carbonate nanoparticles during early stages of crystallization. J Chem Phys 128: 221101

Quigley D, Rodger PM (2009) A metadynamics-based approach to sampling crystallisation events. Mol Simul 35:613-623

Quigley D, Rodger PM, Freeman CL, Harding JH, Duffy DM (2009) Metadynamics simulations of calcite crystallization on self-assembled monolayers. J Chem Phys 131:094703

Radha AV, Fernandez-Martinez A, Hu Y, Jun Y-S, Waychunas GA, Navrotsky A (2012) Energetic and structural studies of amorphous $\mathrm{Ca}_{1-\mathrm{x}} \mathrm{Mg}_{\mathrm{x}} \mathrm{CO}_{3} \cdot \mathrm{nH}_{2} \mathrm{O}(0 \leq x \leq 1)$. Geochim et Cosmochim Acta 90:83-95

Radha AV, Forbes TZ, Killian CE, Gilbert PUPA, Navrotsky A (2010) Transformation and crystallization energetics of synthetic and biogenic amorphous calcium carbonate. Proc Nat Acad Sci USA 107:16438-16443

Radha AV, Navrotsky A (2013) Thermodynamics of carbonates. this volume

Radhakrishnan R, Trout BL (2002) A new approach for studying nucleation phenomena using molecular simulations: Application to $\mathrm{CO}_{2}$ hydrate clathrates J Chem Phys 117:1786-1797

Rahaman A, Grassian VH, Margulis CJ (2008) Dynamics of water adsorption onto a calcite surface as a function of relative humidity. J Phys Chem C 112:2109-2115

Railsback LB (1999) Patterns in the compositions, properties, and geochemistry of carbonate minerals. Carbonates Evaporites 14:1-20.

Raiteri P, Demichelis R, Gale JD, Kellermeier M, Gebauer D, Quigley D, Wright LB, Walsh TR (2012) Exploring the influence of organic species on pre- and postnucleation calcium carbonate. Farad Discuss 159:61-85

Raiteri P, Gale JD (2010) Water is the key to nonclassical nucleation of amorphous calcium carbonate. J Am Chem Soc 132:17623-17634

Raiteri P, Gale JD, Quigley D, Rodger PM (2010) Derivation of an accurate force-field 
for simulating the growth of calcium carbonate from aqueous solution: A new model for the calcite-water interface. J Phys Chem C 114:5997-6010

Reeder R, Tang Y, Schmidt MP, Kubista LM, Cowan DF, Phillips BL (2013) Characterization of structure in biogenic amorphous calcium carbonate: pair distribution function and nuclear magnetic resonance studies of lobster gastrolith. Cryst Growth Des 13:1905-1914

Rezaei Nejad H, Ghassemi M, Mirnouri Langroudi SM, Shahabi A (2011) A molecular dynamics study of nano-bubble surface tension. Mol Simul 37:23-30.

Rieger J, Frechen T, Cox G, Heckmann W, Schmidt C, Thieme J (2007) Precursor structures in the crystallization/precipitation processes of $\mathrm{CaCO}_{3}$ and control of particle formation by polyelectrolytes. Farad Discuss 136:265-277

Romero-Vargas Castrillón S, Giovambattista N, Aksay IA, Debenedetti PG (2011) Structure and energetics of thin film water. J Phys Chem C 115:4624-4635

Rotenberg B, Marry V, Vuilleumier R, Malikova N, Simon C, Turq P (2007) Water and ions in clays: Unraveling the interlayer/micropore exchange using molecular dynamics. Geochim Cosmochim Acta 71:5089-5101

Rotenberg B, Patel AJ, Chandler D (2011) Molecular explanation for why talc surfaces can be both hydrophilic and hydrophobic. J Am Chem Soc 133: 20521-20527

Rother G, Krukowski EG, Wallacher D, Grimm N, Bodnar RJ, Cole DR (2012) Pore size effects on the sorption of supercritical $\mathrm{CO}_{2}$ in mesoporous CPG-10 silica. J Phys Chem C 116:917-922

Rother G, Ilton ES, Wallacher D, Hauß T, Schaef HT, Qafoku O, Rosso KM, Felmy AR, Krukowski EG, Stack AG, Grimm N, Bodnar RJ (2013) $\mathrm{CO}_{2}$ sorption to subsingle hydration layer montmorillonite clay studied by excess sorption and neutron diffraction measurements. Environ Sci Technol 47:205-211

Rubasinghege G, Grassian VH (2013) Role(s) of adsorbed water in the surface chemistry of environmental interfaces. Chem Commun 49:3071-3094

Sadlej J, Makarewicz J, Chałasiński G (1998. Ab initio study of energy, structure and dynamics of the water-carbon dioxide complex J Chem Phys 109:3919-3928

Saharay M, Yazaydin AO, Kirkpatrick RJ (2013) Dehydration-induced amorphous phases of calcium carbonate. J Phys Chem B 117:3328-3336

Salmeron M, Bluhm H, Tatarkhanov M, Ketteler G, Shimizu TK, Mugarza A, Deng X, Herranz T, Yamamoto S, Nilsson A (2009) Water growth on metals and oxides: binding, dissociation and role of hydroxyl groups. Farad Discuss 141:221-229

Salvalaglio M, Vetter T, Giberti F, Mazzotti M, Parrinello M (2012) Uncovering molecular details of urea crystal growth in the presence of additives. J Am Chem Soc 134:17221-177233

Sarupria S, Debenedetti PG (2011) Molecular dynamics study of carbon dioxide hydrate dissociation. J Phys Chem A 115:6102-6111

Schacht CS, Vlugt TJH, Gross J (2011) Using an analytic equation of state to obtain quantitative solubilities of $\mathrm{CO}_{2}$ by molecular simulation. J Phys Chem Lett 2:393396

Schaef HT, Ilton ES, Qafoku O, Martin PF, Felmy AR, Rosso KM (2012) In situ XRD study of $\mathrm{Ca}^{2+}$ saturated montmorillonite (STX-1) exposed to anhydrous and wet supercritical carbon dioxide. Int J Greenhouse Gas Control 6:220-229

Schreiber A, Ketelsen I, Findenegg H (2001) Melting and freezing of water in ordered 
mesoporous silica materials. Phys Chem Chem Phys 3:1185-1195

Sel O, Radha AV, Dideriksen K, Navrotsky A (2012) Amorphous iron (II) carbonate: Crystallization energetics and comparison to other carbonate minerals related to $\mathrm{CO}_{2}$ sequestration. Geochim Cosmochim Acta 87:61-68

Shao H, Ray JR, Jun YS (2011) Effects of salinity and the extent of water on supercritical $\mathrm{CO}_{2}$-induced phlogopite dissolution and secondary mineral formation. Environ Sci Technol 45:1737-1743

Sherman DM (2009) Electronic structures of siderite $\left(\mathrm{FeCO}_{3}\right)$ and rhodochrosite $\left(\mathrm{MnCO}_{3}\right)$ : Oxygen $\mathrm{K}$-edge spectroscopy and hybrid density functional theory. Am Miner 94:166-171

Shi H, Luo W, Johansson B, Ahuja R (2008) First-principles calculations of the electronic structure and pressure-induced magnetic transition in siderite $\mathrm{FeCO}_{3}$. Phys Rev B 78:155119.

Singer JW, Yazaydin AO, Kirkpatrick RJ, Bowers GM (2012) Structure and transformation of amorphous calcium carbonate: A solid-state ${ }^{43} \mathrm{Ca}$ NMR and computational molecular dynamics investigation. Chem Mater 24:1828-1836

Skelton AA, Fenter P, Kubicki JD, Wesolowski DJ, Cummings PT (2011) Simulations of

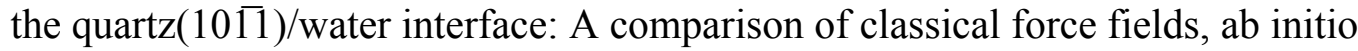
molecular dynamics, and X-ray reflectivity experiments. J Phys Chem C 115:2076-2088

Skorodumova NV (2005). Stability of the $\mathrm{MgCO}_{3}$ structures under lower mantle conditions. Am Miner 90:1008-1011

Sonnefeld J, Löbbus M, Vogelsberger W (2001) Determination of electric double layer parameters for spherical silica particles under application of the triple layer model using surface charge density data and results of electrokinetic sonic amplitude measurements. Colloid Surface A 195:215-225

Spagnoli D, Kerisit S, Parker SC (2006) Atomistic simulation of the free energies of dissolution of ions from flat and stepped calcite surfaces. J Cryst Growth 294:103-110

Spiteri EJ, Juanes R, Blunt MJ, Orr FM (2008) A new model of trapping and relative permeability hysteresis for all wettability characteristics. Soc Petrol Eng J 13:277288

Stack AG, Raiteri P, Gale JD (2012) Accurate rates of the complex mechanisms for growth and dissolution of minerals using a combination of rare-event theories. $\mathrm{J}$ Am Chem Soc 134:11-14

Stashans A, Chamba G (2011) A new insight on the role of Mg in calcite. Int J Quant Chem 111:2436-2443

Stephens CJ, Kim Y-Y, Evans SD, Meldrum FC, Christenson HK (2011) Early stages of crystallization of calcium carbonate revealed in picoliter droplets. J Am Chem Soc 133:5210-5213

Stipp SL, Hochella MF (1991) Structure and bonding environments at the calcite surface as observed with X-ray photoelectron spectroscopy (XPS) and low energy electron diffraction (LEED). Geochim Cosmochim Acta 55:1723-1736

Stöckelmann E, Hentschke R (1999) Adsorption isotherms of water vapor on calcite: A molecular dynamics-Monte Carlo hybrid simulation using a polarizable water model. Langmuir 15:5141-5149 
Sugita Y, Okamoto Y (1999) Replica-exchange molecular dynamics method for protein folding. Chem Phys Lett 314:141-151

Sun R, Duan Z (2005) Prediction of $\mathrm{CH}_{4}$ and $\mathrm{CO}_{2}$ hydrate phase equilibrium and cage occupancy from ab initio intermolecular potentials Geochim Cosmochim Acta 69:4411-4424

Takenouchi JW, Kennedy GC (1964) The binary system $\mathrm{H}_{2} \mathrm{O}-\mathrm{CO}_{2}$ at high temperatures and pressures. Am J Sci 262:1055-1074

Takenouchi JW, Kennedy GC (1965) Dissociation pressures of the phase $\mathrm{CO}_{2} \cdot 53 / 4 \mathrm{H}_{2} \mathrm{O}$. J Geol 73:383-390

Takeya S, Udachin KA, Moudrakovski IL, Susilo R, Ripmeester JA (2010) Direct space methods for powder X-ray diffraction for guest-host materials: applications to cage occupancies and guest distributions in clathrate hydrates. J Am Chem Soc 132:524-531

Tohidi B, Yang J, Salehabadi M, Anderson R, Chapoy A (2010) $\mathrm{CO}_{2}$ hydrates could provide secondary safety factor in subsurface sequestration of $\mathrm{CO}_{2}$. Environ Sci Technol 44:1509-1514

Tokunaga TK (2009) Hydraulic properties of adsorbed water films in unsaturated porous media. Water Resour Res 45:W06415

Tokunaga TK (2012) DLVO-based estimates of adsorbed water film thicknesses in geologic $\mathrm{CO}_{2}$ reservoirs. Langmuir 28:8001-8009

Tokunaga TK, Wan J (2013) Capillary pressure and mineral wettability influences on reservoir $\mathrm{CO}_{2}$ capacity. this volume

Tribello GA, Bruneval F, Liew C, Parrinello M (2009) A molecular dynamics study of the early stages of calcium carbonate growth. J Phys Chem B 113:11680-11687

Tung YT, Chen L-J, Chen Y-P, Lin S-T (2010) The growth of structure I methane hydrate from molecular dynamics simulations. J Phys Chem B 114:10804-10813

Tung Y-T, Chen L-J, Chen Y-P, Lin S-T (2011a) Growth of structure I carbon dioxide hydrate from molecular dynamics simulations. J Phys Chem C 115:7504-7515

Tung Y-T, Chen L-J, Chen Y-P, Lin S-T (2011b) In situ methane recovery and carbon dioxide sequestration in methane hydrates: A molecular dynamics simulation study. J Phys Chem B 115:15295-15302

Uchida T, Takeya S, Chuvilin EM, Ohmura R, Nagao J, Yakushev VS, Istomin VA, Minagawa H, Ebinuma T, Narita H (2004) Decomposition of methane hydrates in sand, sandstone, clays, and glass beads. J Geophys Res 109:B05206.

Ungureanu CG, Cossio R, Prencipe M (2012) An ab-initio assessment of thermo-elastic properties of $\mathrm{CaCO}_{3}$ polymorphs: Calcite case. Calphad 37:25-33

van Beest BW, Kramer GJ, van Santen RA (1990) Force fields for silicas and aluminophosphates based on ab initio calculations. Phys Rev Lett 64:1955-1958

Vega C, de Miguel E (2007) Surface tension of the most popular models of water by using the test-area simulation method. J Chem Phys 126:154707

Villegas-Jiménez A, Mucci A, Whitehead MA (2009) Theoretical insights into the hydrated (10.4) calcite surface: structure, energetics, and bonding relationships. Langmuir 25:6813-6824

Vinograd VL, Winkler B (2010) An efficient cluster expansion method for binary solid solutions: Application to the halite-silvite, $\mathrm{NaCl}-\mathrm{KCl}$, system. In: Wentzcovitch $\mathrm{R}$, Stixrude L (eds), Reviews in Mineralogy and Geochemistry, Volume 71, 
Theoretical and Computational Methods in Mineral Physics: Geophysical Applications. Minerogical Society of America, p 413-436

Vinograd VL, Burton BP, Gale JD, Allan NL, Winkler B (2007) Activity-composition relations in the system $\mathrm{CaCO}_{3}-\mathrm{MgCO}_{3}$ predicted from static structure energy calculations and Monte Carlo simulations. Geochim Cosmochim Acta 71:974-983

Vlcek L, Chialvo AA, Cole DR (2011) Optimized unlike-pair interactions for watercarbon dioxide mixtures described by the SPC/E and EPM2 models. J Phys Chem B 115:8775-8784

Vorholz J, Harismiadis VI, Panagiotopoulos AZ, Rumpf B, Maurer G (2004) Molecular simulation of the solubility of carbon dioxide in aqueous solutions of sodium chloride. Fluid Phase Equil 226:237-250

Vorholz J, Harismiadis VI, Rumpf B, Panagiotopoulos AZ, Maurer G (2000) Vapor+liquid equilibrium of water, carbon dioxide, and the binary system, water+carbon dioxide, from molecular simulation. Fluid Phase Equil 170:203-234

Vrabec J, Stoll J, Hasse H (2001) A set of molecular models for symmetric quadrupolar fluids. J Phys Chem B 105:12126-12133

Wada N, Yamashita K, Umegaki T (1999) Effects of carboxylic acids on calcite formation in the presence of $\mathrm{Mg}^{2+}$ ions. J Colloid Interface Sci 212:357-364

Wallace AF, Hedges LO, Fernandez-Martinez A, Raiteri P, Gale JD, Waychunas GA, Whitelam S, Banfield JF, De Yoreo JJ (2013) Microscopic evidence for liquidliquid separation in supersaturated $\mathrm{CaCO}_{3}$ solutions. Science 341:885-889

Wang F-F, Kumar R, Jordan KD (2012a) A distributed point polarizable force field for carbon dioxide. Theor Chem Acc 131:1-8

Wang J, Becker U (2012) Energetics and kinetics of carbonate orientational ordering in vaterite calcium carbonate. Am Miner 97:1427-1436

Wang L, Zhang M, Redfern SAT (2003) Infrared study of $\mathrm{CO}_{2}$ incorporation into pyrophyllite $\left[\mathrm{Al}_{2} \mathrm{Si}_{4} \mathrm{O}_{10}(\mathrm{OH})_{2}\right]$ during dehydroxylation. Clay Clay Miner 51:439444

Wang Q, Grau-Crespo R, de Leeuw NH (2011) Mixing thermodynamics of the calcitestructured $(\mathrm{Mn}, \mathrm{Ca}) \mathrm{CO}_{3}$ solid solution: a computer simulation study. J Phys Chem B 115:13854-13861

Wang S, Edwards IM, Clarens AF (2012b) Wettability phenomena at the $\mathrm{CO}_{2}$-brinemineral interface: implications for geologic carbon sequestration. Environ Sci Technol 47:234-241

Wang X, Chou I-M, Hu W, Burruss RC (2013) In situ observations of liquid-liquid phase separation in aqueous $\mathrm{MgSO}_{4}$ solutions: Geological and geochemical implications. Geochim Cosmochim Acta 103:1-10

Wasylenki LE, Dove PM, De Yoreo JJ (2005a) Effects of temperature and transport conditions on calcite growth in the presence of $\mathrm{Mg}^{2+}:$ Implications for paleothermometry. Geochim Cosmochim Acta 69:4227-4236

Wasylenki LE, Dove PM, Wilson DS, De Yoreo JJ (2005b) Nanoscale effects of strontium on calcite growth: An in situ AFM study in the absence of vital effects Geochim Cosmochim Acta 69:3017-3027

Wasylenki LE, Dove PM, Wilson DS, De Yoreo JJ (2005c) Nanoscale effects of strontium on calcite growth: An in situ AFM study in the absence of vital effects Geochim Cosmochim Acta 69:3017-3027 
Wensink EJW, Hoffmann AC, Apol MEF, Berendsen HJC (2000) Properties of adsorbed water layers and the effect of adsorbed layers on interparticle forces by liquid bridging. Langmuir 16:7392-7400

Wiebe R (1941) The binary system carbon dioxide-water under pressure. Chem Rev 29:475-481

Wiebe R, Gaddy VL (1939) The solubility in water of carbon dioxide at 50, 75, and $100^{\circ}$, at pressures to 700 atmospheres. J Am Chem Soc 61:315-318

Willard AP, Chandler D (2010) Instantaneous liquid interfaces. J Phys Chem B 114:1954-1958

Wolf SE, Leiterer J, Kappl M, Emmerling F, Tremel W (2008) Early homogenous amorphous precursor stages of calcium carbonate and subsequent crystal growth in levitated droplets. J Am Chem Soc 130:12342-12347

Wolf SE, Müller L, Barrea R, Kampf CJ, Leiterer J, Panne U, Hoffmann T, Emmerling F, Tremel W (2011) Carbonate-coordinated metal complexes precede the formation of liquid amorphous mineral emulsions of divalent metal carbonates. Nanoscale 3:1158-1165

Wolthers M, Di Tommaso D, Du Z, de Leeuw NH (2012) Calcite surface structure and reactivity: molecular dynamics simulations and macroscopic surface modelling of the calcite-water interface. Phys Chem Chem Phys 14:15145-15157

Xu T, Apps JA, Pruess K, Yamamoto H (2007) Numerical modeling of injection and mineral trapping of $\mathrm{CO}_{2}$ with $\mathrm{H}_{2} \mathrm{~S}$ and $\mathrm{SO}_{2}$ in a sandstone formation. Chem Geol 242:319-346

Yang SO, Cho SH, Lee H, Lee CS (2001) Measurement and prediction of phase equilibria for water + methane in hydrate forming conditions. Fluid Phase Equil 185:53-63

Yang N, Yang X (2011) Molecular simulation of swelling and structure for Na-Wyoming montmorillonite in supercritical $\mathrm{CO}_{2}$. Mol Simul 37:1063-1070

Yang X, Zhang C (2005) Structure and diffusion behavior of dense carbon dioxide fluid in clay-like slit pores by molecular dynamics simulation. Chem Phys Lett 407: 427-432

Yu K, McDaniel JG, Schmidt JR (2011) Physically motivated, robust, ab initio force fields for $\mathrm{CO}_{2}$ and $\mathrm{N}_{2}$. J Phys Chem B 115:10054-10063

Yu Y, Yang X (2011) Molecular simulation of swelling and interlayer structure for organoclay in supercritical $\mathrm{CO}_{2}$. Phys Chem Chem Phys 13:282-290

Zhang H, Singer SJ (2011) Analysis of the subcritical carbon dioxide-water interface. J Phys Chem A 115:6285-6296

Zhang Z, Duan Z (2005) An optimized molecular potential for carbon dioxide. J Chem Phys 122:214507

Zhao L, Lin S, Mendenhall JD, Yuet PK, Blankschtein D (2011) Molecular dynamics investigation of the various atomic force contributions to the interfacial tension at the supercritical $\mathrm{CO}_{2}$-water interface. J Phys Chem B 115:6076-6087

Zhu A, Zhang X, Liu Q, Zhang Q (2009) A fully flexible potential model for carbon dioxide. Chin J Chem Eng 17:268-272

Zucchini A, Prencipe M, Comodi P, Frondini F (2012) Ab initio study of cation disorder in dolomite. Calphad 38:177-184 
